\title{
A CASE STUDY ON THE USE OF FOCUS GROUPS AS PARTICIPATORY RESEARCH
}

A Thesis presented to the Faculty of the Graduate School

University of Missouri-Columbia

In Partial Fulfillment

of the Requirements for the Degree

Master of Science

by

TIM BIELLO

Dr. James (Sandy) Rikoon, Thesis Supervisor

MAY 2009 
The undersigned, appointed by the Dean of the Graduate School, have examined the thesis entitled

\section{A CASE STUDY ON THE USE OF FOCUS GROUPS AS PARTICIPATORY RESEARCH}

Presented by Tim Biello

A candidate for the degree of Master of Science

And hereby certify that in their opinion it is worthy of acceptance.

\begin{tabular}{c}
\hline Dr. Sandy Rikoon \\
\\
\hline Dr. Soren Larsen
\end{tabular}

Dr. Soren Larsen

Dr. Stephen Jeanetta 


\section{ACKNOWLEDGMENTS}

Thank you very much to Sandy Rikoon who throughout my time at the university was a trusted and always available advisor, a source of inspiration and motivation, and a friend. Thank you to Steve Jeanetta for his consistent support and his invaluable advice regarding methodology and research approaches. And thank you to Soren Larsen for his genuine interest in this project, his advice regarding qualitative research and his encouragement. I am also grateful to the other staff and faculty in Rural Sociology, as well as my fellow graduate students, all of whose support was invaluable throughout my M.S. journey.

I would also like to thank those who were intimately involved in this research. First, thank you to the FEP and the HVA. In particular, thanks to Conrad and Claudia (and Otter!) who welcomed the opportunity to work with, and trust in, a motivated but still green researcher. It was a pleasure to work with such a talented family-team. I hope that our partnership has been as beneficial for all of you as it has been for me. Tory Shelley also deserves a special thank you for volunteering to be a note-taker and then becoming not just the recorder, but also a reviewer and an integral part of the research process. And, of course, thank you so much to all of the focus group participants who volunteered to share their time and ideas during the summer and beyond.

Finally, I would like to thank and honor my mother. Without her lifetime of guidance, and her enduring belief in the value of education, it is unlikely that I would have pursued post-secondary education, much less found in it a personal inspiration for positive social change. Thank you, Mom, for your love, your strength and your good example. 


\section{TABLE OF CONTENTS}

Acknowledgements....................................................................... ii

List of Tables................................................................................ v

List of Illustrations................................................................................ vi

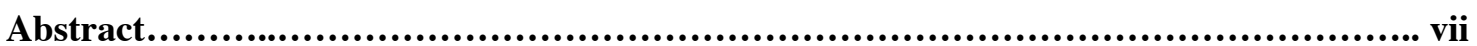

Chapter I: Introduction........................................................ 1

Background and setting.............................................. 2

The Quieter Revolution......................................... 2

The Farmscape Ecology Program................................ 4

From Conservation Biology to Focus Groups........................ 6

Statement of the Problem and Justification of the Study.................... 8

Purpose of the Study.................................................... 9

Research Objectives.............................................. 9

Limitations of the Study ......................................... 10

Chapter II: Review of Literature............................................... 13

Introduction...................................................... 13

Focus Groups................................................... 13

A Brief History of the Focus Group Interview....................... 13

The Methodologies of Focus Groups................................ 15

The Uses and Limitations of Focus Groups, Room for Improvement...... 17

Participatory Research................................................. 20

A Brief Background on Knowledge Systems, Academia and Participatory

Research........................................................ 20

Participatory Research Principles.................................. 23

Critiques of Participatory Research, Room for Improvement.............. 26

Reflexivity in the Research Process...................................... 29

Justifying Reflexivity ............................................ 29

Reflexivity and Participatory Research.............................. 30

Reflexivity in Focus Groups...................................... 32

Summary: Connecting the literature to the thesis....................... 34

Chapter III: Procedures............................................................. 37

Research Design....................................................... 37

Population and Sample.............................................. 40

Instrumentation.......................................................... 40

Data Collection..................................................... 42

Data Analysis................................................... 42 
Chapter IV: Focus Group Stages Reviewed....................................... 45

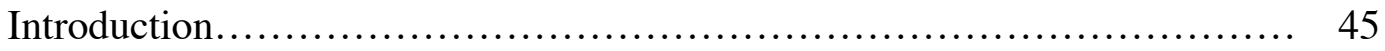

Pre-Focus Group Planning............................................ 45

Recruiting ............................................................... 52

Developing the questions.............................................. 62

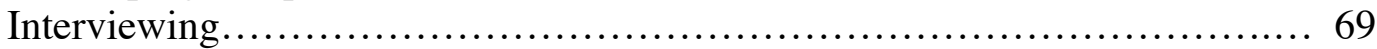

Debriefing............................................................. 86

Post-Focus Group Analysis and Reporting................................ 94

Chapter V: Focus Group Stages Analyzed....................................... 103

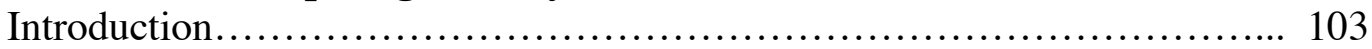

Pre-Focus Group Planning............................................ 103

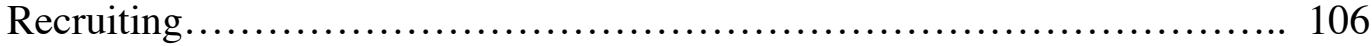

Developing the questions................................................ 113

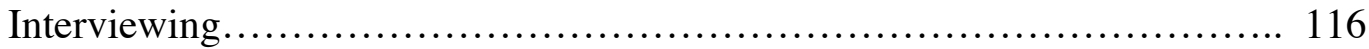

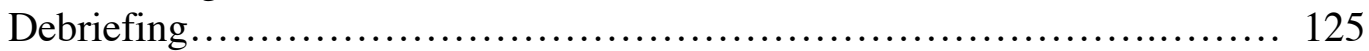

Post-Focus Group Analysis and Reporting.............................. 129

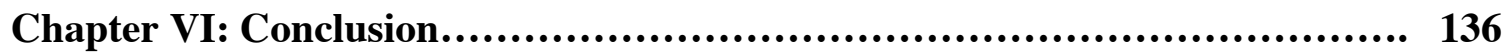

Lessons Learned......................................................... 136

Considerations for Future Research.................................. 143

Recommendations for Future Researchers................................ 144

Focus Groups and the Quieter Revolution............................. 145

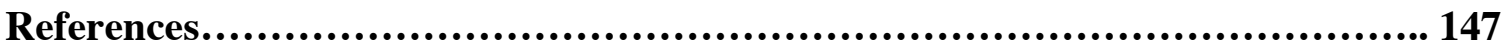

"To be able to see and describe the world as it is, you have to be ready to be always dealing with things that are complicated, confused, impure, uncertain, all of which runs counter to the usual idea of intellectual rigor." $\quad$ Pierre Bourdieu 


\section{LIST OF TABLES}

Table 1. Focus Group Uses....................................... 18

Table 2. Focus Group Limitations................................... 18

Table 3. Elements of Participatory Research............................ 26

Table 4. Elements of Participatory and Conventional Research.............. 28

Table 5. Intensive and Extensive Research............................ 46

Table 6. Evaluation Responses....................................... 124

Table 7. Selected Participatory Research Principles......................... 137

Table 8. Focus group stages' evaluations................................. 138 


\section{LIST OF ILLUSTRATIONS}

Figure 1. Analysis Map.............................................. 39

Figure 2. Timeline of Embedded Units.............................. 40 


\title{
A CASE STUDY ON THE USE OF FOCUS GROUPS AS PARTICIPATORY RESEARCH
}

\author{
Tim Biello
}

Dr. James (Sandy) Rikoon, Thesis Advisor

\begin{abstract}
Participatory approaches to research involve the commitment of a researcher, as well as those supporting the researcher (i.e., academic institutions, funding organizations), to the other people who are also involved in the process, to the 'subjects' of conventional research. In this way, participatory approaches make explicit the relationships involved in a research process. Furthermore, they endeavor to make these relationships beneficial to all parties involved, yielding both insights on a topic of study for researchers as well as providing actionable and empowering information for participants.

This thesis explores the proposition that the focus group interview is a research strategy that lends itself well to the principles and promises of participatory research. Using a reflexive analysis, each of the stages within a specific focus group research process are isolated and evaluated against a selection of participatory research standards in order to assess how and why each was more or less successful in meeting those standards. This research concludes that focus groups are, generally, well suited to function as a participatory research strategy; however, contextual factors within any research process are deemed to be quite influential and can either augment or diminish the participatory qualities inherent to the focus group methodology.
\end{abstract}




\section{INTRODUCTION}

Public participation in land management processes within the United States has increased during the past thirty years (Beierle and Cayford 2002, Mason 2008). This represents a shift towards a participatory democratic ideal in natural resources management, one in which public participation in decision-making processes occurs directly, in contrast to indirect or representative means (Lauber and Knuth 2000). As Beierle and Cayford (2002) describe it, “...public participation has taken center stage in the play of influences that determine how society will manage and protect the environment" (p1).

Questions remain, however, regarding the best means for fostering and utilizing this participation (Lauber and Knuth 2000). For example, within a particular natural resource management context, what types of participatory strategies are most likely to be successful? How can stakeholders participate throughout the entire process beyond the initial stages of decision-making? What makes for a "well-informed" citizenry that is able to participate effectively (ibid., p28)? Questions also remain as to whether the results of these participatory land management strategies, in light of their "immense" influence on the landscape, will be more or less successful than the top-down practices that preceded them (Mason 2008, p279). And it remains to be seen if this participatory trend will even continue. Yet it would be glossing over the subject if one did not also recognize that there is a great deal of hope and optimism within, and for, these more participatory strategies (ibid.) 
It should be noted that I share this optimism; thus, this thesis begins with the belief that public participation in land management issues is a desirable process. However, as with the authors just mentioned and the many others who are yet to be discussed, I recognize that there is uncertainty about both the best means for enacting participatory approaches and the ultimate impacts of participation. The scope of the latter issue goes beyond the focus of this research. I focus instead on the actual processes of participation during the initial stages of a larger research project. In order to do so, I reflexively analyze my involvement as researcher and moderator in a series of focus groups used to develop a participatory project for a place-based research and education organization in upstate New York. The goal is to explore, and contribute to, the methodology of the focus group as a participatory approach by focusing on the particularities that made the focus group method more and less successful in this context.

The first step, then, is to describe the three contexts that inform this research project: 1) a trend toward devolution in the control of land management processes in the United States; 2) a farm- and place-based research and education organization in upstate New York that works with the public to develop a more informed and active citizenry regarding the landscape, its functions, and its possible uses; and 3) my involvement with this organization and the development of this research project.

\section{Background and Setting}

The Quieter Revolution

Following a boom of federal environmental regulations in the 1960s and early 1970s, the federal government's role in regulating land use waned during the 1980s and 
1990s (Mason 2008). At the same time, the roles of state and local governments in land use issues began to increase. Fred Bosselman and David Callies (1971) termed this trend in land management devolution the "quiet revolution" (quoted in Mason 2008, p2).

The quiet revolution has also been described as the third era or "wave" of “America's environmentalism” (Mason 2008, p19). The first era comprises the late $19^{\text {th }}$ and early $20^{\text {th }}$ century, when the nation's forest and park systems were developed, along with federal agencies responsible for their oversight. This was the time of Gifford Pinchot, Theodore Roosevelt, "Fighting Bob" La Follette and other better and lesserknown icons of America's early conservation movement (Meine 2004, Mason 2008). And as the election of the latter two, according to Curt Meine, "marked the arrival of the Progressive Era during which conservation emerged as a coherent movement" (2004, p42), the first wave of American environmentalism roughly corresponds with the Progressive era.

The second wave is similarly identified with the creation of federal environmental regulatory agencies and other federal programs focused on conservation, but this time within the context of the New Deal. Some of the agencies created during this period include the Soil Conservation Service, the Tennessee Valley Authority, the Civilian Conservation Corps, and the Works Progress Administration. As Mason (2008) describes it, these endeavors "tended to be top down and paternalistic, affirming the centrality of government in directing environmental policy" (p19). The quiet revolution of the 1980 s, by contrast, enhanced the power of state and local governments in landmanagement issues. It therefore stands in contrast to the previous two eras in which federal authority reigned. 
While this periodicity simplifies America's environmental history, it still highlights identifiable trends. By focusing on the features that define these periods, one can begin to discern the development of America's fourth wave of environmentalism. Mason (2008) calls this the "quieter revolution" and he describes it as having an "emphasis on place-based, public-private, multistakeholder approaches that treat the human occupants of valued places inclusively and respectfully" (p3). As with the third wave, the quieter revolution is also associated with devolution in land management decision-making processes. Yet it is further defined by the increasing role of 'place' as a formative factor in the development of land use strategies, specifically in the form of public interest and concern for local places. This increase in what Mason (2008) terms the "politics of place" is evident in the growing presence of land trusts, watershed associations, place-based education programs, and other examples of locally based and focused organizations involved in local land use issues (p4-5).

\section{The Farmscape Ecology Program}

Although the quieter revolution is neither the focus nor the immediate context of this research, the concept is both a backdrop and a lens through which the research can be appreciated. Indeed, the venue of this research is arguably exemplary of the quieter revolution: a place-based research and education organization - the Farmscape Ecology Program (FEP).

The FEP is a component of Hawthorne Valley Farm (HVF), a 400-acre, Demetercertified, Biodynamic farm located in Columbia County, New York. Originally established in the early 1970s as an on-farm, stewardship experience for New York City 
students, HVF has grown into an agricultural enterprise. It now incorporates a bakery and numerous value-added products along with vegetable, dairy and meat production to supply a 250 member Community Supported Agriculture (CSA) program, the New York City Green Market, the Hawthorne Valley Farm Store, and other retail stores in the Northeast. There are also three educational institutions located at HVF, including a Waldorf School (HVF website, 2/23/08).

The FEP is a part of this larger agricultural and educational organization. Established in 2003 by Drs. Conrad Vispo and Claudia Knab-Vispo, the FEP is dedicated to exploring the relationships and interactions between agriculture and the local environment of Columbia County (HVF website, 2/23/08). One of the motivating factors in their work is "to help the general public see the potential positive interactions between regional farming and nature conservation" (FEP website, 2/23/08). To do so, the FEP has partnered with a variety of local and state, private and public, organizations ${ }^{1}$ as well as with volunteer researchers over the past four years. In addition to these partnerships, the FEP publishes and posts semi-annual reports of their research, a newsletter - The Fritillary and Bluestem - and numerous newspaper articles to keep people abreast of their work as well as opportunities for participation. They also host a variety of public programs such as nature walks and talks, which take place both on-farm and throughout the county.

One of the FEP's most recent endeavors is the "Know Your Place Project" (KYPP). When the research that informs this thesis began, Conrad described the KYPP

\footnotetext{
${ }^{1}$ As an example, a current FEP project, Stream Corridors of Columbia County: Sharing their Biodiversity Value and Encouraging their Conservation, involves the Columbia Land Conservancy, the Columbia County Soil and Water Conservation District and Hudson Basin River Watch, as well as volunteer researchers (Personal communication, 11/2007).
} 
as "a participatory research project designed to map the history, ecology and socioeconomics of Columbia County through a process that invites diverse public participation... to stimulate informed public involvement in land use decisions" (Personal communication, C.Vispo to author, 12/2008). Overall, his long-term hope was for the KYPP to be an emergent and generative process that would foster a continuing capacity for place-based sustainability (Personal communication, C.Vispo to author, 1/2008).

In order to address the goals of the KYPP, Conrad organized it into two overlapping components: a product and a process. The first of these was the tangible end product: a countywide atlas of landscape changes ${ }^{2}$ that was to be created using people's input and involvement. Second but of equal or greater importance were the participatory strategies that would be developed to plan, research, disseminate, and evaluate the project as well as continue to engage people with the landscape and land use decisions (Personal communication, C.Vispo to author, 12/2008).

\section{From Conservation Biology to Focus Groups}

My involvement with the FEP began when I contacted Conrad in October 2007. I was searching for a field-based research internship that would fulfill a conservation biology graduate certificate requirement. I was interested in their upcoming, 2008 research, which was focused on the hydrogeomorphology of riparian forests in Columbia County. At that time, I was neither very familiar with the FEP's work nor did I have any conception of the KYPP. I only knew the FEP existed because I had visited Hawthorne

\footnotetext{
2 For references to similar projects, see "The Adirondack Atlas: A Geographic Portrait of the Adirondack Park" (Jenkins and Keal 2004) or the University of Vermont's PLACE Program (http://www.uvm.edu/place/) (C. Vispo, personal communication, $11 / 2007$ and $1 / 2008$, respectively).
} 
Valley Farm once before in the summer of 2006 as part of a farmer apprentice program called CRAFT: Collaborative Regional Alliance for Farmer Training³.

Again, rather than looking for a means to study participatory research per se, my reason for contacting the FEP in October 2007 was to intern with their floodplain forest research project. As we discussed that project, however, and the possibility of my working for the FEP, we began to talk about the KYPP. The FEP - Conrad, in particular - was looking to get input for the Project from a sociological perspective and was therefore interested in my input as a graduate student in rural sociology (Personal communication, C.Vispo to author, 10/2007). And after talking about the KYPP, I found that I was interested in its broadly inclusive approach and the diverse yet related topics it sought to explore: agriculture, community development, ecology, education, history, natural history, and socioeconomics. I valued its ultimate aim of connecting people to the landscape through a combination of research, outreach, and public participation. It also matched up well with the master's degree I was pursuing in rural sociology with an emphasis on agriculture and the environment ${ }^{4}$. By December 2007, Conrad and I had begun to develop plans for integrating my conservation biology internship with work that would address both my thesis interests and requirements and the goals for the KYPP. This work was to focus on developing and implementing the KYPP's initial participatory approaches.

We eventually selected and used the focus group interview to develop the KYPP with public participation. This thesis is based on the 5 focus groups we conducted during the summer of 2008. It is a reflection on the processes of developing, conducting, and

\footnotetext{
${ }^{3}$ At the time, I was working on a farm in the region and was a participant in the CRAFT program. See the CRAFT website for details of the program: http://www.craftfarmapprentice.com/.

${ }^{4}$ For further information about the degree program see: http://dass.missouri.edu/ruralsoc/grad/
} 
analyzing them, with particular consideration given to the strengths and weaknesses of the methodology as a participatory approach to research. These strengths and weaknesses are specifically considered in light of both the goals of participatory research and those of the FEP - the integrated purposes for which the focus group methodology was selected. Finally, in order to evaluate these aspects of the focus group, the contextual elements of this research - the researcher (myself), the FEP, and the community of Columbia County - are also features of the analysis.

\section{Statement of the Problem and Justification for the Study}

There is reason to believe that focus groups can function as a participatory approach to research (Morgan 1996, Morgan 2002). However, there is little known about how focus groups should be modified and conducted in order to make them suitable as a participatory approach. There is similarly little known about the reasons for the methodology's potential strengths and weaknesses as a participatory approach. Morgan (2002) directly cites these methodological issues as areas of needed focus group research. He also offers a reason for their relative neglect and potential value:

This lack of methodological detail is understandable in a form of research that is driven by its action orientation. Yet once the value of focus groups for participatory action research is well established, that should motivate the appearance of "how-to" articles specific to that field. When that happens, focus group researchers outside the field will also be able to benefit from these innovations (p156).

This thesis contributes to bridging the aforementioned gaps of knowledge by examining how my use of the focus group methodology fared as a participatory research approach in terms of: 1) the principles of participatory research for which they were selected, and 2) the stated goals of the organization for whom they were employed. Furthermore, by using a reflexive analysis of the process, this thesis also explores the 
possible reasons the focus groups functioned as they did, which reflects an attempt to make both the successes and failures instructive to future projects. The immediate goal, then, is to reflect on how the focus groups were designed, implemented, and analyzed in order to examine where they were most and least successful as a participatory strategy. The further hope is to contribute to a better understanding of the focus group methodology and its applications for participatory research.

\section{Purpose of the study}

The purpose of this thesis is to analyze reflexively each of the major stages of the focus group methodology as used in the KYPP in order to identify how the methodology performed as a participatory approach to research.

\section{Research Objectives}

1. Describe the four major stages of the focus group methodology - recruiting, developing the questions, interviewing, and debriefing - as well as the pre-focus group planning and post-focus group analysis and reporting stages as they were conducted for the KYPP. This includes reflection on the reasoning behind our decisions and a consideration of what was planned and what actually happened.

2. Describe these six stages of the focus group methodology in terms of how they performed as participatory research by evaluating them against 1) principles of participatory research and 2) the FEP's objectives for conducting the research. Here also, reflect upon the contextual factors that might have influenced these results. 
3. Explore the implications of these results on the use of focus groups as a participatory approach to research.

\section{Limitations of the Study}

Two primary limitations specific to the research methods used in this thesis are addressed here as well as a discussion of biases in the research. First, case studies as well as focus group interviews and participatory research approaches are essentially contextual. While this thesis attempts to identify some of the strengths and weaknesses of the focus group methodology, it can only do so from within the particular contexts of each focus group's development, implementation, and analysis. Second, case studies are commonly critiqued with respect to their "rigor" and for issues related to "scientific generalization" (Yin 2002, p10). None of this is to say that the potential applications of this thesis, or the focus group research that undergirds it, are completely restricted to only the context in which the research was conducted. Rather it suggests that anyone who wishes to utilize this research for any purposes outside of (or even within) its research context needs to consider and account for its situational influences and limitations. To assist such applications, I attempt to mitigate this research's limited scope by 1) using recommended methodologies for case study research as well as for organizing, moderating and analyzing the focus groups (as guided by current literature and "expert" recommendations); and 2) including a concerted reflection on the contextual influences throughout.

Regarding this reflexivity, my own biases, inclinations, and shortcomings (including those that I am unable to recognize and therefore bring to conscious light) will 
likely pervade most or all of this research. But I cannot disclose those features that are outside of my awareness. As Seale (1999) points out, there are many aspects of the researcher that will be present in their work regardless of how reflexive they are. In light of this, I will attempt to use what he refers to as a "fallibilistic attitude" in my analysis (p161), neither trying to remove myself from the process by hiding behind my reflexivity nor focusing too heavily on my influence and thus failing to let the data speak.

It is still important to note those values that I consciously bring into this research and of which any reader should be aware. First, I have an interest in and I support the concept of participatory research. Were it not for such an interest, I would not have put so much time into the focus groups and their analysis in order to assist the FEP with the KYPP, nor endeavored to spend so much time reflecting upon the focus group process in order to write this thesis. Second, I do not believe in the neutrality of either the researcher or of scientific processes. Therefore, taking the advice of Guba and Lincoln ${ }^{5}$ (1994), I disclose that I approach the research process with a paradigm similar to what David Orr (1992) called "constructive postmodernism ${ }^{6}$." This relates both to my interest in participatory research and my interest in attempting a reflexive analysis in order to bolster the methodology of the focus group as a participatory approach. Third, I am a novice to the field of research in general and focus group research in particular. I am writing this thesis as a candidate for an M.S. in Rural Sociology. This research is the first

\footnotetext{
5 "Paradigm issues are crucial; no inquirer, we maintain, ought to go about the business of inquiry without being clear about just what paradigm informs and guides his or her approach" (Guba and Lincoln 1994, p116).

${ }^{6}$ In the introduction to Ecological Literacy: Education and the Transition to a Postmodern World, Orr (1992) describes his version of constructive postmodernism: "Going beyond the modern world will involve transcending its individualism, anthropocentrism, patriarchy, mechanization, economism, consumerism, nationalism, and militarism. Constructive postmodern thought provides support for ecology, peace, feminist and other emancipatory movements of our time, while stressing that the inclusive emancipation must be from modernity itself. The term postmodern, however, by contrast to premodern, emphasizes that the modern world has produced unparalleled advances that must not be lost in a general revulsion against its negative features" (quoted from the introduction, no page number).
} 
time that I have organized, conducted, and analyzed focus groups. It is also the first time that I have undertaken an academic case study. There will likely be some mistakes but perhaps also some useful insights associated with the resultant learning curves.

These three considerations along with the limitations already mentioned should all be borne in mind while reading and interpreting the following analyses. 


\section{REVIEW OF LITERATURE}

Three areas of literature stand out as particularly relevant to this thesis. The first concerns focus groups. The second literature addresses participatory research,

particularly as related to the social sciences and, where possible, to focus groups. The third is literature that relates to reflexivity and the role of context (i.e., the researcher, organization, community, and environment) in evaluating the research process.

\section{Focus Groups}

\section{A Brief History of the Focus Group Interview}

Group interviews are not a new form of research. Perhaps the earliest published group-interview-based research in the social sciences was in 1926 (Morgan 1997). Around that time, there were concerns within the social sciences regarding the methodology of interviews in general, and researchers were beginning to search for alternative methods (Krueger and Casey 2000). In particular, there was an interest in developing techniques that would allow the researcher to "take on a less directive and dominating role" than was common in individual interviews (ibid., p5). This led to an increase in non-directive interviewing, which was based on open-ended questions that provided less direction as to the types of answers that respondents might give (Krueger 1994, Krueger and Casey 2000). But the focus group interview as a specific research technique in the social sciences was not developed until the 1940s (Berg 1998, Morgan 1997, Morgan 2002). 
During World War II, focus group interviews were first used by the United States military to explore issues relating to morale (Krueger and Casey 2000). Sociologists Robert Merton and Paul Lazarsfeld are typically credited as the pioneers of this research (Berg 1998, Morgan 1997, Morgan 2002). As the story goes, Merton was introduced to the idea when Lazarsfeld invited him to attend a group session testing people's responses to radio programs designed to boost morale in the army. Afterwards, Merton picked up the idea of using group strategies to assess attitudes and opinions, and he continued to work with Lazarsfeld on the "radio response project" (Berg 1998). Then, in 1956, Merton and Patricia Kendall published an article in the American Journal of Sociology, which was called "The Focused Interview." In 1957, he and two others published a book of the same title (ibid.).

Over the next two decades, the use of focus groups in academic research was limited. Yet while they were used only minimally in academic social sciences, perhaps because of the relative dominance of quantitative methods in that time period, the focus group remained a commonly used technique in applied marketing research (Krueger and Casey 2000, Morgan 2002). And there they remained until the early 1970s. At that time, social marketers began to "apply their technique to 'social problems,' not just to the marketing of goods and services," which eventually led to a partnership with applied demography (Morgan 2002). But the phase of more "active experimentation with focus groups" in the academic social sciences did not begin until the mid to late 1980s (ibid., p142).

From the 1980s throughout the 1990s focus groups became more common. They continued to be used in the field of applied marketing but also were increasingly adopted 
by public and nonprofit agencies and in a variety of academic fields such as communication studies, education, political science, public health, and sociology (Krueger and Casey 2000, Morgan 1997, Morgan 1996). And although they are typically conducted in person, some focus groups have even been used in on-line settings (Litoselliti 2003). By the end of the 1990s, more than 200 articles making use of focus group research were published per year in Sociological Abstracts and Psychological Abstracts (Morgan 2002). Rosaline Barbour and Jenny Kitzinger (1999) note a similar trend, citing a three-fold increase in focus group studies published in academic journals since the mid-1990s. Indeed, they preface their 1999 compendium on focus group research with the following: "This volume is a response to the unprecedented popularity currently being enjoyed by focus groups" (p1). It is clear, then, that there has been a marked increase in the use of the focus groups over the past few decades. But how is the focus group defined as a methodology?

\section{The Methodologies of Focus Groups}

Until the 1990s, the methodology of the focus group was fairly vague. This was perhaps a result of their being more typically used as a marketing tool; the need for a well-documented methodology was neither a necessity nor was it of primary importance to marketers as it would have been for academics (Morgan 2002). Over the past two decades, however, the increased use of focus groups in academia has yielded a greater methodological rigor as well as a variety of opinions on what constitutes a focus group and how and when they should, or should not, be used (ibid., Krueger and Casey 2000, Litoselliti 2003, Morgan and Krueger 1998). 
Morgan (1996) offers a concise definition that highlights the essential, yet also interpretable, qualities of the focus group. He defines them as "a research technique that collects data through group interaction on a topic determined by the researcher" (p130). This definition identifies three critical features: 1) focus groups are a research and data collection methodology, 2) focus groups rely on group interaction as the source of their data, and 3) the researcher is an active part of this group interaction and discussion. The definition also excludes other potentially related but ultimately dissimilar group methodologies, such as those used for purposes other than research (i.e. therapy, education) or those that do not involve group interaction (i.e. Delphi Groups) (ibid.).

Because it is group interview-based research, a focus group requires someone to interview the participants as well as provide guidance. This is provided through the position of a facilitator, usually called a moderator (Berg 1998). The moderator's role is of critical importance to the focus group process (Litoselliti 2003, Morgan 1996). Their fundamental job is to guide the group's discussions but not participate in them (Krueger 1998). This means that moderators do not share their views about the topic(s) being studied or engage in the discussion; rather their role is to ensure that the topical questions of the research are addressed by establishing a comfortable atmosphere within the group, paying careful attention to participant responses and body language, encouraging all participants to be a part of the discussion and managing the time (Krueger 1994, Krueger 1998, Litoselleti 2003).

Finally, the focus group process can be neatly summarized into four stages. These stages, which will be explored in a modified form in Chapters IV and V, are drawn from Krueger and Morgan's (1998) six part Focus Group Kit: 
1. Planning the research

2. Developing the questions

3. Moderating the focus group

4. Analyzing the data

\section{The Uses and Limitations of Focus Groups, Room for Improvement}

Focus groups have broad appeal as a research tool, as evidenced by their variety

of academic and non-academic functions. But like any research tool, they have advantages and disadvantages that make them more or less suitable to any particular project. For example, and again as with any research tool, they are subject to "careless or inappropriate use," potential data manipulation and even mistreatment or exploitation of participants (Barbour and Kitzinger 1999, p 2). The question, then, is what are the recommended times and reasons to use focus groups and when should their use be avoided?

One way of answering this question is to identify the utility and limitations of the focus group methodology. In Using Focus Groups in Research, Lia Litoselliti (2003) summarizes the work of seven academic researchers regarding the appropriate uses and the limitations of focus groups. The former are summarized in Table 1, the latter in Table 2, below: 
Table 1: Focus group uses

Focus groups are useful for:

1. Discovering new information (for example, about a new product) and consolidating old knowledge (for example, examining people's habits)

2. Obtaining a number of different perspectives on the same topic, in participant's own words

3. Gaining information on participant's view, attitudes, beliefs, responses, motivations and perceptions on a topic; 'why' people think or feel the way they do

4. Examining participants' shared understanding of everyday life, and the everyday use of language and culture or particular groups

5. Brainstorming and generating ideas, with participants discussing different angles of a problem, and possibly helping to identify solutions

6. Gaining insights into the ways in which individuals are influenced by others in the group (group dynamics)

7. Exploring controversial issues and complex or sensitive topics.

(Litoselliti 2003, p18)
Table 2: Focus group limitations

\section{Potential Limitations of focus groups:}

1. Bias and manipulation: danger of leading participants and encouraging them to respond to your own prejudices; participants saying what they think you want to hear

2. 'False' consensus: some participants with strong personalities and/or similar views may dominate the discussion, while others may remain silent

3. Difficulty in distinguishing between an individual view and a group view: groups sometimes appear more consistent than they are because individuals who disagree may not say so; groups often generate more emotion than any of the individual participants may feel about the issue; individual behavior is subject to group influence

4. Difficulty in making generalizations based on the focus group information (not only because of the limited number of participants, but also due to the difficulty of having a really representative sample)

5. Difficulty of analysis and interpretation of results (due to the open-ended nature of focus groups and the influence of many immediate situational factors)

(Litoselliti 2003, p21)

Many researchers note that focus groups are not often suggested for quantitative data collection (Barbour and Kitzinger 1999, Krueger and Casey 2000); instead, focus groups are typically employed in the collection of qualitative information (Morgan 1998).

However, focus groups can be used either independently as qualitative research or in combination with other methods, including quantitative techniques. For example, Morgan (1996) notes that a content analysis of published research in Sociological Abstracts showed that in $60 \%$ of the cases where focus groups were used they were conducted in combination with other research methods. Thus, the focus group is 
common as a "self-contained" methodology, but it is also frequently paired with other data collection techniques (ibid., p130).

There is a great deal of leeway and interpretation possible in the use and implementation of a focus group. This variability is linked to issues of the focus group's broad applicability, the characteristics of the study's population, the size of the focus group, the focus group's environment, the moderator(s), and the amount of structure provided during the focus group itself (Berg 1998, Morgan 1997). Recognizing this flexibility, the authors of the Focus Group Kit (1998) state that:

Perhaps the greatest myth is that there is 'one right way' to do focus groups. We thus encourage you to find the way that is right for you - and that most definitely includes experimenting with new ways to do focus groups...

(Krueger and Morgan 1998, p54).

That quote highlights the current status of focus groups as a simultaneously welldefined methodology - i.e. “...it is a systematic and disciplined approach...” (Krueger 1994) - that is also highly interpretable, situational and relatively new, at least in terms of its more recent re-emergence within the field of sociology (Krueger and Morgan 1998). Therein is the connection with this thesis: to explore the advantages and limitations of the focus group methodology as a participatory strategy based upon the particular context within which the research took place.

The call for this type of research is identified in the focus group literature. In the early 1990s, for example, a group of social science researchers convened regarding the use of focus groups. This meeting eventually resulted in Morgan's 1993 synthesis: "Future Directions for Focus Groups" (Morgan 1996). And in his more recent work he echoed many of those academics' recommendations, which indicates their continuing relevance (Ibid.). 
One of the specific recommendations that Morgan (1996) notes is "the need to further define the strengths and weaknesses of the method" (p148). He also addresses what he considered to be the "promising new uses for focus groups" (p149), one of which is participatory research. Other researchers have also identified this potential, yet still to be explored and refined, use of the focus group (Baker and Hinton 1999, Cornwall and Jewkes 1999, Krueger and Casey 2000).

The next two sections of the literature review will explore the concepts of participatory research and reflexivity in order to identify standards by which a focus group's implementation can be measured and refined.

Participatory Research

A Brief Background on Knowledge Systems, Academia and Participatory Research

Rachel Baker and Rachel Hinton (1999) introduce their essay, "Do focus groups facilitate meaningful participation in social research," with a question: "What does 'participation' mean in a research context" (p79)? This is pertinent because, as with focus groups, participatory strategies in academic research are relatively new phenomena, and are often contested (Cornwall and Jewkes 1999, Strand et al. 2003). At least in part, this lack of participation is related to the different ways in which knowledge in academia has been defined and valued.

Typical dichotomies of knowledge tend to differentiate between 'scientific' and 'non-scientific' or 'universal' and 'local' knowledge (Arce and Long 1992, Kloppenberg 
1991). As Jack Kloppenberg $(1991 ; 529)$ describes it, the general tendency has been to validate the former over the latter ${ }^{7}$ :

But today it is not the herbalist but the biochemist, not the midwife but the obstetrician, not the craftsperson but the engineer, not the campesino but the agronomist who dominates knowledge production and deployment. What we all know as scientific knowledge has attained a virtually undisputed intellectual hegemony, while local knowledge has been pushed to the epistemic peripheries, its utility so poorly understood that we have difficulty even labeling it.

A constructivist or postmodernist critique of this zero-sum relationship between the two forms of knowledge would claim that the reality of the ambiguity and contextual nature of knowledge has been suppressed in favor of a single way of knowing (i.e. "the truth") through objective, positivist science (Guba and Lincoln 1994, Fontana 2002, p162). As Arce and Long (1992) point out, however, knowledge can be defined in a way that applies to multiple ways of knowing, both to "scientific" and "everyday forms of knowledge" (p211). Their understanding is that "Knowledge is constituted by the ways in which people categorize, code, process and impute meaning to their experiences;" and their suggestion is that we should not therefore "equate knowledge with some profession, specialized or esoteric set of data or ideas" (p211). In other words, scientists and other professionals can still produce valuable knowledge but so can everyday people.

The legitimation of diverse knowledge systems is part of a broader set of challenges to the divide between scientific and lay knowledge. In the social sciences, these challenges can be heard in discussions about differing paradigms or worldviews, such as positivism and constructivism (Guba and Lincoln 1994) or modernism and constructive postmodernism (Orr 1992). Or they can be found in the works of critical

\footnotetext{
${ }^{7}$ Guba and Lincoln (1994) would call the scientific knowledge system described by Kloppenberg (1991) a positivistic worldview; they describe this positivist worldview as having "dominated the formal discourse in the physical and social sciences for some 400 years" (108).
} 
theorists seeking to "combine, rather than separate or eliminate, the poles of explanation and understanding, structure and agency," so as to transform "reflexive social inquiry into practical knowledge" (Bohman 2003, p91-92). In particular, these discussions call into question the 'reality' of objective science and suggest that cultural, social, historical, and other contextual factors influence ways of knowing (Guba and Lincoln 1994). In many ways, these discussions challenge the superficiality of the division between scientific and lay knowledges; thus, they have contributed to weakening the divide between objective and subjective forms knowledge. Indeed, in the past few decades, a variety of disciplines have begun to acknowledge that the two ways of knowing are mutually compatible and to incorporate lay knowledge systems and local values into the scientific approach.

Participatory research is one example of this (Cornwall and Jewkes 1999, Hayward et al 2004, Israel 1998).

Participatory research has also been used as a means of removing the unnecessary boundaries between academic, information-oriented research and applied, action-oriented research. For example, Strand et al. (2003) identified three reasons for the development of community-based research ${ }^{8}$ in Universities. These included 1) criticisms of higher education's lack of involvement within their communities; 2) criticisms of the narrowly specified definitions of scholarship; and 3) increased recognition that campuses were not adequately preparing their students to be socially responsible and civically and politically engaged (ibid.). But there is still work to be done regarding the incorporation of participatory approaches into academia. Consider Morgan's (1996) description regarding the use of focus groups in participatory research as one of the method's "promising

\footnotetext{
${ }^{8}$ Community-based research is one type of research that, for the purposes of this research, falls within the overarching category of participatory research. This is addressed below.
} 
alternatives" (p149). In his opinion, the feature that underlies participatory approaches, and to which focus groups could contribute, is that they endeavor "to break down the division between using groups as a means for gathering data and as a means for educating, mobilizing, or intervening with participants" (ibid., p149). In this case, he is advocating that a specific connection be made between research for information and for action, which implies a current lack of such a connection in academic focus group research.

Finally, none of this is to suggest that expert or scientific knowledge should be discredited (Orr 1992); rather, a purpose of participatory research is to re-elevate and acknowledge the value of knowledge that is produced and transferred by everyday people through means other than strictly conventional academic, scientific routes (Stoecker 1999). Thus, the inclusion of people other than academic researchers in the research process is one way to bridge the gap between these two forms of knowledge. This, then, brings us back to Baker and Hinton's (1999) question: what does participatory research mean within the context of research?

\section{Participatory Research Principles}

Participatory research is a bridging strategy of scientific research, spanning the gap that has been created between scientific and local knowledge. Cornwall and Jewkes (1999) put it this way: "Participatory research offers ways of making conventional science more relevant, by creating an environment in which new knowledge can be synthesized through a dialogue between Western scientific and local knowledges"

(p1674). Participatory research, or what Pain and Francis (2003) call "participatory 
approaches" (p46), also tends to be an umbrella term. For the purposes of this thesis, it is viewed as largely synonymous with action research, participatory action research, collaborative research, community-based research, community-based-participatory research, and other similar models (Stoecker 2005). Although nuanced distinctions do exist between the various analogues of participatory research, they share more in common than they differ.

One basic point of agreement is an emphasis on conducting applied research that directly incorporates people's perspectives and input, if not their direct involvement in all or portions of the research process (Israel et al. 1998, Lauber and Knuth 2000, Rowe and Frewer 2000, Strand et al. 2003). As Pain and Francis (2003) suggest, “...real participation in research must go beyond contact with the researchers during data collection" (p51). Participatory research is also frequently conducted for the explicit use of those involved or affected by the inquiry, so as to affect some type of change desired by the participants (Barbour and Kitzinger 1999, Israel et al. 1998, Strand et al. 2003). Indeed, participatory approaches are often related to the principles set forth by Paulo Freire's (1970) Pedagogy of the Oppressed; these include, for example, the validation of local agency and knowledge, the empowerment of people to own the process, and their ability to affect change (Cornwall and Jewkes 1999, Strand et al. 2003).

Participatory research is also essentially contextual ${ }^{9}$. Quite the opposite of a universal prescription for research, many scholars insist that participatory research requires an attentive, situation-dependant research formation and implementation process, one that depends on and accommodates the needs and interests of both researchers and

\footnotetext{
${ }^{9}$ Hayward et al (2004) suggest, "Participation is a rich concept that means different things to different people in different settings. For some, it is a matter of principle; for others, a practice; and for still others, an end in itself" (p98).
} 
participants (Cornwall and Jewkes 1999, Chase et al. 2004, Conley and Moote 2003, Gatseyer and Flora 2000, Israel et al. 1998, Stoecker 2005). Reflexivity and flexibility are commonly suggested practices that can be used to identify and address those needs and interests through the creation of greater transparency and by allowing for mutual improvements in the participatory process (Cornwall and Jewkes 1999, Pain and Francis 2003).

Many authors also claim that participatory research is more of an attitude toward the research process than a specific technique (Cornwall and Jewkes 1999). For example, some authors argue that participatory research is best viewed as part of a process and not solely as a means to a research-oriented end; it is empowerment in and of itself (ibid., Stoecker 1999). The point of this distinction is that participatory research is not just about producing data. It is also about empowering the participants to affect change, and it is "only a method to achieve these broader goals" (Stoecker 1999, p845). Other authors, however, such as Hayward et al. (2004), contend that participatory approaches can and in fact should be used both as a means and an end ${ }^{10}$. They suggest that participatory approaches should simultaneously empower and organize action within a community (ibid.).

In short, participatory research must be both applied (action-oriented) and engaged by the study participants. Stoecker (2005) offers a simple, three-part overview of the common features of participatory research (Table 3). These three elements call attention to the principles summarized in the review above.

\footnotetext{
${ }^{10}$ See Hayward et al (2004) for a selection of authors who view participation as either, or both, a means and/or end.
} 
First, a participatory approach

needs to address the goals and interests of

the researchers and the participants,

it needs to respond to mutually desired

means and ends. Second, participatory

Table 3: Elements of participatory research

Participatory Approaches to Research: Common Elements

- Focuses on being useful

- Employs diverse methods

- Emphasizes collaboration

(Stoecker 2005, p30)

approaches often make use of a variety of methods. The method(s) chosen should suit

the context of the research and make sense to the participants so that empowerment takes

place as new knowledge is generated. Finally, a participatory approach should work with

participants to address the previous two elements and during all aspects of the research

process, from identification of research questions to construction of final products and

actions (Stoecker 2005).

\section{Critiques of Participatory Research, Room For Improvement}

Perhaps the most common critique of participatory approaches concerns the difficulties of their application in research, a challenge of moving from the ideal to the real. Stated differently, "The ideals of democracy the methodology embodies create contradictions in the context of its use" (Cornwall and Jewkes 1999, p1671). In other words, it is difficult for a research project to achieve complete adherence to participatory ideals, such as definitely affecting a desired change or achieving full participation in all stages of the research ${ }^{11}$ (ibid., Pain and Francis 2003, Stoecker 1999).

There are also more serious critiques of participatory approaches. In many cases these criticisms have emerged from one of the original contexts of participatory

\footnotetext{
${ }^{11}$ It's important to note here that some authors suggest that full participation in all of the research stages is not necessarily the best measure of participation. For example, there may be times where people desire less participation and have thus exercised their own choice to remain less involved (Hayward et al 2004).
} 
research $^{12}$ : international development (Pain and Francis 2003). Three main categories of criticism have been identified: 1) participatory research is conducted in name only, and may, in fact, be extractive research that is neither equitable nor beneficial to the participants; 2) there are weaknesses in the methodology, such as a lack of reflexivity and validity; and 3) there are times and events wherein participation cannot live up to its claims, making it potentially 'tyrannical' (ibid., p48). This third criticism attacks the very foundations of participatory research.

Another critique of participatory approaches is that it sometimes results in contrary and undesirable consequences. This might include, for example, participants being put at risk or growing alienated within their community because of their involvement (Baker and Hinton 1999, Cornwall and Jewkes 2003). Some authors also suggest that participation is not always or entirely appropriate, or that there are cases where it might be desirable to influence local knowledge with scientific knowledge, such as with medical research into the aetiology of a disease (Cornwall and Jewkes, 2003). Conversely, there are some cases where reflexive and participatory research is complimentary and beneficial to medical research (ibid., Bohman 2003).

Perhaps more germane to this thesis, participatory research runs the risk of raising people's expectations about what a research process can do and how it will be used (Barker and Hinton 1999). They may also, at times, provide little in the way of actionable results. The complex reality of participatory approaches is that, like any research strategy, they comprise many tools and techniques whose results may vary.

\footnotetext{
12 According to Park (1999), the term "participatory research" was first used by development workers in Tanzania, who utilized local participants in order to improve upon their data gathering and project implementation.
} 
In light of these critiques, it is useful to have a clearer understanding of the differences between participatory and conventional approaches. In their article, "What is Participatory Research?” Cornwall and Jewkes (1999) illustrate these differences by presenting the approaches as two distinct, idealized types of research (Table 4). These typologies identify the ideals of local inclusion and empowerment that are common to participatory approaches. They also highlight how participatory practices are conceived differently from conventional research conducted in most academic institutions.

\section{Table 4: Elements of participatory and conventional research}

\section{Participatory research \\ Conventional research}

Action

Local people

Local people's

Local priorities

Empowerment, mutual learning
Understanding with perhaps later action Institutional, personal and professional interests Scientists'

Funding priorities, institutional agendas, professional interests

Disciplinary conventions, 'objectivity' and 'truth'

Who takes part in the research process?

Problem identification

Data collection

Interpretation

Analysis

Presentation of findings

Action on findings

Who takes action?

Who owns the results?

What is emphasized
Local people

Local people

Local concepts and frameworks

Local people

Locally accessible and useful

Integral to process

Local people,

with/without external support

Shared

Process
Researcher

Researcher, enumerator

Disciplinary concepts and frameworks

Researcher

By researcher to other academics or funding body Separate and may not happen

External agencies

The researcher

Outcomes

(Cornwall and Jewkes 1999, p1669)

Pain and Francis (2003) recognize a similar distinction between participatory and conventional approaches to research. They note that academic research is one area in which the implementation of participatory approaches tends to be more problematic than 
is often recognized. Other researchers support this claim. Stoecker (1999), for example, suggests that "compromises" are common to participatory approaches used for academic purposes. Also discussing the academic context, Strand et al. (2003) note, "In practice, however, the full and equal participation of community members in every phase of the research may be somewhat problematic" (p11). Clearly, there is room for improvement in the implementation of participatory approaches in the academic context.

One goal of this thesis, then, is to explore how the focus group methodology, as an academic research method, is successful as a participatory approach. This may come about by virtue of the focus group process itself, because of the circumstances of its use (i.e. the people involved, the research topic, the organization and moderation, etc.), the results, or, more likely, from a combination of the method's qualities and other situational factors. Similarly, the thesis considers how the characteristics of the focus group methodology and its use in a specific context limit its function as a participatory tool. The following sub-section considers the role of reflexivity in focus group interviews and participatory approaches as well as in research analysis more generally.

\section{Reflexivity in the Research Process}

\section{Justifying Reflexivity}

As noted earlier, there has been an increasingly critical eye cast upon the ideal of an "objective" view of the world (Guba and Lincoln 1994). A number of implications arise from such criticism ${ }^{13}$. Within the purview of this thesis, however, the two relevant issues are the importance of context and reflexivity.

\footnotetext{
13 Guba and Lincoln (1994) call attention to a set of internal and external critiques of the positivist paradigm (intraparadigm and extraparadigm, respectively). For both categories of critique the influence of qualities, such as
} 
In Guba and Lincoln’s (1994) review of four major paradigms or worldviews, they contrast and compare positivism, postpositivism, critical theory, and constructivism. The latter three can be categorized as alternative perspectives that stand in contrast to the dominant (although increasingly critiqued) positivist paradigm. Of these three, the latter two are most relevant to the thesis because they focus on the contextual nature of knowledge, including features such as gender, ethnicity, culture, and history; they also concern social, political, and economic factors as well as multiple realities. Finally, they address the contextual and interactive nature of a methodology that is the transactional nature of research and the existence of relationships between researcher and participants (ibid., Israel et al 1998). Taken together these perspectives call for reflection upon the conditions in and through which research is conducted in order to evaluate the results ${ }^{14}$.

\section{Reflexivity in Participatory Research}

An important aspect of participation is its ability to bring about change, specifically as identified by the researchers and the participants. One can see, then, the inherent role of reflective practices in participation to determine for whom, and by whom, changes are pursued. Paulo Freire (1970), a noted source of inspiration for participatory practices, conflates action and reflection into the concept of praxis. As he sees it, "Only men are praxis - the praxis which, as the reflection and action which truly transform reality, is the source of knowledge and creation" (p91). This quote rallies the potentially

\footnotetext{
values, meanings and context, specifically in not-solely quantitative terms, are often identified as remedial to positivist flaws and/or as intrinsic to a more accurate and/or realistic worldview. Although a greater depth of discussion regarding their interpretations could be relevant to this thesis, herein it will suffice to note these critiques as a justification for the importance of qualitative research in general, and reflexive and participatory research more particularly.

${ }^{14}$ Paulo Freire (1970) states something similar: "Neither objectivism nor subjectivism, nor yet psychologism is propounded here, but rather subjectivity and objectivity in constant dialectical relationship" (p35).
} 
transformative capacity of humans as well as the necessity of their distinctly reflexive involvement in the process of transformation. Thus, for Freire there is an indissoluble element of reflection in participatory approaches.

Freire is not alone in calling for the union of reflexivity and participation.

Reflection is still identified as a valuable if not necessary aspect of current participatory approaches as well. Whether it is identified as a foundational characteristic of the approach or as a remedy to its potential weaknesses or misuses (Cornwall and Jewkes 1995, Pain and Francis 2003), reflexivity is at least miscible with if not intrinsic to the concept of participation.

According to Hayward et al. 2004 (95-96) however,

Participatory approaches to research and development have had relatively little academic or practitioner critique, resulting in a mythologizing of the power of participatory methodologies to accomplish problem solving, emancipation or empowerment

These authors suggest that the solution is to develop a more critical and reflexive understanding of the philosophy and practice of participation (ibid.). Likewise, in order to better evaluate participatory projects, Pain and Francis (2003) specifically call for reflexivity in the research process. They also suggest greater "openness" regarding the goals and the effects of the projects, arguing that "researchers should be honest and self critical about what was planned and what actually happened" (ibid., 53). The purpose of such transparency is to better understand where and how participatory approaches are strong, where they are weak and, in both cases, why. It is also intended to expose how the researchers own belief systems, values, and decisions might impact the data collection and, especially, the analysis. Without the academic honesty none of that is possible or, at 
least, it becomes a much greater challenge to make any improvements in participatory research.

\section{Reflexivity in Focus Groups}

Like many other authors of focus group literature, Litoselliti $(2003 ; 5)$ describes the importance of the roles of the moderator(s). She notes:

It should be acknowledged that, as with any method where there is communication between the researcher and the participants, the data produced will be influenced by the presence, role, and perceived background of the moderator and the participants

For Litoselliti, this is a preface to recommending that moderators consider what they disclose to participants as well as the optimal level of their involvement in the focus group (ibid.).

The quote above could just as well be used to justify the need for increased reflexivity in the focus group methodology. Indeed, being honest about the purpose of research is already identified as an important process in determining if the focus group is the right method to use for a project (Litoselliti 2003, Morgan and Krueger 1998). Some also suggest that researchers should more openly express their purpose and intentions to focus group participants. This is recommended to assuage participant concerns and allow them the ability to be reflexive about their own needs and the ways in which they would like to participate (Baker and Hinton 1999). Reflexivity is also incorporated into the focus group process by means of an on-going analysis: data are analyzed and considered throughout the process of conducting focus groups in order to inform and potentially change the techniques being used (Litoselliti 2003). 
The quote above could also function as a call for increased reflexivity in terms of considering how the researcher influenced the results, and suggesting that analysis should reflect such an understanding; although this is not the typical case. For example, most practitioners recommend that a data trail be created during analysis. This consists of a well-documented, systematic analysis and verification process that involves participants and can be evaluated by external parties (Krueger and Casey 2000, Krueger and Morgan 1998). The reasoning behind such documentation and verification, however, is to foster construct validity, to validate the concepts of "researcher neutrality and systematic procedures" (Krueger and Casey 2000, p1999) as well as to quell claims that focus group analysis are too "subjective" (ibid., Morgan and Krueger 1998). Certainly there are some benefits to maintaining a level of objectivity in the methodology, but such a focus somewhat obscures the researcher's ability to consider their role in affecting the data.

This focus on objectivity may well reflect the relative dominance of positivist methods in science in general and their influence on what gets published, as well as their influence on sources of funding and the need to justify one's research findings as "objective" (Guba and Lincoln 1994). Positivism has also influenced the use of focus groups more specifically (Cunningham-Burley et al 1999). However, it doesn't make null the influential role of the moderator in the focus group process, which many researchers already recognize (Litoselliti 2003, Morgan 1996, Krueger and Morgan 1998), nor the fact that they must also, therefore, influence the findings. Sarah Cunningham-Burley et al. (1999), for example, argue that focus groups are most successful when they are reflexive about their context. In particular, they specify that 
power relations, such as between funders and researchers, are of critical importance because "these underpin the generation of data and therefore knowledge" (198).

Improving our understanding of how researchers influence the process and outcomes of focus group research can thus help to improve the methodology. Any such improvements on the process and the data produced by focus groups through greater reflexivity will also be a boon if they are to be used in participatory research; recall that the dual purpose of a participatory approach is to provide an empowering process and useful outcomes (Cornwall and Jewkes 1994, Hayward et al. 2004, Israel 1998, Stoecker 2005, Strand et al. 2003). Therefore, if focus groups are to embrace their "promising" future role in participatory research projects more fully (see Morgan 1996), they will require much more reflexivity throughout the entire process. Morgan $(2002 ; 154)$ described it as such:

Paying serious attention to the argument that methods are shaped by the social and historical contexts in which they are used creates the possibility of revising and reinventing research methods. But doing so requires a reflexive awareness of why researchers use their methods in the ways that they do

\section{Summary: Connecting the Literature to the Thesis}

The areas of literature discussed in this review have been used to point to the existence of certain commonalities between the history and current understandings of participatory research and focus group approaches. These can be purposively organized to indicate the intentions of the upcoming analysis:

1) Participatory research approaches and focus groups are relatively new in the field of academic, social science research.

2) Participatory approaches and focus groups share an important methodological feature in common: although focus groups are more structured in terms of their definition 
and protocols, both are somewhat principled rather than dogmatic in application, making them particularly malleable to the influence of the researcher(s), the participants, and other contextual elements of the research process ${ }^{15}$.

3) Combined with their contextual approach to research, the relatively new status of participatory research and focus groups affords them a degree of flexibility that simultaneously allows for multiple and broad applications as well as a relative uncertainty about their strengths and weaknesses.

4) Literature indicates that participatory research and focus groups would benefit from increased reflexivity.

Even in light of the critiques of participatory approaches, there is still a call to reform conventional research to make it more participatory. As Cornwall and Jewkes (1994) put it, "Conventional research can, and has an imperative to, adapt to increasingly participatory agendas" (p1674). With these claims in mind, and considering the previously discussed features of the focus, there is an identifiable need to consider how focus groups function as participatory approaches.

In order to make these improvements, to understand the contextual factors that influence the focus group methodology and its potential as a participatory process, reflexivity is needed. In the absence of reflection, a researcher is likely to miss some of the factors that influence the research; thus, the results may be misguided, ineffective, or even wrong. With reflection, however, a researcher may become more aware of the factors that affect the process and outcomes of research, thereby conducting, reporting and making more effective use of their work. This may also improve the utility of the

\footnotetext{
${ }^{15}$ I posit here that the influence of the researcher, and other contextual elements, plays a significant role in the research process and outcomes of most, if not all, scientific research. This thesis, however, is only structured to explore these influences within a specific set of the focus group interviews.
} 
research for those who participate in research and/or use its results: they can more easily take into account the researcher's experiences and perspectives in order to utilize the data more effectively for their own purposes, an important consideration for any participatory approach. 


\section{PROCEDURES}

\section{Research Design}

This research uses a case study design to describe the processes of using focus groups as a participatory research approach in a place-based project - the Know Your Place Project (KYPP). Yin (2002) defines a case study as "an all-encompassing method, covering the logic of design, data collection techniques, and specific approaches to data analysis" (p14). He also identifies the following as the primary characteristics of the "technical definition" of case studies:

1. A case study is an empirical inquiry that

- Investigates a contemporary phenomena within its real life context, especially when

- The boundaries between the phenomena and context are not clearly evident.

2. The case study inquiry

- Copes with the technically distinctive situation in which there will be many more variables of interest than data points, and as one result

- Relies on multiple sources of evidence, with data needing to converge in a triangulating fashion, and as another

- Benefits from the prior development of theoretical propositions to guide data collection and analysis.

(Yin 2002, p13-14)

The specific type of case study used here is a single case design with embedded units of analysis (Yin 2002, p 40). The single case being studied is the process of using focus groups for the KYPP. The embedded units of analysis are the stages of each of the individual focus group interviews - recruiting, developing the questions, interviewing, 
debriefing $^{16}$ - as well as the planning that preceded the focus groups and the overall analysis and reporting that followed.

Furthermore, this thesis is an intensive (Stoecker 2005, p7) and exploratorydescriptive research project. Ary et al. (2002) define descriptive research as "Research that asks questions about the nature, incidence, or distribution of variables; it involves describing but not manipulating variables" (p558). Because there will be no manipulation of variables, and no hypothesis made in this research, there are no causal distinctions made between the characteristics of the subjects, such as into dependent and independent variables.

In the terminology of case study research, this thesis utilizes a descriptive analytic strategy (Yin 2002, 114) wherein the embedded units of analysis (i.e. pre-focus group planning or interviewing) are isolated and described so as to understand an overall pattern of interest, namely how well, and where, the focus group methodology functioned as a participatory research approach. Furthermore, the embedded units are analyzed chronologically. This chronological analysis occurs at the macro- and micro-level. In the case of the former, the analysis proceeds chronologically through the embedded units (i.e. the analysis begins with pre-focus group planning and ends with post-focus group analysis and reporting). At the micro-level, a chronological analysis occurs within the four embedded units that comprise the main stages of the focus group methodology. For example, the recruiting stages for each of the individual focus groups are reviewed as an embedded unit wherein each is analyzed chronologically (i.e. beginning with focus group

\footnotetext{
${ }^{16}$ The reader will note that the title and order of these stages is different from the stages listed on page \#17 of this thesis. The first two stages on page \#17, 'planning the research' and 'developing the questions,' have become the embedded units 'pre-focus group planning,' 'developing the questions' and 'recruiting.' The third stage, 'moderating the group,' has become 'interviewing' and 'debriefing.' And the final stage 'analyzing the data,' has become 'postfocus group analysis and reporting.' This new schema was introduced to allow for a finer examination of the processes as well as to reflect the way that I approached organizing, conducting and analyzing focus groups.
} 
\#1 and ending with focus group \#5). Then, the developing the questions stages for each

of the individual focus groups are reviewed chronologically as a single embedded unit.

The same process occurs for the interviewing and debriefing units (Figure 1).

\section{Figure 1: Analysis Map}

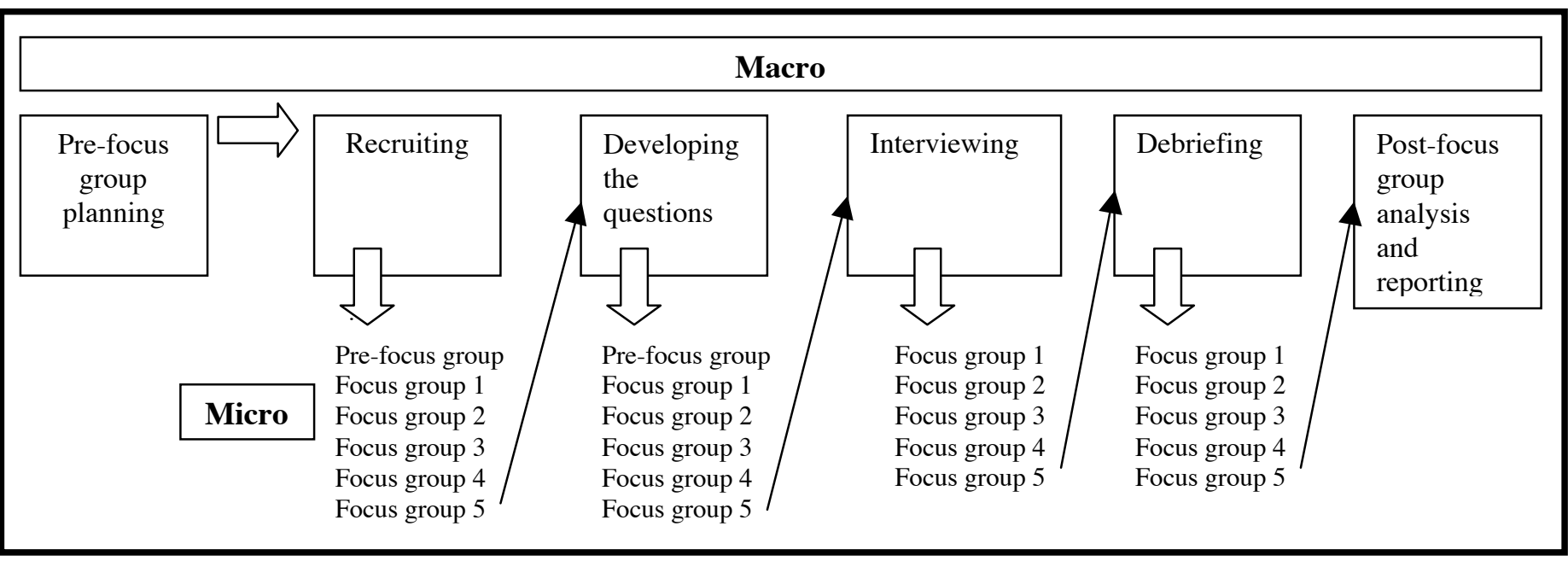

The ability to follow and describe the entire process in chronological progression from the development and implementation to the final analysis and reporting is a quality of the case study approach (Yin 2002). It also makes sense to examine focus groups chronologically because the methodology includes an on-going analysis, each focus group informs the subsequent interviews. As Litoselliti $(2003 ; 87)$ describes it:

Early and continuous analysis of each of a series of focus groups will help you to determine the number and focus of subsequent meetings, and will allow you to revise your topic guide or moderating techniques in light of the information gathered

The basic structure of this thesis, therefore, is a chronological, descriptive case study. The processes took place over the course of roughly one year, beginning in October 2007 and finishing in November 2008 (Figure 2). 
Figure 2: Timeline of embedded units

Pre-focus group planning (10/2007-6/2008) $\rightarrow$ Recruiting (2/2008 - 7/2008) $\rightarrow$ Developing the Questions

$(3 / 2008-7 / 2008) \rightarrow$ Interviewing $(7 / 2008) \rightarrow$ Debriefing $(7 / 2008) \rightarrow$ Post-focus

group analysis and reporting $(7 / 2008-12 / 2008)$

\section{Population and Sampling}

The data analyzed in this thesis are primarily drawn from the processes of developing, conducting, and analyzing five focus groups with the FEP in July 2008. Please refer to the discussion of my involvement with the FEP from Chapter I as well as the overview of the sampling and recruitment methods presented in Chapter IV. Additional 'Population and Sampling' topics such as frame error, sampling error, selection error, and non-response error are discussed in the next section.

\section{Instrumentation}

Yin (2002) identifies four criteria that case studies must address: construct validity, internal validity, external validity, and reliability. To address the first issue, this thesis uses two frameworks to analyze the participatory nature of the focus group process. These are described in the 'data analysis' section that follows. The thesis also uses three other procedures to address construct validity including "multiple sources of evidence" (see 'data collection'), maintaining a "chain of evidence" (see below regarding reliability and the case study database), and having the FEP and focus group participants review the reports I generated from the focus groups (ibid., p36). 
Internal validity is primarily a concern for explanatory and causal research, and so is not an issue here because of the exploratory-descriptive research design. External validity is relevant, however. External validity concerns the generalizations made from a research process, although an important distinction needs to be made regarding external validity in case studies. The purpose of this research is not to generalize to population or process, that is, to make statistical generalizations from the focus group data to the county or from this focus group process to all focus group processes. Furthermore, because random sampling for statistical inference is not an issue, frame error, sampling error, selection error, and non-response error are also not concerns. This research is instead focused on making analytic generalizations from a particular series of focus groups to their general utility as a participatory approach to research. Yin (2002) describes this as a process that seeks to "expand and generalize theories" (p10). Therefore, external validity, in the sense of analytic generalization, is addressed by this thesis' focus on five specific focus groups and their performance in relation to principles of participatory research.

Finally, the reliability of this research is addressed via transparency and documentation, which are also relevant to construct validity and external validity. Transparency and documentation are achieved by the provision of a clear description of the analytic frameworks as well as the description and documentation of the processes used for data collection, analysis, and reporting (Chapters IV and V). This documentation was done in an effort to create the "case study database" discussed by Yin (2002, p101). 


\section{Data Collection}

The focus groups are the primary source of data for this thesis, including the verbatim transcriptions and subsequent reports as well as notes and observations made before, during, and after the sessions. However, there are also emails, phone calls, and other conversations with the FEP as well as with residents of Columbia County, which were recorded and used to inform decisions made during the overall research process. There are also a limited number of individual and small group interviews conducted for the KYPP that informed the process. Additionally, throughout the summer's research, the FEP and I consulted various professors and advisors from universities and professional organizations in the United States. The advice from these consultations was also recorded, most frequently in the form of field notes, and funneled back to inform our methodological decisions. Finally, the reports I drafted following the focus groups were sent to the FEP and focus group participants for verification and commentary. Their responses, entirely in the form of emails, were saved for use in the analysis; nonresponses are commented upon as well.

\section{Data Analysis}

Two analytic frameworks are applied to the embedded units of this case study overlap. The first framework consists of the idealized standards of participatory research. However, because there are not any well-specified standards against which a participatory approach should be measured, much less a participatory focus group, Tables 3 and 4 will be used as the general benchmarks. These standards are applied to each of the six embedded units of analysis. 
Although each stage will be analyzed in terms of participation, the same participatory research standards do not necessarily apply across each stage. For example, one of the standards identified in Table 3 is "focuses on being useful," which is to say that the outcomes of the research process are usable by those involved. It does not make sense to evaluate this particular standard in the 'pre-focus group planning' unit of analysis. Therefore, in Chapters IV and V, I select the relevant participatory standards for each of the focus group's stages. These standards are then evaluated within each stage.

The second analytic framework addresses the specific purpose for which the focus group research was conducted: to help the FEP develop the KYPP in a participatory manner. Specifically, the FEP was interested in a participatory approach that would address the following questions:

1) Is the KYPP a good idea, a project worth pursuing? If so,

2) What maps and what themes of interest should be included in the KYPP?

3) What formats are most accessible for people?

4) In what ways do people want to be involved ${ }^{17}$ ?

The first framework is clearly relevant to these objectives. For example, the participatory principle that research "focuses on being useful" can be evaluated by considering how well the focus groups met the FEP's objectives. Even so, these four goals are considered in separate fashion from, though often simultaneously with, the first analytic framework. This differentiation is imposed in order to highlight and discern the strengths and the weaknesses of the focus groups as a participatory process (the first

17 (Personal notes, 1/2008) 
analytic framework) and as a functional, participatory input and data gathering method (the second analytic framework). The second framework, like the first, will also be described and evaluated, as appropriate, in Chapters IV and V. 


\section{FOCUS GROUP STAGES REVIEWED}

\section{Introduction}

This analysis is a tour of the process of developing, conducting, and analyzing the five focus groups I conducted with the Farmscape Ecology Program (FEP). Its purpose is to reflexively review the actions taken during this process, as well as the decisions that underlay those actions, in order to provide a more complete perspective on the methodological question of the thesis: how did the focus groups function as a participatory approach to research, and why? Chapter IV is a reflexive description of the six embedded units of this study. Its purpose is to develop the context of planning, conducting, and analyzing the focus groups. It sets the stage for the evaluation of these processes as participatory research approaches. Chapter V is the reflexive analysis. It involves the application of the analytic frameworks described in the previous chapter.

\section{Pre-Focus Group Planning}

The decision to use the focus group methodology for research precedes the processes of focus group planning, recruiting, moderating, and analysis. Like most methodological selections, this decision is often justified by the use of literature and the consideration of a method's application within a particular circumstance based upon previous researchers' recommendations (i.e., Tables 1 and 2). It is likely that additional often unstated factors are also involved in the selection of the research method. This 
embedded unit of analysis is oriented toward understanding these latter considerations:

the contextual factors of decision-making and methodological selection.

As described in the Chapter I, Conrad and I made the decision to use focus groups for the Know Your Place Project (KYPP or the Project) in early 2008. This decision, however, was not made without considering alternative methods as well as discussing the implications of using focus groups. Three pertinent questions are 1) what were the alternative methods and why were they not selected; 2) why were focus groups eventually chosen; and 3) what were the implications of focus groups that were $\operatorname{discussed~}^{18}$ ?

Regarding the first question, Conrad and I considered mail questionnaire surveys and individual interviews as our two initial options. These two methods were considered with respect to their dichotomous approaches to research. Using Stoecker's (2005) terminology, the distinction that I recognized between the two methods was that of "intensive research" versus "extensive research" (p7). Table 5 displays the differences between these two approaches. We discussed mail questionnaire surveys as a Table 5: Intensive and extensive research

Intensive Research

- Focuses on one or a few cases

- $\quad$ Strives for detail and depth of analysis

- Good for causal analysis

Extensive Research

- $\quad$ Focuses on a large number of cases

- Limits analysis to a few characteristics

- $\quad$ Good for mapping population properties

(Stoecker 2005, 7)

way of accessing a large number of county residents. Considering that the county's 2000 population was 63,094 (Columbia County Environmental Management Council website,

\footnotetext{
${ }^{18}$ It should be noted that I was the Conrad's primary source of information on methodologies. This is not to say that he was entirely unfamiliar with social science methods; rather, he was particularly interested in my input on methodological options based upon my academic background, as well as my access (as a graduate student) to professors and other "experts" in this field.
} 
12/9/08), however, we did not expect to be able to hear from every resident. Conrad was, nonetheless, explicitly interested in designing the KYPP as an inclusive project. He considered the entire population of the county to be the group from which input was sought. In one email on this topic, Conrad acknowledged the challenge that such inclusivity posed while making clear his broad interpretation of who and what the KYPP should be for:

From my perspective, everybody in the County is a stakeholder. I know that seems frustratingly broad, but the point is that I want to avoid focusing particularly on the interests of members of political or special-interest groups. Rather, I would like to understand which different approaches appeal to people from different socio-economic groups and with different personal interests...I would be very curious to know how you or your professors might tackle the task of getting input from a cross-section of the society, focusing on nothing more particular than past and future change in the socio-economic and ecological landscape of the County. We're not trying to get input in relation to any particular proposed change, we're not trying to build consensus, we're not even trying to alter behavior in any pre-specified way OTHER THAN getting people to think more about and be more observant of the change happening around them. We are trying to understand how best to inform people about the issues they care about with regards to this overall theme.

(Personal communication, C. Vispo to T. Biello, 1/10/08; emphasis added)

Eventually, we decided that while a mail questionnaire was desirable for its extensive qualities, it was probably not the most preferable method because the KYPP was still a nascent and thus somewhat vague project. There was some concern, for example, that there might not be enough public interest in the Project to justify the cost and effort of conducting a mail survey. We were also interested in getting more in-depth input into Conrad's main questions than we thought a mail survey could afford. Additionally, I was concerned about this option because of our uncertainty regarding people's familiarity with the KYPP's topic or the language that we might use to describe it (in writing the survey). My recommendation was that a mail questionnaire survey could be conducted in the future, perhaps even at the end of the summer, if Conrad was 
interested in pursuing that option based upon the results that we would get from some other, more intensive method.

The second option that we discussed was the individual interview. We expected that we could use individual interviews to get in-depth information about KYPP topics as well as mitigate the challenges posed by the KYPP's relatively nascent status. From this perspective, we considered both one-on-one interviews with selected participants (i.e. farmers, educators) as well as convenience interviews conducted at public events (i.e. county fairs). We eventually decided that individual interviews, while valuable for the aforementioned reasons, might best be used in partnership with some other method that was at least slightly more extensive.

As a compromise between the more extensive mail questionnaire and the intensive individual interview, I suggested the use of focus groups. In the summary report I wrote following the summer's focus groups - for Conrad and focus group participants - I described my reasoning for this selection:

I recommended using focus groups because they are a particularly useful way to understand people's ideas and opinions about a particular topic - the 'what' and the 'why.' Furthermore, as group-based interviews they involve a high level of interaction between participants; thus, they incorporate the sharing of, and group generation of, information. They are also structured with a somewhat open format so that while the moderator does influence the group's discussion (i.e. determining the questions or keeping to a time schedule) the participants are able to respond to questions and direct the discussion according to their interests (i.e. as opposed to a questionnaire with strictly predetermined questions and answers). This last aspect was especially important to us because we wanted the process of developing the KYPP to be truly participatory and reflective of people's interests and involvement.

(Emphasis added)

I came to these understandings through means typical for a graduate student researcher who is deciding on a research method, by using the available literature (see 
Chapter II). In many cases, I was directed to the literatures on methodological options through discussions with professors and extension specialists at the University of Missouri. Coupled with my own research, their recommendations convinced me that the focus group methodology could provide, by itself, a useful and participatory means for incorporating people's perspectives and involvement into the KYPP's development. It could also be used to inform future surveys and it could be used simultaneously with other methods (i.e. individual interviews).

My recommendation to use focus groups, however, was neither generated nor received uncritically. Indeed, the third question regarding the pre-focus group planning decisions involves discussing the implications of focus groups. Of particular concern to Conrad was a desire to maintain a somewhat neutral position both specifically on the Project itself, but also within the county more generally. For example, Conrad did not want to direct people's behaviors or decisions in relation to the landscape or land management. He did, however, want to determine the aspects of the landscape people wanted to know more about as well as to increase their capacity to understand and interact with the landscape. In this regard, Conrad described the FEP's intentions as being “information activists" (Personal communication, 1/2008). During one of our phone conversations, he likened the KYPP to the metaphor of a library: a library does not tell you what to read but does encourage you to read; similarly, the KYPP is not about telling people how to think about or manage the landscape, but it does ask them to consider these topics in an informed manner (Personal communication, 1/31/08).

It was important to Conrad that the FEP not be viewed as affiliated with any particular groups in the county, particularly if such affiliations would deter involvement. 
As regards the use of focus groups, Conrad was initially hesitant that the methodology might appear overly political (i.e. favoring certain people who are selected to participate over those who do not). The following quotation from an email exchange regarding the selection of our methodological approach highlights some of these concerns. It also demonstrates Conrad's willingness to use my input in determining the method. Additionally, note that at the end of the quotation, there is a reference to the "studying of our process." From the start of our coordination on the KYPP, the FEP was aware that our work was being analyzed as part of my thesis project. Thus, reflexivity was built into the entire process.

\section{I don't have anything particular for or against focus groups.}

Basically, we want to assess the degree and directions of people's interest in an 'atlas of change' project - what themes might they be interested in (in a broad sense)? What approaches (e.g., printed atlas, web site, walks, school programs) might be most effective in reaching them? In many ways, these are individualized questions and, if we did focal groups, I believe it would be important to make sure that everybody had their say. As we discussed on the phone, there may be some questions which are better asked in a focal group situation and others which are better asked on an individual basis. In some ways, focal groups seem more demanding (from the public's perspective) to me than questionnaires. For example, I could envision calling around to individual farmers during the growing season and asking them questions, but would feel rather sheepish drawing them away from their work for an afternoon just to answer our questions. I would imagine that the interest that people have in attending a focus group will depend upon how demanding their schedule is along with how appealing the meeting sounds. Perhaps the focal group/individual questionnaire decision might be group dependent to some degree.

So... I am sending the ball back into your court. If you and your advisors believe that focal groups are the most appropriate approach for gathering the data that we want, I'm fine trying it provided we're respectful of people's time, don't raise false expectations, and make it clear we have no political agenda other than opening our "library". Perhaps as we work further on the questions and flesh-out the process, the proper approach will become apparent. (I would almost guess that this could already be a part of our studying our process.) And, of course, I am glad to give feedback.

(Personal communication, C. Vispo to T. Biello, 2/6/08; emphasis added)

Our eventual decision was to use the focus group methodology with the understanding that we would likely conduct additional interviews too (i.e. individual or group interviews, either in person or by phone). Two factors are important to mention in 
this regard. First, time-wise, I felt that I could organize, conduct, and analyze the focus groups during the time I would be in New York, which was also shared with the ecological fieldwork I was doing with the FEP. Funding was the second factor. For example, I had applied for, but not received, a fellowship dedicated to funding participatory research; my plan had been to use that fellowship to fund the focus groups. I had, however, received a Conservation Biology Fellowship through the University of Missouri. I was therefore able to fund the ecological internship portion of my summer's work. This freed up some of the FEP's funding since they no longer had to pay for my internship. Thus, we did have a limited amount of funding to support our participatory approach. Considering these time and funding factors as well as the intensive/extensive trade-offs of our methodological decisions, the focus group interview seemed to be a good fit. An email exchange illustrates the plan we settled upon:

...Order of outreach/public input research: Over the past couple of decades, the research path for many social sciences (in terms of developing means for gathering social data via surveys) has been to first conduct input processes at finer scales, before moving to a broader survey of the public.

In our case, for example, this could mean using the focus groups earlier in the Summer, rather than later, to help us get some in-depth (rich) information regarding people's perceptions/preferences about the project, it's focus, it's outcomes and their participation. This could then inform our other outreach efforts - personal interviews (in person, by phone, by email) and more accidental/convenience surveys (at county events...), and maybe an eventual county-wide mail questionnaire (I imagine that this last option would probably develop depending on funding and overall interest in making this project a multi-year, definite plan)

I think this sequence makes a lot of sense.

(Personal communication, T. Biello to C. Vispo, 2/22/08; C. Vispo's response is italicized, emphasis added)

We then began to consider where we would host the focus groups, how we would organize them, and who the participants might be. These stages included developing the 
recruitment process (i.e. means of recruitment and incentives) and the focus group's questions (i.e. moderator's guide).

\section{Recruiting}

The recruitment phase of the focus group process began in early 2008 and continued until the final focus group was conducted on 20 July 2008 . Initially, I suggested that we recruit for the focus groups by contacting the members of identifiable groups in the county (i.e. the Columbia Land Conservancy, Historical Societies, local hiking/outdoor organizations, teachers/educators groups, and librarians). My thought was that we could target particular groups for which the KYPP was especially relevant and recruit participants from their memberships. By selecting from a variety of groups, I thought we might get useful information for developing the KYPP from some of the people who would be highly likely to make use of it personally and professionally. I also felt that this approach had the potential to develop longer-term connections and commitment to the Project among these groups.

Conrad, however, was cautious to recruit from these groups. Again, this was mainly a concern about being perceived as political or partisan. He did not want the KYPP to be viewed as having a particular agenda beyond information activism. He felt that by targeting particular groups for input on the KYPP county residents might come to see the Project as associated with those particular agendas. We therefore discussed other ideas that could be complementary with, additional to, or in place of the purposive sampling for which I initially advocated. 
One such idea was snowball sampling. In an email from Conrad penned after he had just been to a KYPP meeting he mentioned "snowball interviewing." The two people he had met with were acquaintances of his and were serving as advisors to the KYPP; one was a former director of the county's land conservancy organization and the other worked for the state on projects related to the Hudson River. During their meeting, they had discussed the KYPP as well as our proposed use of focus groups. The email that I received from Conrad indicated support for the use of focus groups and suggested the use of snowball recruitment. He wrote:

Neither saw a problem with focus groups, and the idea of forming them by working outwards through "friends and relations", apparently called snowball interviewing, seemed appropriate.

(Personal communication, C. Vispo to T. Biello, 2/13/08)

In a response to this suggestion, I wrote an e-mail supporting the use of a snowball approach to recruitment. I also suggested using that approach in combination with a more purposive method. I wrote:

...Who to involve: Your suggestion of using snowballing to identify potential attendees seems appropriate. It seems to me that we could do a mix of methods to get participation - both snowballing and more purposive means. In other words, we could use acquaintances and 'word of mouth' to attract participation for one or two groups, combined with identifying, for the other FGs, some more specific groups (ie - teachers, home-owners, second home owners, etc...).

Yep.

(Personal communication, T. Biello to C. Vispo, 2/22/08; C. Vispo's response is italiczied, emphasis added)

By late February 2008, I began to draft our focus group plan and recruitment strategy $^{19}$. I completed the former document in early April. Its basic purpose was to

\footnotetext{
19 The vast majority of my focus group plan and recruitment process were developed using Krueger and Morgan's (1998) The Focus Group Kit. I also used the input gleaned from discussions with my thesis committee and various advisors at other universities as well as private organizations.
} 
ensure that I was organizing an input process consistent with the Conrad's interests. As such, it included a section describing the purpose and background of the KYPP and our proposed use of the focus groups, the types of questions we were looking to explore, the anticipated short-term and long-term goals of the Project and a proposed timeline and budget for the summer's research.

By mid-April, I had also written a recruitment process document to use in coordinating the development of a cohesive, well-planned approach for recruitment. One topic covered in this outline was incentives for the participants. My suggestions were to provide a dinner to focus group participants following the interview as well as a parting thank you gift of an HVF valued-added product (i.e. a specialty cheese). Conrad was supportive of these ideas, but wanted to be sure that we were not giving off the impression of "bribing" people to participate or promoting HVF products. Included below is a portion of my recruitment process outline taken from the 'screening' section of the document with the Conard's comments included:

5. Determine if they have any dietary restrictions and/or preferences (i.e. vegetarian, lactose intolerant...) and remind them that there will be a meal provided for them during the FGs. They will also receive a value-added product from HVF as a parting, thank you gift for their participation. [do we want to advertise this gift up-front or simply provide it? I don't want people to think we're bribing them out-right, nor that this is a veiled Hawthorne Valley 'try our products' event.]

(Personal communication, T. Biello to C. Vispo, 4/24/08; C. Vispo's response is italicized)

I highlight this particular comment to again emphasize the consistent attention that Conrad gave to promoting a non-political image throughout the entire focus group process. In this case, for example, he was even endeavoring to avoid being overly affiliated with the FEP's own host organization, Hawthorne Valley Farm (HVF): “nor that this is a veiled Hawthorne Valley 'try our products' event". This desire to promote a 
non-political image was intricately connected to his interest in making the entire process of the KYPP as inclusive as possible.

The bulk of the recruitment document was focused on the means to develop participation in the focus groups. I organized the basic components of our recruitment process into two categories: snowball sampling and targeted (purposive) sampling. For the former, I suggested that Conrad first identify "information rich" candidates in the county, which I defined as county residents he thought would be able to provide useful information for the KYPP's development. I then recommended that he select "key informants" from the information rich candidates. I defined key informants as the people who could potentially participate in the focus groups and contact others in their 'group' (i.e. low-income residents, long-term residents, second homeowners) to be participants.

It was my feeling that we could develop a successful, snowball recruitment method by using this "word of mouth" of mouth approach combined with other techniques. For example, I recommended providing "key informants" with a postcard they could distribute to encourage acquaintances to participate. I envisioned the postcards including a brief background on the KYPP and the FEP along with my contact information. Conrad was generally supportive of this, but suggested a looser approach. For example, in response to the section in the recruitment process document that described using postcards with the "key informants," he wrote:

In general this seems fine, I would probably just ask "key informants" what they are most comfortable with - distributing post cards, contacting potential participants themselves, or giving us the contact info and saying we could use their name.

(Personal communication, C. Vispo to T. Biello, 4/24/08) 
The other recruitment category, purposive sampling, was oriented specifically to educators $^{20}$. I initially suggested using a mixed-methods approach for their recruitment, which included the snowball recruitment method described above, directly contacting teachers that Conrad already knew, and contacting teachers unfamiliar to Conrad by talking to the staff of school offices. Conrad's response to this suggestion indicated an interest in using a blend of the first and second approaches: snowball, or word of mouth, recruitment of known educators as well as targeted recruitment of known educators. This included contacting known-teachers from schools directly as well as other educators in the county (i.e. environmental educators), and encouraging them to invite other teachers who they thought would be interested in participating in the KYPP focus groups. Conrad wanted to hold off, however, on contacting a broad array of teachers, such as via contacts through school offices, until the KYPP was further developed ${ }^{21}$.

During the development of these recruitment processes from February until May, we mutually decided that Conrad would begin contacting participants before I arrived in New York. The basic idea was for Conrad to make initial contacts and recruit participants for the focus groups as soon as possible. I was also planning to be involved in the recruitment process after I arrived in New York in late May.

As it turned out, however, Conrad was not able to make many contacts before my arrival. Furthermore, our ecological fieldwork took up a great deal of time in late May and early June; as a result, active recruitment methods were again somewhat neglected. These two factors likely resulted in the cancellation of three focus groups during the

\footnotetext{
${ }^{20}$ Educators - teachers and "informal" educators - were the one group that the FEP was comfortable targeting directly versus going through what they perceived to be the less political route of snowball recruitment.

21 This illustrates another consistent focus of Conrad's (i.e. in addition to the non-political, inclusive focus), which was to avoid raising false expectations among participants throughout the focus group process. In this case, he wanted to wait until after we had received some initial feedback before contacting educators more extensively.
} 
summer because participation rates were lower than I felt acceptable (fewer than 4 commitments to participate in each case). Two of the cancellations were in late June and one was a focus group that had been scheduled for educators in early July.

I was disappointed by these cancellations, particularly because I had tried to pay special attention to recruitment. Based on my readings of The Focus Group Kit and other literature, for example, my opening statement in the recruitment process document was:

Recruitment is one of the most important steps in conducting focus groups (FGs). It is also one of the most frequently cited causes of unsuccessful FGs. As such, developing a 'doable' and appropriate recruitment strategy is very important.

(Personal communication, T. Biello to C. Vispo, 4/24/08)

I began to consider the challenges we were experiencing following the initial, June cancellations. Specifically, I considered these challenges in relation to the FEP as a non-profit organization with a small staff, funded by grants and fairly overcommitted with projects. The lack of human and financial resources seemed to be a major obstacle to using the focus groups successfully. For example, without me putting a great deal of time into recruitment, the FEP had neither the time nor the familiarity with the focus group methodology to do so. They also did not have the funding to hire a dedicated recruiting company. Regarding the interconnected issues of human resources, time, and money, I wrote:

Recruitment has been, or at least is becoming, one of the bigger challenges to getting the focus groups set up. In part this is because the FEP is so busy with other FEP work; thus the KYPP hasn't received as much attention. Whereas it was previously discussed that they would help with recruitment by utilizing contacts they know/had in mind, there has only been (to my knowledge) a limited amount of this.

As planning, developing and moderating the focus groups are mostly in my hands, I have a feeling that recruitment issues have slipped their minds (as in they may be thinking that I can do recruitment as well). $\rightarrow$ This is an interesting challenge for the focus group process for a smaller, grant to grant funded organization that already has a great deal of projects to attend to.

(Personal notes, 6/12/08, emphasis added) 
After considering this issue further, and after more time had passed so that I was able to reflect on the successes and failures of our recruitment techniques, I realized that our most successful approaches were those that were more personalized. For example, neither the flyers, which I posted at the farm store and in HVF employee mailboxes were very successful, nor the newspaper postings sent out to the county's three main newspapers $^{22}$. Sending out mass emails to the FEP's list-serve, however, had slightly better results (some people had responded with interest). I drew three conclusions from this experience: 1) the more personalized the contact the better; 2) I needed to get the list of the people that Conrad would have contacted before my arrival in New York had we been able to stick to the initial recruitment plans; and 3) I needed to begin a more involved process of contacting these people by phone and personal emails.

On 24 June 2008, I came across a comment in Krueger and Morgan's (1998) The Focus Group Kit that addressed a common recruitment issue for non-profit and volunteer based organizations. I felt it was so relevant to the struggle I was experiencing in recruiting that I wrote in my field notebook:

From FG Kit \#2 $\rightarrow$ recruiting participants differs from recruiting volunteers... "their usual procedures for getting volunteers are not likely to produce the right participants for focus groups."

(Personal notes, 6/24/08)

On June 25, I received the list of contacts from Conrad. Beginning around four in the morning, he sent me approximately 40 emails, each containing one or more contacts. I spent the next three-and-a-half hours organizing these contacts. That evening, I reflected on our circumstances:

\footnotetext{
22 The flyers and newspaper postings did, however, draw in a few of the focus groups' participants.
} 
How late are we in recruiting? I should have asked for this list of contacts as soon as I arrived. I could have produced the flyers and press release as well, but I should not have done them in lieu of. I think we're beginning, now, on our original plan, from earlier in the year (February, March, April...). I suppose that puts us 1.5 months behind where I thought we would be. (better late than never)

(Personal notes, 6/25/08)

The groups that I organized these contacts into were created based upon conversations with Conrad regarding the specific 'communities' that he was interested in hearing from during this initial phase of the KYPP outreach. These included: 1) HVF employees, 2) educators, 3) residents of Hudson (i.e. urban residents, perhaps lowincome, outside of the FEP's typical network), 4) long-term, medium-income county residents, and 5) Second-homeowners (i.e. upper-income residents).

A draft focus group schedule that I created identified these groups as well as the tentative dates on which we planned to host the interviews. Based on Conrad's preference that we offer people a selection of dates and times for the focus groups rather than pre-determining these factors, the schedule indicated more than one date and time per group. Therefore, as I was contacting people to participate in the focus groups throughout the month of July, I tailored the dates of the focus groups to meet the interests of those who were willing to participate. We thus endeavored to structure our recruitment process with a high degree of flexibility in an attempt to make the focus groups fit participant availability.

While our recruitment process began formally and intensively in mid- to lateJune, it continued throughout the period of time when the focus groups were hosted. Regarding the timing of recruitment, I tried to contact participants for each focus group with as much advance notice as possible. I also made a thorough effort to re-contact each person who had committed to participate in a focus group on the day before or on the 
interview. However, as the more intensive recruitment had not begun until late June, it was not until early July, while the focus groups were being hosted, that I was able to recruit with what I felt was the adequate, or at least desirable, advanced notice of two weeks. I again reflected on the challenges of trying to coordinate focus groups from within the context of an already busy organization with limited human and financial resources as well as limited experience with focus groups (myself included):

(My advisor) indicated that focus groups are fast and easy to organize. I suppose this is true for some people/organizations. And perhaps, because of my novice status with focus group organizing, I'm slower than others in getting them organized; however, they are proving to be fairly time consuming. It's particularly difficult trying to work around an already busy work schedule... One key has been more direct recruitment: more personal emails and calls. Another has been having enough recruitment time. I got the contact list on the day before our $2^{\text {nd }}$ focus group was supposed to be held. And only now, 1.5 weeks later, am I near to caught up. By which I mean able to recruit for a focus group 2 weeks in advance. Still, with other work ongoing, I'm struggling to keep pace and make contacts.

(Personal notes, 7/13/08, emphasis added)

These recruitment procedures - multiple means of recruiting, early contact, and follow-up confirmation - continued from our first focus group on 2 July 2008 until the fifth and final focus group on 20 July. This was generally a successful approach to recruitment. For example, people who agreed to participate did show up to the focus groups, for the most part. There was only one focus group (17 July 2008) where only four of the thirteen people who were scheduled to attend showed up. Some had cancelled previously; some confirmed their participation, but then did not attend; and some who did not attend were unreachable and not heard from again. Aside from this anomaly, however, there were usually only one or two people per group who did not show up after agreeing to participate; and in most of these cases, I had already talked with them on the day before their focus group and knew that they would not be attending the interview. Fortunately, I had planned for a certain amount of 'no-shows' and followed the advice of 
Morgan and Krueger (1998) to over-recruit by 10-20 per cent. Thus, the number of participants for the five focus groups was, generally, what we had hoped to achieve, which was between six to ten participants.

One final recruitment issue to mention was the challenge faced in recruiting from certain groups. As noted above, Conrad had identified five 'communities' in Columbia County that he wanted to hear from. The two that we had the most challenges recruiting from were long-term county residents and Hudson residents (i.e. "old timers" and urban residents). In addition to noting the absence of these two groups, we also noticed that we were tending to get participants who had similar opinions about the KYPP and, more generally, topics in the county such as environmental conservation. Conrad noted these challenges while we debriefed after the fourth focus group. During this debriefing, he commented that:

...we still haven't really connected, definitely we didn't connect tonight, with longterm residents... And I would really like to hear, you know, from people who have a somewhat different perspective on the county...it's not that we haven't had any, but it's that I think, I think the predominance has been more people who are coming in new into the county... and they have certain concerns which may or may not parallel with, with the concerns of other people. And maybe there isn't very much difference, but I don't know (laughing). I guess that's the question.

(Transcription, 7/17/08, emphasis added)

To address these issues, we discussed the participants for the remaining weekend focus group. We also discussed the potential of organizing an additional, sixth, focus group, the purpose of which would have been to target long-term or Hudson residents. Conrad was willing to get more involved in the recruitment for these particular 'communities' but was not sure that we had the time or energy available to organize the meetings. 
Following our fifth focus group interview, however, we decided that we would not host any further groups. We planned instead to organize individual and informal interviews with selected county residents whose input was of particular interest to Conrad. A sample of these residents included: the county planner, the director of a regional land trust, an environmental consultant and advisor to the Project, a representative from the county's historical society, a social worker and advisor to the Project, and a few regional farmers. We did, in fact, conduct some of these interviews, and the advice we received was incorporated into the summary report I wrote for the FEP and into this thesis.

\section{Developing the Questions}

This stage of the focus group process was largely simultaneous with the pre-focus group planning and the recruiting stages. The first portion of this stage took place during some of my earliest conversations with the FEP - with Conrad, in particular - in November and December 2007. This was when we first began to discuss the KYPP. During these discussions, I was interested in understanding what exactly Conrad was hoping the KYPP would become, how he envisioned the Project developing, and what information he would want to know from an outreach/input process. At the time, I did not conceive of these discussions as informing our focus group questions (we had not yet selected focus groups as our method), but these discussions certainly did influence the eventual development of the questions.

The more involved portion of this stage began in late March when I drafted the first set of questions for the focus group interviews. I modeled the basic structure of the 
questions on the recommendations of Krueger and Morgan (1998). The typical question format followed this arrangement: 1) opening/ice-breaker question, 2) introduction question, 3) transition question, 4) three or four key questions, 5) summary question, and 6) final question. For content, I used Conrad's KYPP documents and our prior conversations about the KYPP to guide me. I then sent a draft of the questions to Conrad for feedback.

He responded with comments and suggestions to my draft questions, which I incorporated and then returned for subsequent revision. A sample of Conrad's revisions to the first draft is included below. The sections in italics are his comments, revisions and suggestions (note the significant input that he made to this initial set of questions):

2. (Introduction - 2-5 min) In thinking about making an Atlas, we would like to depict those physical, biological and cultural/economic aspects that are important to people, what characteristics (or features) describe the landscape of Columbia County for you?

3. (Transition - 2-5 min) We also want to include then-now-tomorrow time maps of things that have changed in the County. We're not saying change is good or bad, but we do believe that it's important for people to appreciate change. So, what changes have you noticed in the county's landscape?

4. (Key - $15 \mathrm{~min}$ ) How do we translate your answers to question one into maps and/or other materials? Which landscape features and changes do you think should be included as maps in the KYPP atlas?

5. (Key - 10-15 min) What would be the best (and/or easiest) way for you to access these maps and this information? (I think the strength of presenting this as an atlas is that people can immediately 'get the picture'; the risk is that they think of nothing else. I think it will be important to show them documents such as what the PLACE program produces to make sure that they think broadly.)

6. (Key - $10 \mathrm{~min}$ ) In what ways do you think people could participate in the KYPP? (Should we give options? For example, (the PLACE program) does continuing education courses plus public field trips, evening lectures and town-scale reports; we have done a few evening lectures, plus a fair number of field trips around the County. Which venues are best for lectures? Should schools be involved?)

(Personal communication, 5/9/08) 
This process of feedback and revision continued through the final focus group. In addition to working together on question development, Conrad and I also consulted with experts in relevant fields and professions (i.e. focus group professionals, community development specialists, professors at various universities). These advisors provided valuable feedback throughout our focus group process, both specific to the development of the questions but also in regards to the other stages. For example, in the week prior to the first focus group, I wrote the following in my field notes:

Tonight - if I get time in between phone calls and emails - I should think out the moderator's guide (considering my advisor's responses). Most importantly, considering how the questions flow together, and anticipating how to use the volunteers... as well as anticipating questions, responses and possible sticking points.

(Personal notes, 6/25/08, emphasis added)

Taking into account the feedback from these advisors and incorporating Conrad's comments and suggestions helped to generate a set of questions that we felt would address the goals of our summer's outreach/input process. We did not, however, establish a pilot group with which to test our questions. The use of a pilot group is a standard recommendation in all of the focus group literature, was included in my thesis proposal's methodology section, and was suggested to me by numerous advisors. As an example of the latter, one advisor wrote to me:

I have read through your script, questions, evaluation, and consent form. I think they all look pretty good. What I would suggest, if it's not too late is to try it out with a couple of people who are not going to be part of your focus group. If you don't have time for that then I would suggest having someone there who is not participating but observing the process so you can make good adjustments for the next one. It's tough to do that as a facilitator or recorder because you're so busy with the meeting itself. You don't want them evaluating the content so much as how people are participating and determining if they are answering the questions they way you want them too.

(Personal communication, 6/27/08, emphasis added) 
In spite of my intention, no independent pilot group to test the questions was conducted. For our first focus group, however, a number of the participants were already familiar with one another or with the FEP. More than half of them, in fact, worked for the Hawthorne Valley Association (HVA): five of the nine participants in this focus group $^{23}$. Of the remaining participants, one was the husband of an HVA employee and the other three were at least somewhat familiar with the FEP's work. It should be noted, however, that even though these participants worked for the HVA or were familiar with the FEP most did not know much or anything at all about the KYPP. Thus, while we had not organized a pilot group, this was a comfortable first group with which to test the focus group format ${ }^{24}$.

Both Conrad and a volunteer recorder were present during each focus group. Together, the three of us acted as observers, gauging the successes and weaknesses of the various questions and the overall process. Following each interview, the three of us would discuss the questions and other aspects of the focus group including what questions worked well, what questions seemed difficult for people to understand, and what changes should be made to the questions for the next focus group. Thus, as with our recruitment process, the questions were being developed, improved, and updated while we were hosting the focus groups ${ }^{25}$.

After the first focus group, for example, we discussed two of our key questions, which addressed the landscape themes that the KYPP should map and people's

\footnotetext{
${ }^{23}$ In total, 10 of the 38 focus group participants were employees of the Hawthorne Valley Association (including the farm, the farm store and the bakery, the Waldorf school, and the visiting students program).

${ }^{24}$ I had initially planned on hosting our first focus group with only HVA participants as a pilot group. However, after this group and the second one like it were cancelled because of the low recruitment, I put this group together with other county residents.

${ }^{25}$ Beyond what is included here, many of these discussions will be described within the fifth embedded unit: 'debriefing.'
} 
participation in the KYPP. For the former question, I passed out index cards and asked participants to write down their mapping suggestions individually before sharing them with the group. During the first debriefing, we decided that the index card process was not explained clearly enough and had caused some confusion for the group. However, we also felt that the process allowed for multiple modes of thought and included individual reflection. We therefore felt that we should keep it as a part of the questioning process. Based upon these reflections, for the next group I planned to provide a clearer explanation about the purpose of the note card exercise.

Regarding the question about people's participation, we decided that the wording and perhaps the topic itself were confusing to participants. To address this, we agreed that I should slightly reframe the question on participation and be prepared to offer some suggestions about types of participation (i.e. county residents as researchers) in order to help people understand what we were trying to get at and to stimulate the discussion. We also decided that I should explicitly remind the participants that we were not asking them to sign up and volunteer with this question. Conrad wanted the question to clearly indicate that we were only exploring the ways in which people would, hypothetically, most like to participate in the KYPP.

Following the second focus group, we again reconvened to discuss the mapping and participation questions. We agreed that both had been improved: the questions were clearer and the information we received was more on target with the type of responses we were looking for. Still, these two questions along with our other key question about KYPP formats continued to be major discussion topics during our post-focus group meetings. 
Because it was specifically geared toward educators, Conrad and I had developed a separate and modified set of questions for out third group. To do this, Conrad suggested condensing our first three questions into an overview of the KYPP wherein I would describe the Project by incorporating some of the input from the first two focus groups. I received the following email regarding this suggestion:

Why don't you sketch out what the questions might look like following your model? I believe the key issue is that we have enough time to thoroughly explore the techniques etc. My feeling is that some people leave the focal groups still unsure of exactly what we are up to. That's fine for the general focal groups, but teachers might need to grasp a more complete picture if we expect them to think about classroom integration. I think the success of your approach will depend on how well you can wrap up the first part of the questioning and translate it into something the teachers can 'bite into'.

(Personal Communication, 7/14/08, bold font added for emphasis)

Following an overview of the KYPP, the plan was for me to ask for the educators' input on that overview. I would then ask for their suggestions regarding the themes to be mapped by the Project. The remaining questions were also modified to orient them specifically towards educational settings and needs. A sample of these educator-specific questions is included below:

5. (Key - 15 min) These focus groups, and our other outreach, are part of the process of developing the KYPP as a participatory project, using the input and involvement of county residents to create it. One reason for hosting a focus group specifically for educators is to hone in on the possibility of developing the project in coordination with educational programming. How can you see this project fitting in with your educational programs?

- What types of involvement - e.g., talks, walks, GIS labs, student data gathering projects - are most interesting and possible for you?

- What sort of activities do you have time for?

- Is this best thought of as an in-class or after-school activity? standards?

6. (Key $-15 \mathrm{~min}$ ) Should we focus on linking maps and activities to the teaching

- How else could the program fit your curricula?

- In what subject area(s) does this project best fit?

- What grade levels might work best? 
7. (Ending - $10 \mathrm{~min}$ ) What would make it easier for you to incorporate the KYPP into your educational programs?

- If someone from the FEP taught the programs?

- If the programs were funded?

- Other?

(Personal document, 7/16/08, emphasis added)

As with the previous focus groups, we had a meeting immediately following this interview. We reviewed the information and talked about the portions of the interview that we felt had been most successful as well as the most challenging. For example, we decided that the in-depth summary-overview was too long and made for a slow start to the focus group. We did not feel the need to refine this issue, however, since we were not planning to host any additional educator focus groups. Nevertheless, the discussion did inform our thinking about the remaining focus group questions.

Our post-focus group debriefings also addressed more than our key questions. We often discussed the other questions as well to consider if we were getting the information we wanted; if not, we explored how the questions might be improved. For example, after the fourth focus group, we discussed the issue of bringing up information that previous focus groups had suggested. We did not want to lead participants in their responses, but there were certain topics that Conrad was specifically interested in and topics that we had not initially thought of but that participants from other focus groups had suggested and seemed relevant (i.e. is the countywide scale of the Project the right scale and oral histories, respectively). Based on our conversations, we concluded that such topics could be introduced. We did feel, however, that we should only introduce these topics after participants had had enough time to discuss a question without our input, and also assuming that we had already covered the other key questions with enough time remaining to discuss additional information. 
By the time of our fifth and final focus group, we were still discussing some of the same issues that had come up earlier. Thus, some of our debriefing brainstorms were occasionally more hypothetical than directly applied. Our questioning route and use of maps during the fifth focus group, for example, was largely the same as before. This should not imply that we did not make to our questions or arrangement based upon our debriefings and evaluations of the processes. Rather, it should demonstrate that while we endeavored to learn from our experiences, we were only able to incorporate some of our reflections into a future focus group whereas other ideas and feedback were more challenging to address and incorporate.

Interviewing

The early drafts of the moderator's guide included the focus group questions, as mentioned in the previous embedded unit. They also included the facilitator's introduction to the focus group interview. The first drafts of this document were written in late March 2008. The process of drafting and commenting on the document continued throughout the entire focus group period. Our revisions to the moderator's guide included a focus on both the introduction and the questions' sections. However, as the development of the questions has already been described, this embedded-unit is focused upon the development of the introduction portion of the moderator's guide as well as moderation during the actual interview process.

I wrote the earliest drafts of the moderator's guide knowing that we would revise them. I even included questions that I had for Conrad within the first draft. The excerpt 
below demonstrates this and highlights three aspects of the development phase of the

moderation guide:

Begin by thanking everyone for participating and being willing to share their time and experiences (and/or opinions). Explain, very briefly, the current status of the KYPP and the FEP's reasons for seeking public input on the atlas project, as well as on public participation (this can be done in a way that makes it clear where the FEP is coming from and minimizes the possibility of raising false expectations; i.e., no guaranteed funding nor are we even sure it's wanted; the participants are 'design consultants'; this is a break-even enterprise, to the extent that we can, we want all access to programs, atlases and information to be free, although depending on costs and funding, we may need to charge for printed materials, gas on trips, etc). Explain a little bit about the FG process and let everyone know that their participation is voluntary and they are free to decline to answer any questions and/or leave as need be. Also, explain that the FG will be audio-recorded, but that their answers will be kept confidential for all analyses purposes. (Should we give them the option of saying no, they don't want to be recorded?)

(We still need to decide if we want to offer any examples of the atlas' maps. I'm waiting for a meeting to discuss this with folks here at MU; based on my conversation with an advisor and past experience, I would tend to say yes, and we certainly have a few maps we could share, probably pick a diversity of maps - one historical, one physical, one biological. One related issue is probably when do we show people this info. - should we get some 'unadulterated' input first and then show people maps, documents, etc and see if that brings out any new ideas or should we show them something up front so that they get the gist of what we're doing?)

Introduce who we are and where we're coming from (geographically, academically). Do they have any initial questions for us?

(Personal communication, 5/9/08; C. Vispo's comments are italicized, emphasis added)

Conrad's comments, above, address issues related to the Project's funding as well as expectations about the materials and programs that might result from the KYPP. Two issues should be mentioned in this regard. First, this exemplifies Conrad's consistent focus on not raising false expectations. As much as he was interested in inclusivity, he was also focused on maintaining realistic expectations for the KYPP and ensuring that our outreach/input process did not 'lead anyone on.' His comments also addressed his intention to keep the Project's materials and programs free, if possible, while also recognizing that some materials may have a cost. Here too, he 'hedged his bets.' He addressed his intentions in combination with his recognition of the Project's uncertain 
future in an effort to put forth realistic expectations (i.e. people may not even like the idea of the Project, or there may not be funding even if people do).

By the time we conducted the focus groups, we had divided the moderator's guide into two components: Conrad's introduction followed by my introduction and moderation. In his introduction, Conrad expanded on the funding comments discussed above. He highlighted funding as both a liability and an opportunity. For example, he described the FEP's lack of funding as a potential disadvantage because it meant that there was no guarantee we could actually implement people's suggestions. He also described it as a potential advantage because it meant that people could suggest anything freely, including criticisms of the Project or any idea that they were interested in, since we were not committed to any particular path or limited by any funding restrictions.

The quote above also documents the interview dilemmas we faced both before and during the focus groups: how should we use existing ideas and materials to help people get a better idea of the Project without unduly influencing their perspectives and suggestions? This was briefly described in the previous embedded unit in terms of our deliberations about whether or not to bring up topics of particular interest to Conrad (i.e. socioeconomic maps or the countywide scale of the atlas) or that had come up in previous focus groups (i.e. oral histories). In this regard, and in terms of the actual interview process, one of our decisions was whether and how to use maps that Conrad had already created for the KYPP.

Conrad was in favor of using some of the FEP's existing maps (i.e. “...based on my conversation with (an advisor) and past experience...") but he was not sure when or how to use them within the interview process. I, on the other hand, received mixed 
advice from some of my advisors. For example, one of my advisors suggested using as many maps as we wanted: the more we could show participants the more visual stimulus they would have to respond to (Personal communication, 5/8/08). Another of my advisors, however, commented with an opposite perspective:

At first, I thought it might be helpful to have examples of community atlases available for the participants -- something they could refer to so as to get a handle on what the end product might be -- but then I thought that might "distort" their responses. Once people understand the concept and potential layout of the Columbia atlas, I believe they will jump in with their input. I'm just afraid that presenting them with examples might undercut your effort to get "raw" responses and information from the participants.

(Personal communication, 6/24/08)

The above statement is not entirely against the use of relevant maps. Instead, it identifies some of the same concerns that Conrad and I shared about the potentially 'guiding' influence of too much information and material. It was also in-line with most of the advice that we were receiving about the interview process. In general, most of our advisors suggested that the concern was not about the maps themselves, or other information that we might present, but rather how their use might cause an unwanted 'guiding' effect. Taking all of this into account, we decided that maps should be used, but to a limited extent, within the focus group interviews.

The third aspect that the excerpt (from page 70) highlights is Conrad's sensitivity to the focus group participants. He addressed two issues: 1) people's concerns about being recorded and 2) the desire to address their potential questions. Regarding the first of these issues, I agreed that this might be a potential concern. However, I also saw audio recording as essential to our use of the focus groups (i.e. for transcription and in-depth analysis). And we eventually attempted to mitigate this concern by addressing the audio recording in our recruitment process and during my introduction to the focus groups, 
specifically while I was distributing the participant consent form. Following Conrad's introduction, for example, I described my involvement with the FEP as a graduate student at the University of Missouri and explained that the focus groups would be used to inform both the KYPP and my thesis research. I then passed out the consent form and described the relevant information that it contained as they were reading it over and signing it. I explained, for example, that no one was under any obligation to sign the consent form or to participate in the focus group and everyone was welcome to not answer any questions or to leave the room if they so desired. As soon as all participants had read and signed the form, I then said the following prior to recording:

I also want to make sure that everyone is aware that we'd like to audio record tonight's focus group. This is very helpful for going back over the focus group discussion and accurately recalling what's been said. If everyone is comfortable with that, (we'll) start audio recording at this point.

(Personal document, 7/2008)

Participants had already been made aware that the focus groups would be audio recorded when they were recruited. For example, the postcard initially developed for recruitment purposes morphed into a one-page description of the FEP, the KYPP, and the focus groups. This document, which explained that the focus groups would be recorded, was sent to most participants via email. By re-addressing the audio recording during the focus group's introduction and in the context of my research as a graduate student, we felt that people would be more comfortable with $\mathrm{it}^{26}$.

The second issue was how to address questions. In this instance, the FEP suggested that people could be given a chance to ask questions just before the focus

\footnotetext{
${ }^{26}$ Only one participant mentioned having a problem with the audio recording. On their evaluation, this member of focus group 4 commented on the question 'which aspect(s) of the focus group did you like the least and why?' section: "Audio Recording - I didn't realize that this would be (though I should have (); ) but it made me nervous and it was harder to think and answer - stage fright $:$ ")
} 
group interview began. From the literature and my advisors' recommendations, I was under the impression that this was a bad time to introduce a pause into the flow of the focus group. I felt that it would be better to invite or encourage audience questions at other times during the process. Therefore, we proactively tried to address potential questions during our recruitment, and we left time at the end of each focus group, typically during dinner, during which time people could ask additional questions or follow up on topics.

After the moderator's guide was divided into Conrad's introduction and my introduction and questions, I left the content of his portion up to him. Likewise, I created the remaining sections of my introduction based on focus group literature, former theses, and consultations with advisors. Conrad and I still conversed about our introductions, but they were mostly done independently and then coordinated to ensure they would address everything we wanted to cover.

By mid-June, we had already created the various forms, maps, and signage for the focus groups; arranged for the groups' snacks, meals, and thank-you gifts; and developed and arranged the room for hosting the interviews. We had decided to use a room in the "old farm store" at HVF, which had a large conference table, an easel for our flip chart, wall space for map, and extra table space for materials, food, and drinks. Our decision to host the focus group in this room was based on the availability of this space, its proximity to the farm's store, and thus the farm store's kitchen where our meal was prepared. Hawthorne Valley Farm also has a relatively central location within the county.

We made the decision in the spring 2008 realizing that it might limit some people's participation (i.e. those without personal transportation). We felt, however, that 
the aforementioned factors justified our choice. With limited time and resources, the existence of a room so well suited to hosting a focus group and in proximity to a kitchen as well as other amenities seemed to be our best option ${ }^{27}$.

Two final dimensions of the focus groups are discussed in the remaining portion of this embedded unit's analysis: 1) a brief overview of each focus group, including a description of the participants, and 2) a review of participants' ability to participate in the focus group based on my observations of their relative amount of talking combined with their responses to the focus group evaluation. The post-focus group debriefings also provide insight into my and Conrad's impressions of how well the interviews went.

The first two focus groups that we originally planned to host in late June were cancelled. The few people who had agreed to participate in these two groups, mostly HVA employees, were rescheduled to participate in what ended up being our first focus group on 2 July. As mentioned earlier, five of the nine participants from this group were HVA employees: the executive director, a farm development director, a farmer, a farm store employee, and an office worker. The other four participants were also familiar with the FEP and its general work, although not with the KYPP. Among this latter group were a real-estate broker, a researcher with a local environmental organization, an herbal gardener, and a retiree. On the whole, this first group had a fairly intimate connection to the FEP and good rapport with one another.

\footnotetext{
27 At one point during recruitment, in early July, I spoke with an entrepreneur in the city of Hudson. This person not only agreed to participate in the focus groups but also offered the use of one his buildings in Hudson for hosting a KYPP focus group. We were not able to take him up on this offer, however; nor, in fact, did he end up attending a focus group. After initially sounding quite interested in the project, I was unable to contact him again (by phone or email) and he did not show up to the focus group interview. Furthermore, even had I been able to contact him, I was uncertain about coordinating an additional focus group in Hudson given the challenges I was already facing with recruiting for our groups at HVF. Also, since the FEP and I were already quite busy with the ecological fieldwork, I did not think we would have the necessary time to organize a focus group in another setting. All of our focus group interviewing therefore took place at HVF in the old farm store.
} 
I can also speculate on some additional demographic information about this group: they were all middle-aged, most had lived in the county for twenty years or more, and they were all probably Caucasian, college educated, and with middle- to upperincome levels. Most of the participants also lived near to HVF. I must "speculate" on these matters, however, because I did not collect much demographic information on participants. Conrad was concerned with asking too many personal questions. For example, I had drafted a questionnaire that I planned to distribute at the beginning of each interview. I planned on having the participants fill it out once they had arrived while they were waiting for the interview to begin. It contained some basic questions about age, education level, ethnicity, income, and residency as well as how familiar the participants were with the FEP. I sent this questionnaire to Conrad for his comment, which is included as the following excerpt:

Re. the questionnaire: We probably already talked about this - sorry if I'm repeating myself. I am somewhat hesitant to ask the initial questions, because they are a bit personal and because I don't think, given our sample sizes, we are going to really be able to categorize inputs based on different audience traits. Couldn't we do just as well if we, for example, ask some semi-anonymous "raise-your-hand-if." questions at the beginning of the FG, and also write down our subjective understanding of who each FG's participants are? I liked the stick-the-dot on the map approach to mapping house locations.

(Personal communication, C. Vispo to T. Biello 6/13/08, emphasis added)

I had initially felt that gathering such information would help us to plan for future KYPP outreach and input. However, as I was neither fully committed to the questionnaire for my own personal use (i.e. it was not necessary for my thesis research), and since Conrad felt hesitant to ask such questions, we agreed to incorporate the less personal questions into the focus groups in other ways, as in, for instance, our ice-breaker question. Designed to develop comfort and rapport within a group, this question asked people where they lived and how long they had been Columbia County residents. 
Another approach we used is mentioned in Conrad's reference (above) to the "stick-thedot on the map approach." His comment came in regard to my suggestion that we print maps of Columbia County and have each participant place an initialed sticker-dot on the map to indicate where they were from. Everyone could thus see where they lived in relation to the other participants and we would also have a rough indication of the geographic distribution of our participants. Therefore, beyond basic information about occupation or residency, the rest of our demographic information was largely anecdotal or based upon Conrad's knowledge.

There are other ways to assess the quality of the interview, however, which leads to the second means of considering the interview process: reviewing the participants' ability to participate in the focus group as determined by their relative amount of talking. One goal of a focus group is to try to hear from every member of the group. Although it is not expected that every person will share the same amount of information or speak for the same amount of time, a general goal is to hear from every participant. It is important to give each participant ample opportunity to share by moderating with strategies that prompt each person's participation and to ensure that all perspectives valued.

One way of to gauge the success of the interview, then, is to evaluate how much each member was able to participate. As a rough scale for participation, I have organized participants into four categories: dominant talkers (those who talk very frequently or for a long time; when they do speak, they may talk over others or speak before others can share); frequent talkers (those who regularly share without needing to be encouraged); infrequent talkers (those who share mostly when asked); and rare talkers (those who share only when asked, and even then only sometimes). The intention of these categories 
is not to quantify the actual amount of time that people spoke during the interview, nor are these categories comparable between focus group as they were considered in context. Nonetheless, a brief mention of these categories helps to provide a picture of the relative frequency of contribution and how much participants spoke. In the first focus group, for example, two members were dominant, three were frequent, two were infrequent, and two were rare. Over half of the group, then, was frequently involved in the discussion; two members were infrequently involved (i.e. when I asked for their opinion); and two people shared only during the times when a question was structured so as to go around the table taking people's suggestions one at a time.

Based upon their own evaluations, members of this focus group felt that they had participated in and contributed to the KYPP. The fourth question on the evaluation asked: "Do you feel that you have participated in the development of the Know Your Place Project? Please explain." Each member of the first focus group indicated that they felt they had participated. Even one of the participants categorized as a "rare" talker responded in the affirmative to this question. This person wrote: "Yes, I think being just a listener in the discussion has made food for thought." A few other participants indicated that they felt they had participated in developing the KYPP because they were getting involved "at its inception," "on the ground floor," and for "the first step in a large project." Another indicated feeling that we (Conrad and I) would make good use of their comments and "get us started on the project." Last, another participant indicated that they felt that the moderator had done "a good job soliciting ideas, and making sure everyone was heard." My perceptions, then, accorded with participant feedback. 
The second focus group also contained a fair proportion of HVA employees, three of the ten participants: a director for the farm's camp, a maintenance worker, and a former educator who was still involved with the association. Other participants included a board member for a local environmental organization, a reporter for a local newspaper, a librarian, a teacher, and an employee of a local land trust. As with the first group, many of the members for this focus group lived fairly centrally within the county near to HVF. One member, however, actually lived outside of the county but was in the process of relocating back to Columbia County ${ }^{28}$. About a third of the group had lived in the county for more than twenty years, a third had lived in the county for between one and ten years, and the rest had lived in the county for less than a year or not at all. Again, all participants were probably Caucasian, college educate, and middle-income. This time, however, the group's age range was more mixed, with some participants in their 20s and 30 s, and others in their 40 s to 60 s.

Much like the first focus group, this assembly had a good rapport. Some of the participants had even previously worked together on various county committees. There was one dominant, six frequent and three rare speakers. Thus, the majority of the group did participate frequently. The general flow of the conversation was also quite easy and we were able to address all of the questions thoroughly. Additionally, everyone responded in the evaluation that they felt they had participated in the development of the KYPP, although one person did state that they felt they had participated only "a little."

\footnotetext{
${ }^{28}$ This highlights one of the challenges we faced in recruitment. Because recruitment had to co-occur with so many other ongoing projects, both related to and independent of the focus groups, as well as be flexible and without asking too many questions of people, our screening process was not particularly tight. As a result, a few of the participants actually lived outside of the county, although all lived near the county and/or had lived in the county and/or worked in the county long-term. Additionally, two members of this group were educators/librarians, which we probably would have incorporated into the educators' focus group (FG3) if this had come to light prior to their participation in focus group \#2.
} 
They followed this up by writing that they did not feel 'up to date' in their knowledge of happenings in the county and therefore did not feel that they had had as much to contribute.

Many of the participants from this group also stated that they felt their group was quite varied in terms of its make-up. This reaction was unlike the first group's estimation. Like the first groups' evaluations, though, most of these participants specifically stated that they enjoyed hearing other people's perspectives on the KYPP's topics. Four members of this focus group, for example, identified everyone's ability to participate during the focus group as a positive feature of the process and most people felt that they valued their ability to share their "unique" personal opinions. I therefore feel that this interview was, like the first, a success.

The third focus group on 16 July was our educators' focus group. The first of the educators' focus groups had been planned for earlier in July but was cancelled due to low recruitment. I tried to reschedule its three participants but most were unable to do so.

In total, seven educators attended the 16 July focus group interview. Two of these participants were employees of the HVA: a director of the association's Visiting Students Program and a high school teacher at the Waldorf school. One participant was, at the time, working with the FEP on ecological research in addition to being a faculty member at a nearby community college. The other participants included an elementary school teacher, the education coordinator for a local farm, an environmental educator for the county's Soil and Water Conservation District, and an extension specialist from the county's Cornell Cooperative Extension office. This group was of mixed-age like the second focus group, with some being in their late 20 s and the rest in their 30 s and 40 s. 
Two participants had lived or worked in the county for almost twenty years or more, three had lived and worked in the county for less than ten years, and two had been in the county for about a year or less. Again, the participants were all probably Caucasian, well educated, and residents of the central townships of the county near to HVF.

This group seemed very comfortable sharing ideas and opinions about the KYPP within the focus group format. This may have been because, as educators, they were comfortable speaking in front of people or because many of them had a preexisting interest in connecting their curricula to the county (i.e. county history, agriculture, ecology). They were also quite interested in one another's professional backgrounds and perspectives. At the beginning of the interview, in fact, one member requested that we go around the table to have everyone provide a more in-depth background. The participant said:

...I'm kind of curious. I know some people here at the table, but others I don't. And I'm just curious what backgrounds are...to help me understand...you know, to understand your perspective and, you know, if I knew what you did I could understand more what you're saying.

(Transcription, 7/16/08)

I was initially hesitant to do this, preferring instead to address the focus group questions. Yet I also recognized that this person was genuinely interested so I asked if the group wanted to discuss their backgrounds immediately or if they would prefer to wait until after the interview was finished. They were unanimously interested in doing it sooner rather than late, and so we did. For the rest of the interview, this group continued to interact very well together and we were able to get a great deal of in-depth information about the education-related topics for the KYPP.

This is not to say, however, that all members were frequent talkers or that all members shared equally. Two were dominant speakers, four were frequent, and one was 
rare. In fact, the two dominant talkers in the group occupied a large portion of the focus group interview, frequently speaking at length about various topics throughout the hour and a half. While I felt that I could have intervened at certain times, I generally waited for a natural pause in their talking. I would then request others' input without cutting them off. Additionally, no one mentioned the dominant talkers in their evaluations. Most described feeling that everyone was given an opportunity to participate and that "all input was valued equally." Everyone responded that they felt they had participated in the development of the KYPP, although two members of the group suggested that they had only participated "modestly" or "a very little. ${ }^{29 \text { ", }}$

Many of the educators also indicated that they had learned new information or obtained materials that would be useful in their future work. Most of them enjoyed hearing about the work of other educators in the county. In addition, all of the educators who responded to the second page of the evaluation expressed that they wanted to stay involved with the KYPP. I therefore felt that this focus group interview was successful in addressing many of Conrad's educator-specific questions, as well as in terms of the educators' involvement in, and reactions to, the process.

The fourth focus group was the only group where a large number of people who had agreed to participate did not show up for the interview. In total, only four people participated. Two of these participants were HVA employees: an office employee, and an educator who also worked in the farm store. One participant was retired and the last was a writer and in-between work. This group was diverse in terms of age and background: three were probably Caucasian and one was Hispanic; two were younger

\footnotetext{
${ }^{29}$ In both of these cases, however, the two participants indicated, overall, having enjoyed the process. One of them is discussed further in Chapter V's analysis of the 'interview' embedded-unit.
} 
(mid to late 20s) and two were older (probably over 60). Also, although two participants lived near to HVF, one was from Hudson on the western edge of the county and one was from a small town in the northeast corner of the county. Finally, as with the other focus groups, most of this group's participants were likely well-educated and middle income.

The small size of this group was a challenge for me. There were no dominant talkers in this group - three were frequent and one was infrequent ${ }^{30}-$ but I had difficulty stimulating the conversation, particularly at the beginning of the interview. With a smaller group, there were fewer people to offer ideas. This made me feel the need to try to fill up additional space such as by trying to probe questions further or to ask additional questions beyond what I typically addressed in the normal questioning route.

The participants' responses to the evaluations were only somewhat reflective of my impressions, however (see Table 6, on page 124). All of the participants indicated that they had participated in the development of the KYPP. Each elaborated on this sentiment, writing that their particular "views" and opinions had been paid attention too and that they were able to share "ideas that are unique to my location/situation within the county." As with previous groups, most members also identified the ability to listen to others' opinions as a positive aspect of the focus group. One participant even identified "the intimacy of the group and the wait time between questions" as having "allowed ample time to gather thoughts and elaborate." Thus, what I had interpreted as a somewhat slow or otherwise unfilled space during the focus group was, at least for one participant, a beneficial aspect. I therefore feel that we had again addressed all of the questions of interest to the FEP, received some new and reinforcing suggestions for the

\footnotetext{
${ }^{30}$ I suspect that the infrequent talker in this group would have been a rare talker in a larger group; however, the small size and intimate nature of this focus group probably encouraged this person to participate.
} 
KYPP, and had a group that seemed to interact quite well and felt positively about the experience.

The fifth focus group was the only group held during the day. It was also the only one held on a weekend. This group was specifically organized through recruitment from second-homeowners in the county and wealthier county residents. As such, the residency status of this group was a mix of part- and full-time, with most of their homes being second residences. Three members of this group had owned a home in Columbia County for approximately six years, two had lived in their current second-home for over nine years, one for more than ten years and the remaining two, one of whom was a full-time resident, had owned homes in the county for more than twenty years. Unlike the previous groups, a couple of this group's participants lived near to HVF, but most lived in the southwest corner of the county and one lived in one of the northernmost townships. Most or all of the participants were probably 40 years or older, well educated, and upper income. I do not have occupational information on this group's participants, but do know that many were affiliated with the FEP in some manner. Some were landowners on whose property the FEP had conducted fieldwork; some had attended or volunteered with FEP programs in the past; and at least one was a donor to the FEP. Additionally, one participant was on the board of a local land trust and many of the other participants were aware of, if not also members of, this organization. Most of the members of this group were, therefore, sympathetic to KYPP topics and had no problem talking within the focus group format; in fact, too much talking was the challenge in this instance.

This group's dynamic was different from that of any other focus group. Although the basic structure of people's talking-participation was similar to previous 
groups - two dominant, three frequent, one infrequent, and two rare speakers - the five most frequent talkers would occasionally promote a topic that was somewhat tangential to the KYPP. As examples, these included topics about politics, the malpractices of other landowners in the county, and internet access in the county. More than for any of the other groups, I felt the need to interject and interrupt this group in order to re-route the conversation back to the KYPP. Some of the participant evaluations even noted this. For example, one of the dominant talkers wrote that the aspect of the focus group they liked the least was "A tendency to lose focus or to get into minute details." For the aspect of the focus group they liked the best, they wrote: "Open exchange. Tim did a good job herding the cats ${ }^{31}$." The other dominant talker wrote: "I may have participated too much. I hope I didn't prevent anyone from sharing their thoughts, it is interesting to know other people's opinions." This group's rating of the overall experience also reflected the choppier flow and slight discontinuity of the questions and discussions (see Table 6, page 124).

Still, as with the earlier groups, most of these participants rated themselves as having participated in the development of the KYPP. Two of these responses were qualified, however. One participant suggested that they were "unsure" about whether they had participated in the KYPP, and that their feeling on participation would depend “on the next steps." This implied that the more concrete steps of creating the KYPP's programs, beyond the information exchange of the focus group, was important to this person's concept of participation. The other participant responded with the indication that they had only participated "peripherally in the past," but planned to participate "more

\footnotetext{
31 This participant also wrote the following, regarding the first question on the evaluation, which asked 'would like to add anything further about your experience: "Focus groups by their nature become like herding cats. I am not sure how to improve the technique however."
} 
in the future." I feel that this plan indicates a positive experience with the focus group process. Finally, as with the evaluations other groups, most of these participants indicated that they enjoyed hearing other people's perspectives and being able to share their own ideas. They also mentioned that everyone's views had been equally valued and that all were encouraged to participate. Based upon these evaluations, and as we did get through all of the essential questions for the FEP, I feel that this fifth focus group interview also went well.

\section{Debriefing}

The dynamics of group interaction were one element commonly discussed in post-focus group meetings. This was true even as early as the first focus group debriefing session. For example, Tory, the volunteer recorder, suggested that I introduce the consent form to the group in a more "lighthearted" manner to make it seem less intimidating and put people more at ease. We also discussed wanting to hear more from participants regarding walks, talks, and other alternative media options for the KYPP. Conrad felt that we had not accessed this information very well during the first focus group and he was particularly interested in hearing from people about such alternative options. Our overall impression, however, was that the first focus group's discussion had stayed on topic and that we had generated relevant and useful information.

In the debriefing that followed the second focus group, we again discussed the mapping and participation questions. This time we felt they had gone better. We felt that the way I had presented the questions had improved, and that the participants seemed to understand and respond to the questions more fully. We also discussed a new topic: 
people's non-participation in the focus group. Specifically, Tory asked about what to do for people who were not as active in sharing their ideas during the interview. And we tried to gauge whether I could do something to get those people to participate. During this conversation, I relayed my understanding from the literature of what was typically expected regarding people's relative participation during focus groups. I said:

...you can expect, sort of, $40 \%$ of the people that come are going to be really interested, and they're going to share a lot... And another $40 \%$ are going to come, they're going to be interested, and they going to share some. And $20 \%$ of the people are going to not share a whole lot... which seems to be kind of true in terms of general proportion.

(Transcription, 7/10/08)

After further discussion, we agreed that the participants were being given ample opportunity to share throughout the focus group and that the quieter participants seemed to share when they were comfortable. I then brought up the idea of minimizing our summary question to make more time for exploring alternative media for the KYPP. I felt that Conrad was particularly interested in these alternative media options (i.e. programs and materials beyond maps) and I wanted to see how else we might address this interest in the focus group. Tory, however, was opposed to the abbreviation or replacement of the summary. Her feeling was that the summary was too important to the interview's cohesiveness and so we decided not to replace or abbreviate it. As she put it:

I think the summary is important...I think putting a roof on the house that you just made, and having people go through it in some sort of linear fashion, is a really useful thing to do

(Transcription, 7/10/08)

Eventually, Conrad described his reasons for wanting to explore additional media options for the KYPP. He felt that people were stimulated to consider and care for the landscape by different features of the landscape and through different avenues of access 
to the land. He wanted to use the KYPP to provide these multiple paths. One of his main goals for the KYPP was thus re-articulated: the importance of identifying and creating a variety of means for connecting people to the county's landscape, means that would appeal to their varied and myriad interests. Commenting on the use of multiple paths, he stated:

But the idea is...to improve knowledge of the landscape through that, or as accompanying that, sort of help people care more for the landscape, know it and care for it more. And the fact is that... people are going to come at it from different directions...some of it's going to come through schooling, some of it's going to come because people are turned on by GIS...some people maybe because they're turned on by food, some people just really love history, some people get a kick out of nature.

(Transcription, 7/10/08)

Finally, we discussed issues related to recruitment and the ages and length of residency of our participants. For example, Tory felt that the second, predominately mixed-age group had yielded a different and valuable perspective on the county. Conrad expressed a somewhat different reaction to this group's demographics. He was concerned that this focus group lacked the perspective of long-term participants, such as those from the first group, and he wanted to hear more from this perspective. After some discussion, however, we concluded that we would stay the course with our processes until we had received more actionable information relevant to the issue of residency.

I felt that the third focus group began more slowly than the previous two groups. I felt that it went well on the whole, but the beginning of this focus group was decidedly unique in my mind. Tory also commented on its slower start. She suggested that it was probably the result of people "processing" the "flood of information" that I had organized into the summary-overview. Conrad agreed, but he added that the overview was, in fact, 
what he had requested. If we were going to host another educators' focus group, we would want to revise it; since we were not, however, we took no action on this.

It is also interesting to note here a comment from Conrad. He mentioned the group's dynamics in regard to the specific occupations of the educators who were present and how that had impacted people's relative contributions. For example, he felt that the two "school teachers" in the group had had to talk more during the interview in order to respond to our questions from a teacher's perspective ${ }^{32}$. He described the situation this way:

It was sort of a funny balance because we only had two school teachers and...three outreach people...per force the teachers talked a lot but they kind of had to because nobody else was there to represent the teaching aspect of things.

(Transcription, 7/16/08)

As we continued to discuss this mix of 'formal' and 'informal' educators, I wondered how it had changed the group's dynamics. As Conrad's comment implies, the educators may have interpreted the questions differently. Was this a weakness of our heterogeneous group? Perhaps, but I also noted that many of the educators had reported that they enjoyed hearing from the variety of educators in the county ${ }^{33}$. While there were perhaps some real or perceived disadvantages to the mixed group, then, there were clearly some advantages as well.

We also talked about issues related to the KYPP during this debriefing. For example, oral histories had come up as a type of project in which people were interested. The two earliest groups had also suggested hands-on, experiential programs and materials for the KYPP, for which the educators were also very supportive. We discussed these

\footnotetext{
32 These two teachers were the participants that I earlier identified in the "interviewing" section as being the dominant talkers.

33 This was also documented in their evaluations.
} 
recurring suggestions as well as one other during this debriefing: using the KYPP as a community-building tool. In the third focus group, a few of the participants had indicated an interest in having the KYPP organize networking-events as opportunities for people and groups to come together to discuss their work and interests regarding the Project. It was presented as an information sharing and community building exercise. As this was already an interest of Conrad's, we considered it further.

In particular, we wondered how the Project might be framed in terms of its description and presentation in order to organize and coordinate all of the various groups, projects, materials, and themes that might comprise it. As part of this question, we also talked about the individual interviews that Conrad hoped I would conduct before leaving New York. There were certain people that we had not been able to reach for the focus groups and we felt that perhaps we could schedule a more informal time (i.e. individual interviews as compared to focus groups) to meet with them. This was the case, for example, for farmers in the county. I had initially wanted to include them in a focus group but Conrad had been hesitant to ask them to participate during the summer ${ }^{34}$. Conrad's thought was that we could instead arrange for more informal, individual interviews with selected farmers rather than asking a group of them to convene for a focus group. The same was also suggested for other county groups that the FEP had in mind.

Last, we discussed the summary report that I would write for the FEP. I asked Conrad how I could organize the report in order to make it useful to the FEP and the

\footnotetext{
${ }^{34}$ I surmise that this was the case for much the same reason that Conrad did not want to contact too many teachers in the county before the Project was further along and more certain (i.e. as discussed in the "recruitment" embedded unit). In other words, I think he was hesitant to 'bother' farmers in the middle of the summer both because he was trying to be considerate, but also because he was being cautious about an uncertain project.
} 
KYPP. He said that he was most interested in having the report identify and draw out the themes that people brought up during the focus groups. He was also interested in the maps and other media that could be used to present this material. In brief, he was interested in a summary that could present the KYPP "as a coherent whole." I had also mentioned to Conrad that I was interested in sending my report to the focus group participants. I ran this idea by him during the debriefing to see if he had any suggestions. His suggestion was that I should send it out in a fairly informal way to everyone who had participated. He felt that I should give them the option to read it and respond without putting them "on the spot" for their feedback. In his words:

...send it out to everybody and just provide a way for people to respond...rather than putting somebody on the spot...send out, sort of like, for your information... here's a summary of what we understood.

(Transcription, 7/16/08)

The fourth focus group, although it was going to be our largest ended up having the fewest participants. I therefore opened up the debriefing session that followed with a comment related to its size. I felt that this group had taken longer to generate a productive dynamic because of the number of participants. I also commented that I had appreciated Conrad's input and additional questions during the interview. I told Conrad that I felt his input had "expanded the group" and "made it easier for people to talk." He agreed that the focus group had been somewhat "slower" than the other interviews, but he also felt that it had a more "intimate" feeling. We then spent some time afterwards discussing how the size of the group may have influenced its slow start. Ultimately, we all felt that this focus group eventually came to have the more casual and free flowing communication of the bigger groups. The difference we perceived was that the larger groups seemed to achieve this dynamic more quickly. 
The conversation then moved into a discussion about the relationship of the participants' ages relative to their comments regarding the landscape. Tory suggested that the older participants had seemed to have more to say about the county's landscape. Conrad agreed and felt that one could say more about the landscape if they had experienced it for a greater duration of time. He suggested that these people have a different "frame" of experience. As in the second focus group's debriefing, he also expressed feeling that we were not reaching many of the county's long-term residents.

This idea of long-term residents, however, proved somewhat problematic for us to define. For example, how long would someone have to live in the county to be considered a long-term resident? While we did not ever directly answer such questions, our discussions on residency did lead to a useful insight. Part of the reason for Conrad's concern with long-term residents was related to his feeling that we were hearing a lot of the same, particular types of information from our participants. Conrad wondered, for example, if the county's newer residents were more concerned about certain issues such as development and conservation, which came up frequently. If we were to reach longerterm residents would we hear different opinions on these issues, or different topics altogether? My response to this suggestion was that our means of recruitment - trying to be "non-partisan, non-group" oriented in how we contacted participants - combined with the fact that we were asking people to self-select to participate in a 'farmscape ecology program' focus group at 'Hawthorne Valley Farm' together were responsible for the similarity of response, more so than length of residency. In other words, I felt that the type of people who would self-select to participate in such a focus group were more likely to be sympathetic to certain issues whether they were long-term residents or not. 
Much of the remainder of this debriefing addressed the issue of recruitment. Specifically, Conrad wanted to know if he should get more involved in contacting participants for the final focus group. His suggestion was not spurred so much by the low attendance of the fourth focus group as by his anticipation for the upcoming interview, which was the weekender/upper income group. Mostly, he was interested in ensuring that we had good participation for this group. He wanted to know if he should re-contact any of the people who had already confirmed attendance. I told him that I had already recruited an adequate number of participants. My only concern was that most of them had been contacted through email. Both Tory and Conrad, however, felt that working by email was common practice, particularly for this group. So we decided that Conrad did not need to do any additional recruiting.

All eight people who had confirmed their participation in the fifth group did indeed show up. Following this interview, however, we had a unique debriefing. First, Tory had not been present for the fifth interview and was, therefore, not present for the debriefing. The debriefing also took place nearly two hours after the meeting because the FEP had previously arranged for a meeting with a consultant regarding a separate project of theirs (typical debriefings occurred much closer to a focus group's conclusion).

The third unusual circumstance was that a consultant who also had experience in community-oriented processes, and who had sat in on a portion of the fifth focus group, joined us ${ }^{35}$. Conrad was interested both in debriefing on the fifth focus group as well as describing the KYPP to the consultant and getting his feedback and suggestions. Unlike previous debriefings, we did not talk very much about the final focus groups' dynamics

\footnotetext{
35 This person came to HVF from Germany to work with the FEP on a water treatment project. As his background included various community development initiatives he was invited to both observe our fifth focus group as well as make suggestions during our debriefing.
} 
or the information we had received other than to say that the group had seemed a little more off-topic than most but that a number of new, useful and reinforcing ideas had still been generated.

Most of this debriefing focused instead on future ideas for the KYPP. For example, the consultant suggested the development of pilot projects that would formalize and publicize the KYPP, thereby helping it get off the ground. He also commented on the importance of providing a hopeful and celebratory project for county residents. We had received this piece of advice from another of our advisors: remember to celebrate the processes. In this case, the consultant suggested hosting a festival related to the Project. Following this debriefing, Conrad and I planned to meet again soon to discuss the overall focus group process and to evaluate our next steps, including the individual interviews.

\section{Post-focus Group Analysis and Reporting}

The final stage of the focus group process, the post-focus group analysis and reporting, formally began when I started transcribing the first focus group interview. I began this shortly after the completion of the fourth focus group. Thus, there was some overlap with this stage and the previous embedded units. Had I begun the transcription process earlier there would have been even more overlap, but I was initially under the impression that I could wait to transcribe until the all of the focus groups were completed. I reasoned that our debriefing analyses were sufficient reviews of the focus group interviews in terms of meeting Conrad's needs during the summer. I did not think, therefore, that I needed to begin transcribing until later. I also felt that I was busy enough with the other on going focus group work (i.e. setting up the interview room, organizing 
for the meals and the thank you gifts, recruiting) and with the field ecology research that I did not fully consider the benefits of beginning transcription sooner. However, after asking one of my advisors for recommendations on the analysis process, such as when I should begin transcribing and how to code, I received the following response:

I would recommend transcribing them as soon as you can. It's easier to transcribe things when they are still fresh in your mind. You'll find that some things that may be hard to understand will be easier to transcribe because you may actually recall the exchange. I wouldn't start coding your transcriptions until after you get back. Coding tends to work best when you can sit down with your data and really spend some time with it.

(Personal Communication, 7/13/08)

Heeding this advice, I began transcribing earlier than I otherwise would have. In retrospect, I should have begun the process even sooner. Listening to the audiorecordings with the focused attention that is demanded for transcription would have been particularly useful for improving my role as moderator. It would have helped to identify additional themes discussed by the participants beyond what Conrad, Tory, and I discussed in our debriefings. In reality, however, there was not much time for this. Even if I had realized the benefits of transcribing sooner, I would have been hard-pressed to start earlier or to put more time into it.

I was solely responsible for transcribing and coding the interviews and for writing the report that followed these steps. Whereas the first two processes were done individually, I did try to incorporate other's input into the resultant reports. For example, I talked with Conrad about the summary report following the third focus group as well as during the meeting alluded to at the end of the previous embedded unit. During that meeting, we talked about our impressions of how the FEP might best begin to develop the KYPP based on the summer research. We discussed the themes that seemed to be most prevalent from the focus groups and the types of information and media in which people 
seemed most interested. We discussed the groups that we felt we had not heard from (i.e. low-income and long-term residents) as well as the individual interviews that we hoped to conduct before I left New York. We also talked about the final, summary report that I would write.

Conrad informed me that he was mostly interested in descriptive information. He wanted a fairly basic review, for example, of our participants, which groups they had participated in, and how many people were present for each focus group. He also wanted an overview of the specific county themes that were of interest to the participants as well as their suggestions about mapping projects and other media for the KYPP. In general, he wanted to know if the KYPP should be pursued further based on our focus group input, and, if so, in what ways (i.e. relative to the FEP's four main questions, page 43).

Keeping his interests in mind while incorporating the literature and advice from advisors, I began transcribing and coding all of the focus groups more intensively after I left HVF in early August. I first transcribed all of the focus groups by listening to the audio-recordings and typing, verbatim, what was said. During this process, I used Tory's notes as well as my own to verify any portions that were difficult to hear.

The entire transcription process took approximately two-and-a-half months. Once it was completed in late September, I began to code each of the focus groups individually. My coding was informed by reviewing the focus group literature and by advice from one of my advisors. I began coding each focus group by reading over the transcription and using a highlighter to identify the major themes of that group's discussion. After creating a list of these themes, I collated the comments that were relevant to each of the themes. I then read over these comments as a whole to identify 
the major topics within that theme; these topics became the sub-themes. I thus created, for each focus group, a list of the themes, the sub-themes comprised therein, and the elements (i.e. the specific comments) constituting the sub-themes. Following this, I wrote a descriptive summary of the focus group. This was done for each focus group, one at a time, beginning with the first group and finishing with the fifth.

After each group was coded and summarized, I sent Conrad and all of the participants a copy of their focus group's report. In fact, I sent Conrad a copy of the first focus group's analysis before I had begun the remaining four analyses and before I had sent anything out to the participants. I wanted both to keep him up-to-date with my progress as well as get his feedback on my analysis approach, format, and results. He responded to my first individual focus group summary by saying that it seemed to be a useful, initial analysis. He felt it was ready to share with the participants and he was interested in knowing if the participants might have any further comments about the descriptive summaries or the KYPP in general. He also shared additional information regarding what he wanted from the analysis:

I see you've been busy. I read over your summary and it seems very useful. I didn't proof-read in part because I take these to be general notes that seem fully understandable and probably don't warrant time spent in detailed polishing. I think their shape is fine for sharing. Does that seem a correct interpretation? Are you going to ask for any additional ideas from people when you share it with them? I'd be curious to hear if anybody chewed on ideas more. Perhaps they could follow-up with both of us (i.e., send to you and CC me or something like that), so that they know there is still on-the-ground interest.

I see using these reports in at least two ways: to get an overall gist of interest and opinion, and to 'mine' for interesting ideas and approaches. Your detailed write-up is certainly useful for both, and I am very grateful for the time you spent compiling this information. The one addition that would help me would be something at the beginning listing the participants and any perceptions you had (and this doesn't need to go back out to participants) of general backgrounds and any group dynamics that may have influenced the results. Nothing in great depth but I do remember that different FGs had different moods that influenced the course of conversation, although I no longer recall who attended which ones.

(Personal communication, 9/27/08, bold font added for emphasis) 
With this confirmation, I continued writing each of the descriptive summaries as I had done for the first. As soon as I finished each descriptive summary, I then sent it out to the participants of that group. In the accompanying email, I briefly described the process by which the focus groups had been transcribed, which was more fully explained in the summary itself, and I explained why they were being sent the summary. The following is an excerpt from one of these emails:

I'm writing today with an update on the Know Your Place Project.

As soon as all of the focus groups were finished this summer (which seems like it was a really long time ago!) I began transcribing them and trying to organize everything that we talked about. Attached to this email is a 'near-to-final' copy of my summary report for your focus group. I was hoping that you might be able to look it over - perhaps within the next week to 10 days - and if you have any feedback to share it with me.

For me, this is an opportunity to share with you what I've done as well as to doublecheck my summary with your recollection of the focus group. If you notice anything in the report that seems missing, or if something seems incorrect to you, please let me know. Also, if you have any other comments about the report (i.e. about the format, grammar, something you really liked, etc...) or about the focus group more generally, or any other ideas or suggestions please feel free to share those with me as well.

You can send any comments to Tim at: trby8b@mizzou.edu. And, because the KYPP is still moving forward, you can also send your comments to Conrad at: fep@ fairpoint.net.

(Personal communication, 11/17/08) ${ }^{36}$

In total, ten of the thirty-five participants responded to the emails containing these initial, descriptive focus group summaries ${ }^{37}$. All of these responses were positive. They generally included peoples' thanks for having been sent the report and for my having done the work that went into it. They were also, generally, very brief. The one in-depth response included thanks for the report, a few grammatical and spelling corrections, the suggestion to include in the report an organization that the KYPP should work with, and

\footnotetext{
${ }^{36}$ Note that this email indicates a suggested time frame for people's responses. After sending out the first three focus group's descriptive summaries, I was advised to include a "reply-by date." I thus included this in the email for the final two focus group participants, such as in the excerpt above. I also resent an email to the participants of the first three focus groups to double check that they had received the reports and to mention a "reply-by" timeline.

3735 emails were sent, rather than 38 , because 3 of the participants did not have email addresses. For the 3 participants without email access, I printed copies of the descriptive summaries and mailed them. There was no response from any of these mailings.
} 
also a question about where the KYPP was heading. Aside from this one involved response, however, most of the replies were fairly short. Also, while six of the ten responses indicated having read all or some of the report, four of the responses indicated that the report had not been read. Of these, three mentioned plans to read the report in the future. The gist of people's responses to these descriptive summaries, therefore, was positive but brief.

After finishing the fifth focus group's descriptive summary, I began drafting the final, summary report for the entire process. I first combined, chronologically, each focus group's descriptive summary themes. For example, each focus group had discussed agriculture, so I arranged each groups' descriptive summaries related to agriculture in chronological order. I did this for each of the themes. I then re-read each of the focus group's descriptive summaries for a particular theme to identify its essential components. I listed and organized each of these components and then compared them among the focus groups. Then I wrote a cross-focus group summary for that theme. I did this for each of the themes discussed during the five focus groups.

I explained this process in the final summary report so that people who read it would understand how the report was generated. I also included an overview of the entire focus group process, which included my reasoning for why focus groups were selected, an overview and descriptive summary of the focus group's participants (i.e. number of participants, gender), and the cross-focus group summaries for each of the major themes that I had 'lifted out' from my analyses. Finally, I included conclusions and recommendations on the focus group process at the end of the summary report. 
My intention for sending the participants the summary report was, again, to keep people involved in the process. I wanted to show them that progress was being made and that their participation had informed this progress. I also wanted to invite their feedback on my analyses and conclusions so as to enable their continuing participation in the Project. But before making the summary report public, I sent it to Conrad and Tory for review. In general, both felt that it was well done, comprehensive, and accessible.

Conrad had a single major critique (and one which I shared): the summary report was lengthy. At 25 pages, he felt, and I agreed, that it was probably longer than many people would read. In an email to me regarding the summary report, he wrote:

In general I think it looks good - it serves me as a very useful summary and distillation of the focal groups. Who, aside from me, is your intended audience? I think people who participated in the focus groups might want something a bit shorter and more concise, while for me, the more ideas which are included the better...

(Personal communication, 12/1/08, bold font added for emphasis)

While I did generally agree with this comment, I was conflicted about consolidating the report further. I had already condensed the over one hundred singlespaced pages of transcripts to approximately 50 pages of individual summaries, which were further condensed into the 25 pages of the summary report. I was concerned that further consolidation of the report would too greatly limit people's access to information. I was also busy writing this thesis and I felt that an additional distillation of the report would be difficult and time consuming. Finally, I felt that people could easily navigate the summary report if they did not want to read the entire document.

I therefore asked Conrad if he felt that it would be acceptable to leave the summary report as it was. My suggestion was to mention the report's navigability in the email accompanying the document, indicating, for example, that one could read portions 
of the summary report or skip to any points of interest without reading the entire

document. By doing so, I felt that I might mitigate the potential for people to not read the report because of its length. Conrad agreed that this would be fine ${ }^{38}$. The final emails to the focus group's participants and all others who worked with us during the focus group process were sent on 12 December 2008. It included the following preface, as well as an update from Conrad on the KYPP:

Good afternoon,

I hope this email finds you well. Attached is a copy of the "Summary Report" from the past summer's Know Your Place Project (KYPP) research. This report provides a background on the KYPP and the focus groups, an overview and summary of the focus groups' results, as well as some final conclusions and recommendations. If anyone would like additional information, beyond what is included here, please let me know.

Please note that while the summary report is $\mathbf{2 5}$ pages, and can be read from start to finish, you can use the Table of Contents (page 2) to navigate to any particular point of interest without necessarily reading the preceding sections. Also, as with the earlier focus group summaries, your input and suggestions regarding this summary report and the KYPP continue to be welcomed and appreciated. Please contact Conrad and/or me with any feedback.

Below, you'll also find an update on the KYPP from Conrad. As you'll see, the project is moving forward. Your involvement is, in no small part, a reason for this progress.

Sincerely, thank you very much. And happy holidays -

(Personal communication, 12/12/08, emphasis added)

I felt that this preface offered a satisfactory compromise between not wanting to overwhelm people with information while not prematurely limiting their ability to access information they might be interested. In total, however, only two people responded to this summary report email. One of the respondents indicated that they had looked at the report, saying that it "Looks really good." The only other respondent (one of the FEP's advisors and someone with whom we had met with outside of the focus groups to discuss the KYPP) had not yet read the report but planned to do so shortly. Both were brief but

\footnotetext{
${ }^{38} \mathrm{He}$ also indicated that his initial criticism was not necessarily intended as a request for a shorter report, but was advice he was giving in regards to any future reports that I might write.
} 
positive about the report summary, but, again, they represented a small proportion of the 35 respondents $^{39}$.

Finally, Conrad and I continue to correspond regarding the focus group process and the KYPP more broadly. I have, therefore, continued with my involvement in the Project and I am now serving as an informal advisor. Using some of the ideas and suggestions that came out of the focus groups as well as input from on-going projects, the FEP was successful in getting a multi-year grant to fund research related to the KYPP. This development, however, is beyond the scope of this thesis. Thus, the final phase of this stage concludes with the dissemination of the summary report and the awareness that it may have cultivated regarding the KYPP.

39 As with the descriptive summaries, I sent emails with the summary report document attached to 35 participants. For the other three I printed copies of the report and hand delivered them to HVF while I was there for a visit in midDecember 2008. 


\section{FOCUS GROUP STAGES ANALYZED}

\section{Introduction}

The analytic frameworks used in the following embedded units are hybrids of the factors listed in Tables 3 and 4. The factors that are germane to each embedded unit are identified at the beginning of each section and referenced throughout to consider the extent to which the processes contained within that embedded unit were more or less successful as participatory approaches to research ${ }^{40}$. The extent to which the embedded unit addressed the FEP's major questions is also considered.

\section{Pre-Focus Group Planning}

The specific participatory factors considered in this sub-unit are: "emphasizes collaboration" (Table 3) as well as "what is the research for," "who is the research for," "whose knowledge counts," "topic choice influenced by," "methodology chosen for," "problem identification" and "what is emphasized" (Table 4). For organizational purposes, this stage has been divided into the following two components within which these factors are considered:

1) Selecting the research topic ("topic choice influenced by" and "problem identification")

\footnotetext{
40 The selected participatory factors, and their evaluation within each of the focus group's stages, are graphically organized in the chapter VI (see Tables 7 and 8 on pages 137 and 138, respectively).
} 
2) Developing the research plan ("emphasizes collaboration," "methodology chosen for," "what is emphasized," "what is the research for," "who is the research for" and "whose knowledge counts")

The selection of our research topic was determined almost entirely by Conrad. He was the primary source and the ultimate arbiter of what the focus groups were eventually used to explore ("topic choice influenced by," "problem identification"). Using the terminology of Table 4, 'local people' and 'local priorities' were the primary influence on the research topic. Furthermore, while our decisions were somewhat influenced by funding (listed under the 'conventional research' column in Table 4), it is important to distinguish between different types of funding constraints. In this case, I had no funding restrictions in the selection of our research topic; rather, we were making decisions between different research methods based upon limited funding and other resources (i.e. human resources). We were acting, in other words, based upon the reality of our limited resources, but not with externally imposed restrictions. Actually, to the contrary, I was indirectly able to stretch Conrad's available funds. By paying for my ecological internship using the Conservation Biology Fellowship funds, Conrad was able to apply the funding that he would have otherwise used to pay for an intern to pay for some of the expenses of the focus groups. Thus, this component of the pre-focus group planning embedded-unit was highly participatory between Conrad and I.

The development of the research plan and selection of the methodology were similarly highly participatory. For example, adapting materials from the National Civic League, the Community Development Academy defined collaboration as: 
Exchanging information, altering activities, sharing resources, and enhancing the capacity of another partner organization for mutual benefit and to achieve a common purpose... Organizations share risks, responsibilities and rewards through new structure with full commitment to a common mission...

(Community Development Academy, 2007)

At this stage, the primary collaboration was between Conrad and I ("emphasizes collaboration"). As an example, Conrad was focused on using an inclusive methodology as a means of ensuring that all people's voices could be heard. County residents were, therefore, a direct consideration in the research although they were not yet directly consulted. Instead, Conrad and I collaborated to determine the best method for incorporating county residents" input ("who is the research for," "whose knowledge counts"). There was a high level of collaboration during this stage, which included a great deal of back-and-forth exchange of relevant literature and resources, input from our various advisors, and our own ideas. The email highlights one example of our exchanging information from the literature and sharing opinions on how to plan for the summer's research:

2. Number of FGs: Based on the FG literature, I think a good starting point for our Summer FGs would be to conduct 4. Doing them early on allows us both to use the data to inform, and in relation to, our other input methods, but it also allows time for us to decide if we'd like to do additional FGs in the middle or later in the summer (if we think they worked really well, or if we realize that we'd like to get some additional, particular group's input, for example).

Sure. I wouldn't want to say "Four and only Four" but we need to start somewhere. I believe that some simultaneous, informal, individual discussions with various people could also help shape ideas.

(Personal communication 2/22/08; section in Italics is Conrad's response, emphasis added)

This stage of focus group was also highly participatory for other reasons. For example, the methodology was specifically chosen as a means of encouraging interaction and community building among both participants as well as between participants and the FEP (“methodology chosen for" as well as "emphasizes collaboration”). Focus groups 
were also selected for being something of a compromise between Conrad's intensive and extensive research interests ("who is the research for"). Finally, we planned to use the focus group methodology with the express purpose of gathering actionable data that would inform the KYPP's development in a way consistent with input from Conrad and county residents ("what is the research for," "who is the research for" and "whose knowledge counts"). All of these outcomes culminated in our intention that the focus group research be part of an on-going process of capacity building through information activism (i.e. the library metaphor), rather than focusing on immediate, data-based outcomes ("what is emphasized").

\section{Recruiting}

The factors most relevant to this embedded unit are: "employs diverse methods" and "emphasizes collaboration" (Table 3) as well as "who is the research for," "whose knowledge counts," "methodology chosen for," and "what is emphasized" (Table 4). To apply these factors, the recruitment process is considered in two components:

1) Developing the recruitment process ("emphasizes collaboration," "who is the research for," "whose knowledge counts," "methodology chosen for")

2) Recruiting ("employs diverse methods," "emphasizes collaboration," "who is the research for," "whose knowledge counts," and "what is emphasized")

Our recruitment processes were, in general, successful as participatory approaches in both respects. In part, the focus group methodology is inherently participatory during this stage, particularly regarding the first component. Focus groups are easily tailored to 
meet the specific interests of the hosting organization ("who is the research for"). However, we did try to make our recruitment process flexible and responsive to prospective participants, enhancing the participatory aspects this stage ("who is the research for"). Yet while our efforts did contribute to high levels of participation in this embedded unit, a heightened awareness of trying to make the process as participatory as possible may have complicated our recruitment. The reasons for this are discussed during the analysis of the second component below.

The first component was highly participatory between Conrad and I. It included our early discussions about which groups in the county we would try to include as focus group participants and how we might recruit them. It also included the development of the content that informed the focus group plan, the recruitment process document and the focus group schedule document.

Each of these documents required a high level of information exchange and codevelopment, wherein Conrad and I continuously shared our opinions and perspectives on our various options (“emphasizes collaboration"). We both spoke with advisors to get additional feedback that we then brought back to our decision-making table ("emphasizes collaboration," "whose knowledge counts"). I also spent a good deal of time researching the literature on focus groups and other research methods, sending the FEP documents and relevant sources of information on focus groups and recruiting, and relaying my personal opinions on our options.

We eventually compromised on a mixed-methods approach that favored my methodological recommendations but that also incorporated Conrad's desire to be perceived as non-political and to develop an approach that was as unobtrusive to 
participants as possible ("employs diverse methods," "who is the research for," "whose knowledge counts," "methodology chosen for"). It should also be borne in mind that Conrad was specifically interested in getting advice from someone who had the relevant background on the subject and the time to research the various methodological options ("emphasizes collaboration," "who is the research for," "whose knowledge counts"). My influence in determining the methods was, therefore, not a demonstration of researcher control over the process, but rather fulfilling an information gap for Conrad and the host institution.

The participatory nature of the second component of this embedded unit was different from the previous component of recruitment as well as the pre-focus group planning embedded unit. This is because the participants became directly involved in the process at this time and so need to be considered with regard to the ideals of participatory research. This stage was also different in that by attempting to adhere to the ideals of participatory research there were a number of challenges to our recruitment process that otherwise might have been avoided. As is noted below, however, this is not so much a critique of the participatory ideals in general, but of their specific application in this circumstance as well as in relation to my status as a novice researcher in this area.

Much like the first component, the recruiting component of this embedded unit was a highly participatory process. This is not to say that it was entirely successful during all phases of recruitment. I was somewhat dependant on Conrad, for example, to initiate the contacting and recruitment of participants prior to my arrival in New York ("emphasizes collaboration"). Some of these results were discussed in Chapter IV. Here, they are examined in relation to the demands of the focus group methodology. What I 
gleaned from my experiences during the first month that I was in New York was that the recruitment process can demand a large time commitment and perhaps also a level of familiarity that together make it a difficult process for novices, and particularly for organizations without a lot of time, human capital, or focus group experience. The following excerpt from my field notes highlights this learning process:

A key lesson that I've learned thus far is the importance of focusing on the highest priority(ies) at each stage of this process. So, for example, the FEP and I should have selected "groups" for the focus groups and then immediately begun to advertise for the $6 / 19$ focus group. Instead of assuming that the FEP will be on top of the focus group recruitment, I should have been even more pre-planned and involved with them on getting it done...outside of them developing a passion for focus groups or hiring/working with someone with experience (in this case me, a graduate student) the focus group methodology doesn't look like it would have been applied. (Again, it may still be effective, but based on their lack of familiarity, and high level of busyness, they probably would have opted for something more like individual interviews).

(Personal notes, 6/12/08, bold font added for emphasis)

I have no doubt that the FEP had the best of intentions to assist in the recruitment phase before I arrived in New York. But the realities of our busy schedules combined with an underestimation of the time and effort required for recruitment (both theirs and mine) led to an initially unsuccessful recruitment process. After assessing these initial challenges, however, we worked together more effectively and recruited more intensively by using various methods to attract the desired participants ("emphasizes collaboration," “employs diverse methods").

The recruitment component also involved Conrad's considerations for county residents" interests, as well as the direct inclusion of their input ("who is the research for," "whose knowledge counts," and "what is emphasized"). The former consideration developed during the initial planning of the focus group schedule document, in which we addressed the concern that specific dates and times might restrict participation. I 
therefore developed a flexible schedule to account for residents' preferences and availabilities ("whose knowledge counts"). The latter consideration was an extension of the former. It occurred as we concretized our draft schedule by contacting potential participants and incorporating their availability into what became our final focus group timetable ("who is the research for" and "what is emphasized").

This flexible approach was participatory in terms of addressing Conrad's concerns and attempting to cater to participant availability. However, it also created more work for the already time-intensive recruitment process and may not have been the most efficient or successful approach. This additional time stressor may have diminished the overall quantity of focus groups that we might have otherwise hosted. It may also have decreased the outreach time that I was able to put into recruiting from certain groups (i.e. the harder-to-reach populations).

The flexible scheduling may also have left some people feeling that their participation in the focus groups was not as essential (i.e. because of the focus groups' nebulous organization), which could have contributed to non-participation. I suggest this as a possibility because I feel that in our attempts to cater to people's availability we may have come across to some people as having a less organized process. Combined with the already vague nature of the KYPP, this may have resulted in some county residents not taking their participation as seriously as they might otherwise have done.

I can only speculate about these drawbacks because we did not use another recruitment approach for comparison. Consequently, it is appropriate also to speculate about the possible advantages of our approach. It may be, for example, that the flexible nature of our recruitment process demonstrated our genuine interest in people's schedules 
and availability. People may have greatly appreciated this concern: only one participant noted that the timing of the focus group could have been more "flexible." Interestingly, this participant was in the weekend group (number five), which was the only one that offered a more structured, pre-determined schedule. On the whole, though, participants responded positively to our choice of time, date, and location on their evaluations. And regarding the occasional no shows, it is possible that people were simply unfamiliar with the focus group process. Despite my best efforts to specify the importance of their participation during our contacts prior to meeting, some may have simply forgotten to attend or decided not to attend for other reasons. As no effort was made to follow-up and document the no shows, however, I can only speculate ${ }^{41}$.

As Hayward et al. (2004) point out, it is worth noting that non-participation can also be interpreted as an exercise of preference. People can therefore be non-participants in the research process without necessarily diminishing the participatory nature of the process itself. Thus, even without knowing the exact causes of non-participation and non-response (i.e. our flexible approach to recruitment or their decision to not attend for various reasons, respectively), I contend that this stage of the focus group process was still highly participatory.

Finally, regarding the FEP's first research question (Is the KYPP a good idea, a project worth pursuing?), there was an explicit desire to hear from a broad range of county residents. Our recruitment methods were a mixed success in this regard. Our approach was strong, for example, in recruiting county residents with an affinity for the

\footnotetext{
${ }^{41}$ Most county residents that we interacted with, even those who did not participate, responded very positively to the KYPP and to the process of focus groups. Many of the initial responses, for example, expressed interest in the KYPP and the focus groups, but couldn't make the dates/times. It is, however, possible that some were not comfortable with the process. For example, one person responded to an email request for participation by saying, with a clear indication of negative criticism, that process sounded like a 'Karl Rove plan'.
} 
FEP and toward projects such as the KYPP. Our flexible and somewhat non-targeted approach to recruitment promoted self-selection, which resulted in a group of fairly likeminded participants. This did have some perhaps unanticipated benefits. For example, it may have begun the process of developing a core group of county residents who are likely to participate in future KYPP projects (i.e. serving on steering committees, assisting with research). But our recruitment approach was not very successful in achieving diversity on other fronts. We struggled, for example, to recruit from long-term residents, minority populations, low-income populations, and groups within the county that were not as conservation-minded as those who self-selected to participate.

It is likely that this weakness was at least partially due to my lack of familiarity with the diversity of recruitment techniques and approaches available. In other words, as a result of Conrad's decision to work with a novice researcher, our approach was somewhat restricted by my learning curve. I was, in fact, quite aware of this limitation throughout the research, but particularly during recruitment. My awareness translated into some uncertainty regarding how to approach recruitment from the groups we were struggling to reach. I was hesitant to agree to a less-structured approach to recruiting because I felt we would be more effective by directly recruiting participants from identifiable groups in the county; however, I did not feel that I had either the previous experience or the necessary time to insist upon this or devise a means for recruiting from populations outside of the FEP network. Combined with time and resource constraints, my inexperience likely influenced the types of participants who attended the focus groups. Thus, although highly participatory, we had limited success in recruiting from the entire spectrum of county residents. 
The recruitment process was not a failure, though, since we did not expect to get input from every conceivable group within the county. We were able, for example, to make some basic assumptions about our participants (i.e. age, occupation, length of residency). The recruitment process, then, did provide some (limited) demographic information of interest to Conrad, which did in turn enable us to identify some of the residents from who we felt we were not hearing. Remembering that this outreach-input process was an initial phase of the KYPP, future methods can be informed by this information. Stated differently, we were successful in getting relevant information on the Project (i.e. regarding the FEP's other three questions) from some residents, and we were able to identify other populations that still need to contribute. Therefore, I contend that our recruitment process was moderately successful as an initial and highly participatory approach.

\section{Developing the Questions}

The participatory factors included in this embedded-unit's analysis are: "focuses on being useful" and "emphasizes collaboration" (Table 3) and "what is the research for," "who is the research for," "whose knowledge counts," "topic choice influenced by," “interpretation," and "what is emphasized" (Table 4). The following two components are used to evaluate this stage's participatory features:

1) Question development prior to focus groups (“emphasizes collaboration," "what is the research for," "who is the research for," "whose knowledge counts," "topic choice influenced by," and "what is emphasized") 
2) Question development concurrent with focus groups (“emphasizes

collaboration," "who is the research for," "whose knowledge counts," "interpretation," and "what is emphasized")

During the first component of this stage, prior to hosting the focus groups, Conrad and I worked together extensively to co-develop the questions ("emphasizes collaboration). We combined my review of the focus group literature, their interests in specific topics regarding the county's landscape, and our consultations with various advisors to create and validate our questions ("emphasizes collaboration," "who is the research for" and "topic choice influenced by"). As an example, the following email conveys Conrad's comments on one of my early drafts of the focus group questions:

Here are my comments. Looks good. I think these are our central questions, and I've mainly added comments or thoughts relating to context. I'm chewing on this a bit, so I may come back with additional thoughts later on. Once we get a draft or two further down the road, it might be useful to send copies to (our advisors), if only to keep them in the loop...thanks again for all your effort.

(Personal communication, 5/9/08)

This excerpt is included here to highlight two features. The first is the mention of "our advisors," which included professors at the University of Missouri, Cornell University, and the University of Vermont, a professional focus group moderator, and a number of local professionals whose work was germane to the KYPP. In all cases, the consultations helped to expand our perspective on the focus group questions and the Project overall. Conrad was also able to expand and reinforce the FEP's information and support networks through our interactions with advisors, particularly in those cases for which we built upon existing relationships or developed new relationships within the 
region. Thus, the development of our questions was a highly collaborative process (“emphasizes collaboration”).

The second feature is that Conrad and I were in frequent contact regarding question development, and there were extensive revisions made to the questions based on these interactions. This process formally began in late April and continued throughout the focus groups themselves. This high level of interaction demonstrates the extent to which Conrad was involved in determining the questions ("emphasizes collaboration," "who is the research for," "topic choice influenced by," and "what is emphasized"). Furthermore, because the goal of developing these questions was to inform the creation the KYPP, our consistent back-and-forth interaction helped to hone in on the issues that would enhance the FEP's future capacity for action ("focuses on being useful" and "what is the research for"). In these ways, developing the questions was a highly participatory process between Conrad and I.

The second component of this stage was similarly highly participatory. This component occurred mostly during our post-focus group debriefings wherein we tended to evaluate the interview as a whole, but also reviewed our questions. We addressed our questions in terms of their ability to inform the overall quality of information we received ("emphasizes collaboration," "interpretation," "what is emphasized"). It should be noted that we were not modifying our questions to make them more leading or to influence participant responses; rather, we wanted to ensure that our questions were understandable so that the participants were able to respond accurately in accordance with their perspectives and opinions on the topics. The point of the questions, after all, was to hear from county residents regarding their perspectives on the county and the KYPP in order 
to inform the Project's development ("who is the research for" and "whose knowledge counts"). This component of the embedded unit was, therefore, highly participatory between both Conrad and I. Furthermore, it was indirectly participatory in terms of the participants' influence on the process. While they did not directly suggest what questions we should ask, their understanding of our questions as well as their responses and feedback during and following the focus groups informed the evolution of our questions (as well as the KYPP).

Finally, this embedded unit was clearly instrumental to the success of addressing the FEP's main questions. Working together with Conrad, and using advisor input and relevant literature, we developed a suitable set of questions, which set the stage for the interviews. Then our on-going evaluation of people's responses improved our questioning while we hosted the focus groups. We were able to incorporate participant responses and our perceptions to create more useable information for the FEP, which should help to develop the KYPP with respect to county residents' input. In this way, the participatory aspects of the developing the questions stage were successful in creating the instrument that we used to access people's perspectives on and suggestions for the KYPP, and thus addressed the FEP's main questions.

\section{Interviewing}

The participatory factors that are considered in this embedded unit are "focuses on being useful" and "emphasizes collaboration" (Table 3) and "what is the research for,"

"who is the research for," "whose knowledge counts," "topic choice influenced by," "methodology chosen for," "problem identification," "data collection," "interpretation," 
and "what is emphasized" (Table 4). To address this stage's participatory factors, I have divided it into two components:

1) Pre-interview planning (“focuses on being useful," “emphasizes collaboration," "what is the research for," "who is the research for," "whose knowledge counts," "topic choice influenced by," "data collection" and "methodology chosen for")

2) Interviewing ("focuses on being useful," "emphasizes collaboration," "whose knowledge counts," "topic choice influenced by," "problem identification," "data collection," "interpretation" and "methodology chosen for")

Although many of its relevant details have already been mentioned in the previous units, three features of the pre-interview planning stage merit additional comment. The first is related to the Conrad's genuine sensitivity to county residents. For example, his desire was to develop a process that would encourage participants to feel comfortable while sharing their honest opinions. For Conrad, the importance of receiving honest input was to create a project of the greatest interest and use to them ("emphasizes collaboration," "what is research for," "who is research for," "methodology chosen for"). This sensitivity also included his constant focus on inclusivity and the attention he gave to the specter of false or unrealistic expectations. We developed the moderator's guide and recruitment process with these sensitivities in mind. Therefore, we attempted to create an informed atmosphere by addressing people's questions during the entire recruitment process, by providing what we felt was useful background information during the focus group introductions, and by leaving time for people's questions following the focus groups ("who is the research for," "what is emphasized"). We also tried to make 
the participants aware of the audio recording and its purposes. We informed them that their responses were anonymous, that the recording was being used for the KYPP and my thesis, and that they had the opportunity to opt out if they were uncomfortable with the process ("who is the research for"). We also wanted to be sensitive to their experience of the process because it was being used not only to develop the initial stages of the KYPP, but also was intended to be part of a longer-term and on-going participatory project ("focuses on being useful," "emphasizes collaboration," "what is the research for" and "what is emphasized").

In some ways, however, since the input process was uncertain in terms of the eventual outcomes (i.e. there was no funding and we offered no guarantee that we could use the information we received), it partially focused on "understanding with perhaps later action" as described under the conventional research column of Table 4 ("What is the research for"). I was also more attached to audio recording the interviews than was Conrad because I planned on using the focus groups to inform both my report for the FEP and my thesis research. Had this not been the case, Conrad might have opted not to record the interviews. Some of the focus groups also might have requested not to be recorded had the option been made more readily available. In this way, my interests as the researcher were given some priority. This aspect of the interview process therefore falls more into the conventional research description of "who is research for" and "what is emphasized" (Table 4).

The second feature concerns our distribution of work in developing the moderator guide's focus group introduction (“emphasizes collaboration”). After co-developing the moderator guide's initial drafts and revisions, Conrad and I divided the introduction. He 
took responsibility for introducing the FEP, their work, the KYPP, and me. This was intended to provide people with relevant background information and make them comfortable not only with the focus group process but also with me as the facilitator ("who is the research for"). My portion of the introduction addressed the more conventional and bureaucratic aspects of the focus group process and the research overall, such as the issue of audio recording and the consent form. I tried to present these more conventional aspects of research in a manner that would help people participate in the interview. For example, I described my interests in the group process aspects of a focus group interview, emphasizing the importance of sharing information. I wanted to ensure that participants felt that the focus group was a 'safe place' to share ideas and opinions ("who is the research for," "methodology chosen for," "what is emphasized"). Additionally, this was intended to reinforce the fact that we were genuinely interested in their opinions and perspectives and that their suggestions would be used, as much as possible, in the KYPP ("focuses on being useful," "emphasizes collaboration," "who is the research for").

The third issue specific to the pre-interview component is the use of advisor input in informing our use of maps and additional materials during the interviews. Advisors were clearly beneficial to our process, helping to solicit useful advice from expert sources as well as build a network for the FEP's future projects, including the KYPP (“emphasizes collaboration"). Our decision to incorporate some of their advice and to follow Conrad's experiential perspective (i.e. regarding the use of KYPP maps) also blended expert- and practice-based input (“whose knowledge counts”). ${ }^{42}$ This feature

\footnotetext{
42 It should be mentioned here that we never came to what I would describe as an optimal use of these materials. While we certainly attempted to find a balanced use that met our interest in providing enough information about the
} 
therefore demonstrates another participatory component of the interview process.

Although not all of the features discussed in this component were ideally participatory it was on the whole a participatory process. More specifically, it was, again, highly participatory between Conrad and I, and indirectly participatory with regards to the focus group participants.

The second stage of this embedded-unit, interviewing, was likewise a mix of conventional and participatory approaches to research. The most superficially nonparticipatory function within this process was that I facilitated the interviews, rather than, say, Conrad or other community members ("data collection”). The interview process was not entirely conventional, however. Early on, in fact, I had suggested that we might include volunteer researchers in the focus group process or Conrad could moderate or comoderate the interview. He responded with minimal interest in volunteer participation in the interviews, which I assume was related to his uncertainty regarding the focus groups and what might come of them (i.e. not wanting to get people involved in a process with uncertain outcomes). He also preferred to take a less direct role in the interviews than moderating. We thus decided that he would mostly observe the focus groups but could occasionally ask questions to clarify issues ("emphasized collaboration," "whose knowledge counts," "data collection," "interpretation"). The ease with which this type of modification can be made to the focus group process is indicative of its inherent potential for participatory research. Finally, we also felt that by having the FEP there (but not directly moderating the group), we could use my role as an semi-unfamiliar researcher to strike a balance between participant comfort and their willingness to share more honestly

KYPP so that people could "get their heads around it" with our concern about leading people's responses, we were still struggling with this issue going into the final focus group. 
(i.e. it might be easier for them to say something negative about the process or the Project to me since they did not know me) ("who is the research for," whose knowledge counts").

Sharing participant opinions and perspectives was also important to this stage. I paid particular attention to this during my introduction. I tried to ensure that people felt comfortable and knew that we truly valued their 'expertise' as county residents. We were, after all, trying to develop the KYPP with their input ("who is the research for," "whose knowledge counts," "topic choice influenced by"). Indeed, based on their evaluations, participants consistently identified as positive the ability to share their opinions and hear other perspectives in an atmosphere where everyone's voice was given equal attention and was truly heard ("who is the research for").

However, not all members of the focus groups spoke with equal frequency or intensity. This could be interpreted as a fault of the method, but it could also be a result of my status as a novice moderator. Both are likely true to some extent. Yet it should also be recalled that not all people wish to participate to the same extent and that part of what is valuable in a focus group interview is the ability to hear other's opinions and perspectives. Many people identified this latter value on their evaluations, suggesting that they truly enjoyed hearing from others ("who is the research for," "whose knowledge counts," "methodology chosen for").

I can only speculate as to whether or not people participated according their desired level of input. Without a more precise measurement of people's desire to participate, combined with a more thorough evaluation of their perceptions on participating, it is not possible to demonstrate that participation matched the desired level 
of input. It is, however, instructive to mention a conversation that I had with one of the rare talkers from the third focus group. This person had specifically mentioned on their evaluation that they had participated "only modestly. In a listening way." They also indicated on their evaluation that they would have like to have heard more from other people during the focus group; in other words, they truly appreciated their role as a listener.

I spoke with this participant a week after his focus group. It was a brief conversation that took place as I was passing by him at HVF. He stopped me as I was walking past and volunteered that he was really interested in the Project and would "love to use" the maps that might be produced. Following the brief conversation that followed, I wrote this in my field notebook:

...he indicated that he understands the purpose of the focus group and getting people's input; and that even though he didn't share a lot he's very interested and thought it is a great project.

(Personal notes, 7/20/08)

Similar anecdotes suggest that people were given ample opportunity to participate in the process. Furthermore, their participation appears to have taken place via different levels (and avenues) of input, which likely reflected their desired level of involvement ("who is the research for," "whose knowledge counts," "methodology chose for," "what is emphasized").

Finally, the participants consistently rated their focus-group experience highly. Most participants indicated that they felt they had participated in helping to develop the KYPP ("whose knowledge counts," "what is emphasized"). Table 6 (below) depicts a tally of the participants' responses to these two evaluation questions: the first regards 
their overall experience and the second reveals their perception of participation in the development the Project ${ }^{43}$.

These responses should not be received uncritically - people may have responded favorably because they are familiar with the FEP or because they did not want to say something mean. Nor should they be ignored nor discredited. There was consistency, for example, in the participants' responses to these two questions, the second of which allowed for an open-ended response. The responses also jibed well with the other responses on the evaluation as well as with my and others' general perceptions of the interviews. For example, as indicated in Chapter IV's embedded unit on interviewing, focus groups 4 and 5 were more challenging in terms of group dynamics. This is reflected in participant rating of the experience. These were the only two groups where the majority of participants rated the experience as "good" rather than "excellent."

\footnotetext{
${ }^{43}$ Note: these numbers do not add up to 38, the total number of participants, because one evaluation was not returned.
} 
Table 6: Evaluation responses

\begin{tabular}{|l|c|c|c|c|c|}
\hline & $\begin{array}{c}\text { Focus } \\
\text { Group } \\
\mathbf{1}\end{array}$ & $\begin{array}{c}\text { Focus } \\
\text { Group } \\
\mathbf{2}\end{array}$ & $\begin{array}{c}\text { Focus } \\
\text { Group } \\
\mathbf{3}\end{array}$ & $\begin{array}{c}\text { Focus } \\
\text { Group }\end{array}$ & $\begin{array}{c}\text { Focus } \\
\text { Group }\end{array}$ \\
\hline Rate your experience
\end{tabular}

The interview process was the stage in which the greatest participant input was received. People were asked for and gave their opinions on the KYPP's topics. They were, of course, also encouraged to continue their involvement in the Project, but the interviewing stage was the pinnacle of people's direct participation in the focus group process. The interviews explored the landscape features and changes of Columbia County that were of interest to the participants, their preferred formats and media for the KYPP, and the ways in which people desired to participate in the Project ${ }^{46}$. Also, Conrad's feedback on the interviews was positive. Conrad and I both felt that, in general,

\footnotetext{
44 This category is included within the "yes" tally, but is distinguished from the other "yes" responses in order to demonstrate when people's responses were a qualified "yes."

45 This category is not included within the "yes" or the "no" tally. It is separated here to highlight this person's comment that their feeling of participation is dependant upon the outcomes of the focus groups and the KYPP.

${ }^{46}$ People's particular suggestions regarding the KYPP will not be reduplicated here as they have been well documented elsewhere, such as in the summary report.
} 
the interviews had provided the FEP with useful responses to their main questions. Therefore, my perspective is that the interviewing unit was, on the whole, a highly participatory process. This was true both in terms of my relationship and interactions with Conrad, but also in terms of the relationship between the FEP and county residents.

\section{Debriefing}

The relevant participatory factors for this embedded unit are: "focuses on being useful" and "emphasizes collaboration" (Table 3) and "who is the research for," "whose knowledge counts," "topic choice influenced by," "methodology chosen for," "problem identification," "interpretation," "analysis," "presentation of findings," "action on findings," and "what is emphasized" (Table 4). Unlike the other units, the debriefing stage is not divided into different components because it was a homogenous stage. In light of this, the following evaluation considers relevant participatory factors in terms of the people involved in the debriefings, since these sessions were primarily small-group discussions regarding the interviews. This evaluation also addresses the three major purposes for which the debriefings were held: describing our impressions of the interview process, discussing the participants that were present, and evaluating the information that we were receiving.

First, there were typically three people involved in the analysis: Conrad, Tory and me. Conrad's inclusion in each of these analyses, which were oriented to evaluating the focus group process and ensuring that it was of positive value to the FEP and the participants, demonstrates the continuing collaboration between he and I in the focus group process ("emphasizes collaboration," who is the research for," "whose knowledge 
counts"). Tory was also an integral part of the debriefing ("emphasizes collaboration"). However, her involvement represents an additional and as yet unexamined aspect of participation.

For four of the five focus groups, Tory - an intern with the FEP - volunteered to help by taking notes during the interviews. She was interested in the process as a friend and co-worker of mine. She was also interested in volunteering because she felt that the process might be beneficial to her future studies: she was planning to begin a graduate program in the fall of 2008. Thus, while we did not use any Columbia County community members as research volunteers, we did incorporate someone who was largely unfamiliar with focus groups. Indeed, she not only took notes, but also provided valuable input throughout the summer's research ("emphasizes collaboration," “methodology chosen for").

Conrad and Tory both played active roles during the debriefings. Their involvement was, in part, as per my request and was predicated on my desire to have a group debriefing process ("who is the research for"). The specific topics we addressed in the debriefing stage, however, were largely determined as a group and based upon the specific issues at hand ("emphasizes collaboration," "who is the research for," "whose knowledge counts," "methodology chosen for," "interpretation"). Although the debriefing could have been more participatory such as by including a county resident in the interviewing and debriefing stages, the process was successful in highlighting Conrad's particular interests and comparing them with the actual focus group input we were receiving ("focuses on being useful"). It was also a collaborative process wherein our collective input helped to evaluate the focus groups and make improvements 
("emphasizes collaboration," "methodology chosen for"). For these reasons, I feel that this component of the analysis stage was highly participatory.

As described at the beginning of this unit, the debriefing discussions were held for the purpose of reviewing the interview in order to evaluate it, identify the processes that were going well or poorly, and to make improvements where possible ("interpretation," "analysis," "action on findings," "what is emphasized"). In general, the debriefings addressed three main topics. First, we often talked about our general impressions of an individual focus group interview. What were the group dynamics and reactions to the focus group process? Did we perceive them to have understood the questions? Did they respond with a clarity that addressed and informed the KYPP's development? Were people able to participate at their desired intensity and did they feel that they were contributing to the process? These issues were considered in terms of trying to improve people's ability to contribute to the KYPP as well as addressing Conrad's interest in hearing from and incorporating their interests ("what is the research for," "who is the research for," "whose knowledge counts," "Problem identification").

Second, we often discussed the participants in each of the focus groups. Conrad had identified certain groups from whom he desired input (see page 59), which served as one of my indicators for evaluating our process in terms of the FEP's objectives ("focuses on being useful," "who is the research for," "methodology chosen for"). Thus, we evaluated the participants from whom were getting input and identified the resident voices from which we were not hearing ("who is the research for," "analysis"). The purpose of these discussions was, again, to inform near- and long-term future actions (i.e. the upcoming focus groups and the KYPP overall, respectively) as well as attempt to 
continue expanding the inclusive nature of the outreach-input stages for the Project ("what is the research for," "who is the research for," "whose knowledge counts," "action on findings").

Third, we frequently talked about the information that we were presenting and receiving. As already discussed, for example, we talked about how to present existing KYPP materials during the interviews without leading responses. Regarding the reception of information, we discussed how to incorporate input from the focus group participants into the Project (i.e. their suggestions for themes to map or for community building projects). And sometimes these two aspects of information overlapped, such as when we discussed how to present unique or recurring participant suggestions (i.e. oral history projects) from previous focus groups into upcoming interviews. In general, this third aspect of the debriefing process focused on evaluating the best ways to use focus group generated information to inform both the on-going input-outreach process as well as the future development and implementation of the KYPP ("whose knowledge counts," "analysis," "presentation of findings," "action on findings").

Finally, the debriefings were structured to be group-based evaluations of the interviews. In this sense they were intentionally participatory, incorporating the observations and suggestions of Conrad, Tory, and me. Conrad was able to express his opinions on the interviews. Tory was able to take notes and evaluate people's reactions, commenting on the process from that perspective. And I was able to hear these commentaries on the interviews and consider my own observations and impressions so as to adjust the interviews towards the FEP's objectives and participant experiences. These debriefings also addressed stages of the focus group process beyond the interview stage. 
We endeavored, for example, to use participant input to inform the analysis and report and, on a broader scale, to inform the KYPP as it developed. In these ways, the debriefing stage of the focus group process was a highly participatory portion of the focus group process between Conrad and I, and indirectly so in terms of county residents.

\section{Post-focus Group Analysis and Reporting}

The participatory factors that are most relevant to this last stage of the focus group process are "focuses on being useful" and "emphasizes collaboration" (Table 3) and "what is the research for," "who is the research for," "whose knowledge counts," "methodology chosen for," "interpretation," "analysis," "presentation of findings," "action on findings," "who takes action," "who owns the results," and "what is emphasized" (Table 4). As the post-focus group analysis and reporting stage is relevant to how well this stage addressed the four main questions of the FEP, those questions are also considered. But before addressing those questions, the post-focus group analysis and reporting stage is divided into two components in order to evaluate it in light of the relevant participatory factors:

1) Transcription and coding ("focuses on being useful," "emphasizes collaboration," "what is the research for," "who is the research for," "methodology chosen for," "interpretation," "analysis," "what is emphasized")

2) Report writing and dissemination ("focuses on being useful," "emphasizes collaboration" "what is the research for," "who is the research for," "whose knowledge counts," "methodology chosen for," "interpretation," "analysis," "presentation of 
findings," "action on findings," "who takes action," "who owns the results," and "what is emphasized")

Of these two components, the transcription and coding was the least participatory. First, the decision to do a transcription-based analysis was not made by the FEP. It was, rather, a decision based on the recommendations of my thesis committee. The analysis technique I used was, therefore, chosen more for 'disciplinary conventions' than for 'mutual learning' and with a greater focus on the 'outcomes' of the research than its 'process' (see the conventional column of Table 4 for "methodology chosen for" and "what is emphasized"). Furthermore, as I was the sole transcriber and primary analyst, I played the most active role in this stage and had the most influence on the information presented to the FEP and the participants (see the conventional column of Table 4 for "analysis").

This is not to say that the process followed an entirely conventional path. Although I did transcribe and code the focus groups myself, this is partially because I was working in coordination with Conrad, who was explicitly interested in having me develop, implement, and analyze the focus groups. My work as the analyst is in this way a product of our agreed upon roles (“emphasizes collaboration”). Furthermore, my coding of the process was influenced by my intention to produce an analysis that would be useful for the FEP and the development of the KYPP ("focuses on being useful," "what is the research for," "who is the research for"). As such, I tried to code and analyze with a greater focus on description than interpretation, attempting to reflect participants' responses as accurately as possible. Whereas a more interpretive analysis 
might have focused more on the meanings behind participant statements or interactions, my analysis was more focused on the participants' actual responses to the questions. I tried to coordinate and restate their responses to ensure that it was their ideas and suggestions that would come through in the analysis and have an influence the KYPP ("who is the research for," "whose knowledge counts," "interpretation").

The report writing and dissemination was a more participatory process than the first component. It was during this component that I formally incorporated Conrad's input, and that of the participants, into the analysis and reporting. For example, I organized the first focus group's descriptive summary to include a listing of each theme's sub-themes and elements so that Conrad and the participants could see the paraphrased quotations that I used to develop the summaries. I wanted to make this step of the analysis as transparent as possible so that they could make an informed judgment off my analysis ("emphasizes collaboration," "methodology chosen for" "presentation of findings"). Conrad's feedback on these descriptive summaries was positive, indicating that they would be useful for his purposes and comprehensible for the participants. I therefore wrote up the remaining four groups in the same manner ("emphasizes collaboration," "what is the research for," "whose knowledge counts," "presentation of findings").

Also, a major reason for sending all of the participants their focus groups' descriptive summary and the final summary report was to member-check my analysis (“whose knowledge counts"). It was additionally intended as a way to have others review my work to improve upon the final report to the FEP and to improve the utility of the summer's research for developing the KYPP ("focuses on being useful," "what is the 
research for," "action on findings"). I intended for this strategy to continue the participatory nature of the focus group process, too. I felt that by sharing this information, keeping the participants involved, and providing opportunities for them to influence the analysis and reporting, they would be able both to see the results of their participation as well as continue to influence and inform the KYPP if they so desired ("what is the research for," "who is the research for," "methodology chosen for," "who owns the results," "what is emphasized").

However, I was the person who was mostly responsible for the report writing; this component could have been done in a more participatory manner. For example, I could have identified a few participants to serve as reviewers of my analysis. Additionally, my decision not to reduce the length of the final summary report was partially a response to my time limitations. It is possible, for example, that had I reduced the length even further more people would have responded to my emails with their feedback. But I also was cautious to avoid prematurely limiting the participants' access to information. I felt that providing a preface about the report's navigability would mitigate the challenges posed by the report's length while also reinforcing our genuine interest in having participants continue to be involved and influential in the process ("emphasizes collaboration," "who is the research for," "whose knowledge counts" "methodology chosen for," "presentation of findings," "what is emphasized").

The post-focus group analysis and reporting stage was not a highly participatory portion of our focus group process. Yet this probably had more to do with the context and purpose of these focus groups, as well as the manner in which this stage was carried out, than with the stage itself. For example, these focus groups were organized by a 
graduate student researcher new to the use of focus groups, working for an organization that was also unfamiliar with the technique. It is likely that had we been more familiar with focus groups, and had we desired to organize this stage with a greater attention to participation, it could have been conducted in a more participatory manner.

It should be recalled, though, that Conrad was not even certain that the KYPP should be, or could be, pursued at the time. A major reason for the hosting an outreach/input process was to determine if the Project should be developed and, if so, how. Because it was an exploratory process, Conrad did not want to demand too much of a time commitment from participants, particularly since the final results could have been an overall lack of interest. Thus, the low level of participation in this stage actually reflects some of Conrad's considerations for county residents ("who is the research for"). This highlights one of the complicating aspects of defining a participatory research project: some non-participatory processes can be part of an overall participatory process.

Finally, the input that we received throughout the focus groups culminated in this stage in the form of the five individual focus group's descriptive summaries and the summary report. It is, therefore, important to consider here how well the four questions were addressed by the focus group process.

Beginning with the first question, which asked if the KYPP was a good idea and worth pursuing, the focus groups provided an affirmative answer. It has been already been discussed that the self-selection intrinsic to our recruitment process likely led to a group of participants already favorable towards the KYPP. In some ways, then, their support of the project could be superficially glossed over as an expected outcome. However, that would ignore the fact that these participants are part of the county resident 
target group. Even if they are inclined to support the Project, their opinions are still relevant.

These participants were not, furthermore, stooges selected to give us the answers we wanted to hear. Many of them did have a critical perspective on the Project. For example, many participants were concerned that other, similar projects had already been tried and failed. Alternatively, some felt that because similar projects were already ongoing in the county, the KYPP should serve a coordinating function rather than "reinventing the wheel." One participant, however, commented that although there were similar projects in the county, this could be taken as an indication of a broader interest in this type of work. Another participant stated:

Well, he makes a good point. You don't want to be redundant. You don't want to redo work that others are doing. But if others are doing it already you can link to their websites and, you know, bring people together that way and that can be a tremendous strength in your work. And it can also, maybe shed a little light and, you know, bring a new kind of lens to look at all this information through. And that can be a very positive thing. You know if that other stuff is already out there it shows that there is already interest. And so that's fertile ground to build on.

(Transcription, emphasis added)

The participant's point, in the quote above, was that rather than taking extant projects as a reason not to pursue the KYPP, one could see them instead as a supportive foundation from which to build the Project. Other similar comments demonstrate the depth of thought that these participants contributed during the interviews and highlights the fact that their input was not uncritical or unilaterally positive for the Project. They offered considered and informative input regarding why they supported the Project, where they had concerns, and how they felt it could be best developed.

The summary report contained my synthesis of participant responses to our interview questions. As organized in the summary report, these responses are the 
detailed answers to the remaining three questions of the FEP. Therefore, while still recognizing some of limitations of our participant pool, this final stage of the focus group process consolidated and organized the wealth of useful information contributed by participants. In other words, as with the first question, the other three main questions of the FEP were also well addressed during this stage. 


\section{CONCLUSIONS}

\section{Lessons Learned}

Based upon this thesis' analyses, and for both standards that were evaluated - the participatory research principles and the Farmscape Ecology Program's (FEP) research objectives - the focus group process proved to be, on the whole, successful as a participatory approach to research. I believe that this was the case because of the basic nature of the focus group interview process combined with the influence of contextual factors that tended to enhance the participatory capacity of a focus group.

The participatory research principles that were selected and evaluated for this thesis' evaluations (see Tables 7 and 8 , below ${ }^{47}$ ) represent a first attempt at identifying where the focus group was most and least successful as a participatory approach to research. Certainly there is room for improvement both in the selection and application of these standards. They do, nonetheless, serve as a starting point for making these evaluations, for identifying where focus groups are most easily adaptable to participatory research and for what reasons, and for encouraging the inclusion of participatory principles in the use of focus groups.

\footnotetext{
${ }^{47}$ Note that in Table 8 the stages are evaluated against the selected participatory principles and are rated as participatory $(\mathrm{P})$, conventional $(\mathrm{C})$ or as a blend of the two research types $(\mathrm{P} / \mathrm{C})$.
} 
Table 7: Selected participatory research principles

\begin{tabular}{|c|c|c|c|c|c|c|}
\hline $\begin{array}{l}\text { Focus Group } \\
\qquad \begin{array}{l}\text { Stages } \\
\text { Participatory } \\
\text { Standards }\end{array}\end{array}$ & $\begin{array}{l}\text { Pre-focus } \\
\text { group } \\
\text { planning }\end{array}$ & Recruiting & $\begin{array}{c}\text { Developing } \\
\text { the } \\
\text { questions }\end{array}$ & Interviewing & Debriefing & $\begin{array}{l}\text { Post-focus } \\
\text { group } \\
\text { analysis and } \\
\text { reporting }\end{array}$ \\
\hline $\begin{array}{l}\text { Focuses on being } \\
\text { useful }\end{array}$ & & & $\bar{X}$ & $\bar{X}$ & $\mathbf{X}$ & $\bar{X}$ \\
\hline $\begin{array}{l}\text { Employs diverse } \\
\text { methods }\end{array}$ & & $\bar{X}$ & & & & \\
\hline $\begin{array}{l}\text { Emphasizes } \\
\text { collaboration }\end{array}$ & $\bar{X}$ & $\bar{X}$ & $\bar{X}$ & $\bar{X}$ & $\bar{X}$ & $\overline{\mathbf{X}}$ \\
\hline What is the research for & $\bar{X}$ & & $\mathbf{X}$ & $\bar{X}$ & & $\mathbf{X}$ \\
\hline Who is the research for & $\mathbf{X}$ & $\bar{X}$ & $\mathbf{X}$ & $\mathbf{X}$ & $\mathbf{X}$ & $\bar{X}$ \\
\hline $\begin{array}{l}\text { Whose knowledge } \\
\text { counts }\end{array}$ & & $\mathbf{X}$ & $\mathbf{X}$ & $\mathbf{X}$ & $\mathbf{X}$ & $\mathbf{X}$ \\
\hline $\begin{array}{l}\text { Topic choice } \\
\text { influenced by }\end{array}$ & $\mathbf{X}$ & & $\mathbf{X}$ & $\mathbf{X}$ & $\mathbf{X}$ & \\
\hline $\begin{array}{l}\text { Methodology chosen } \\
\text { for }\end{array}$ & $\mathbf{X}$ & $\mathbf{X}$ & & $\mathbf{X}$ & $\mathbf{X}$ & $\mathbf{X}$ \\
\hline Problem identification & $\mathbf{X}$ & & & $\mathbf{X}$ & $\mathbf{X}$ & \\
\hline Data collection & & & & $\mathbf{X}$ & & \\
\hline Interpretation & & & $\mathbf{X}$ & $\mathbf{X}$ & $\mathbf{X}$ & $\mathbf{X}$ \\
\hline Analysis & & & & & $\mathbf{X}$ & $\bar{X}$ \\
\hline Presentation of findings & & & & & $\overline{\mathbf{X}}$ & $\mathbf{X}$ \\
\hline Action on findings & & & & & $\mathbf{X}$ & $\mathbf{X}$ \\
\hline Who takes action & & & & & & $\bar{X}$ \\
\hline Who owns the results & & & & & & $\mathbf{X}$ \\
\hline What is emphasized & $\mathbf{X}$ & $\mathbf{X}$ & $\mathbf{X}$ & $\mathbf{X}$ & $\mathbf{X}$ & $\mathbf{X}$ \\
\hline
\end{tabular}


Table 8: Focus group stages' evaluations

\begin{tabular}{|c|c|c|c|c|c|c|}
\hline $\begin{array}{l}\text { Focus Group } \\
\qquad \begin{array}{l}\text { Stages } \\
\text { Participatory } \\
\text { Standards }\end{array} \\
\end{array}$ & $\begin{array}{l}\text { Pre-focus } \\
\text { group } \\
\text { planning }\end{array}$ & Recruiting & $\begin{array}{l}\text { Developing } \\
\text { the } \\
\text { questions }\end{array}$ & Interviewing & Debriefing & $\begin{array}{l}\text { Post-focus } \\
\text { group } \\
\text { analysis and } \\
\text { reporting }\end{array}$ \\
\hline $\begin{array}{l}\text { Focuses on being } \\
\text { useful }\end{array}$ & & & $\mathbf{P}$ & $\mathbf{P}$ & $\mathbf{P}$ & $\mathbf{P}$ \\
\hline $\begin{array}{l}\text { Employs diverse } \\
\text { methods }\end{array}$ & & $\mathbf{P}$ & & & & \\
\hline $\begin{array}{l}\text { Emphasizes } \\
\text { collaboration }\end{array}$ & $\mathbf{P}$ & $\mathbf{P}$ & $\mathbf{P}$ & $\mathbf{P}$ & $\overline{\mathbf{P}}$ & $\mathbf{P}$ \\
\hline What is the research for & $\overline{\mathbf{P}}$ & & $\mathbf{P}$ & $\mathbf{P}$ & & $\mathbf{P}$ \\
\hline Who is the research for & $\mathbf{P}$ & $\mathbf{P}$ & $\mathbf{P}$ & $\mathbf{P} / \mathbf{C}$ & $\mathbf{P}$ & $\mathbf{P}$ \\
\hline $\begin{array}{l}\text { Whose knowledge } \\
\text { counts }\end{array}$ & $\overline{\mathbf{P}}$ & $\mathbf{P}$ & $\mathbf{P}$ & $\mathbf{P}$ & $\mathbf{P}$ & $\mathbf{P}$ \\
\hline $\begin{array}{l}\text { Topic choice } \\
\text { influenced by }\end{array}$ & $\overline{\mathbf{P}}$ & & $\mathbf{P}$ & $\mathbf{P}$ & $\mathbf{P}$ & \\
\hline $\begin{array}{l}\text { Methodology chosen } \\
\text { for }\end{array}$ & $\overline{\mathbf{P}}$ & $\overline{\mathbf{P}}$ & & $\mathbf{P}$ & $\overline{\mathbf{P}}$ & $\bar{C}$ \\
\hline Problem identification & $\mathbf{P}$ & & & $\mathbf{P}$ & $\mathbf{P}$ & \\
\hline Data collection & & & & $\mathbf{P} / \mathbf{C}$ & & \\
\hline Interpretation & & & $\mathbf{P}$ & $\overline{\mathbf{P}}$ & $\overline{\mathbf{P}}$ & $\mathbf{P} / \mathrm{C}$ \\
\hline Analysis & & & & & $\mathbf{P}$ & $\mathbf{C}$ \\
\hline Presentation of findings & & & & & $\mathbf{P}$ & $\mathbf{P}$ \\
\hline Action on findings & & & & & $\overline{\mathbf{P}}$ & $\mathbf{P}$ \\
\hline Who takes action & & & & & & $\mathbf{P} / \mathrm{C}$ \\
\hline Who owns the results & & & & & & $\mathbf{P}$ \\
\hline What is emphasized & $\overline{\mathbf{P}}$ & $\mathbf{P}$ & $\mathbf{P}$ & $\mathbf{P} / \mathrm{C}$ & $\overline{\mathbf{P}}$ & $\overline{\mathbf{P}}$ \\
\hline
\end{tabular}


The focus group interview is indeed a conventional research methodology, but one that contains many of the qualities intrinsic to participatory research. A focus group interview, for example, is easily designed to address a particular set of questions based on the people and organizations involved, adaptable to the particular context of the places and the people involved, and the interview's results can be analyzed and presented according to the needs of the situation. Focus groups are therefore readily able to function as a participatory research approach.

Still, as the literature indicates, the principles of participatory research are not uniformly applied throughout a research process. Cornwall and Jewkes (2003) illustrate this point by comparing the standards of participatory and conventional research in a table format (Table 4), suggesting that, "Frequently the relationship between the two approaches takes the form of a zig-zag pathway rather than vertically following either one" (p1668). When applied to a focus group interview, this suggests that in its entirety a focus group process would be likely to incorporate both participatory and conventional research features. A participatory research process cannot be considered superficially.

As an example, a researcher and a host organization are not likely to agree on all of the details of how to best carry out a research project. A superficial perspective on participatory approaches might suggest that these decisions should be made with equal weight given to both perspectives at all times. Yet, if one reason for working with a researcher is to develop a project making use of that person's experiences and background, there may be some cases where their expertise should be used to influence the host organization, preferably through transparent dialogue. The results of such a research process, including the usefulness of those results to the host organization, may in 
fact be improved by occasionally giving primacy to a researcher's particular areas of expertise rather than focusing on a rote form of participative equality.

The same point can be argued from the reverse perspective, indicating that there are appropriate compromises for a researcher to make as well. These compromises may involve, for example, a researcher yielding to the expertise of the host organization. In either case, the point is that participation is not about a uniform and universal equity within a research process; instead, participation requires a transparent, communicative, flexible and to some degree shared attitude to the research process. Indeed, this was the case within this thesis' analysis. The broad implication of this is that the dichotomous categorization of research into either conventional or participatory approaches needs to be understood in a more complicated fashion, recognized as a spectrum between ideals rather than as a divide between two distinct realities.

If the research process is approached from this more complicated perspective, one consideration for evaluating the success of a participatory research project (i.e. whether the project settles more towards the conventional end or the participatory end of the research spectrum) is the explicit intentions of those who are coordinating to organize the research. This, too, is suggested in the literature. Consider, for example, Cornwall and Jewkes (2003) claim that participatory research is more of an attitude taken towards the research process than the specific methodology that is used.

In relation to this thesis' analysis, the inherent capacity of a focus group to function as a participatory approach to research can be improved upon, as might be expected, when those who coordinate the research have a clear and shared intention to develop a participatory process combined with the mutual flexibility to do so. Additional 
contextual factors to consider are the broader community involved the research, the location of the research (i.e. geographic and temporal location), and the specific research objectives. In sum, the intrinsic qualities of the focus group methodology that make it well suited to be a participatory research approach are augmented or diminished based on the multiple and overlapping contexts of each, specific application.

The specific contexts of the research project analyzed in this thesis allowed for the inclusion and augmentation of participatory practices throughout much of the focus group process. For example, as a graduate student I had few restrictions on how my research should be conducted or what the outcomes needed to be. I was, therefore, able to coordinate with the FEP with the express purpose of developing a participatory research process, which was a mutual goal. Stated broadly, both Conrad and I were interested in developing a participatory process and we maintained a high level of collaboration throughout that process. Our transparent and communicative relationship combined with our mutual interest in a participatory process created an environment that was typically inclusive of the principles of participatory research.

One complicating factor to my evaluation, however, is the question of participative for whom. Within this thesis, I have argued that the focus groups were successful as a participatory approach to research. I have argued this in recognition of the fact that the greatest participation occurred between Conrad and I. There were also many cases, of course, wherein the participants of the focus groups - the county residents - participated directly and indirectly, but my analysis tended to identify the most prevalent participation between the researcher and the host organization. 
I contend that our overall process was successful as a participatory approach to research in part because of the attitude with which we approached the research. In addition to the evident participation between Conrad and I, this also includes our frequent, although sometimes indirect, consideration of the participants' interests as well as the overall purpose for hosting the focus groups: to use the participants' responses to influence the development of the KYPP. My contention, however, should not suggest that I feel our process was as fully participatory as it could have been; rather I feel that, on the whole, our use of the focus group methodology was participatory.

The research setting of the focus groups considered in this thesis also influences my evaluation. To illustrate this point, consider the following question: will the participatory nature of the focus groups continue to extend beyond the researcher-host organization relationship? This, of course, would be an essential progression if the research process initiated by our focus groups were to continue developing as a participatory approach. It could therefore be argued that it is too soon to tell if the entire process was truly participatory since the KYPP is yet to be fully developed and the full impact of the participants' input from the focus groups is yet to be realized. The critical point to understand, however, is that the focus groups were not intended to lead to the completion of the KYPP; instead, they were organized to expand the sphere of influence on the development of the KYPP. Thus, the focus groups need to be understood within their appropriate setting. They were designed to be a participative, initial approach to getting county residents' input on a project, which is intended to then develop as a participatory project. In this regard they were successful ${ }^{48}$.

\footnotetext{
${ }^{48}$ It should also be recalled that the majority of participants indicated feeling that they had, indeed, participated in the development of the KYPP.
} 


\section{Considerations for Future Research}

In consideration of future evaluations of focus groups (and other methodologies) as participatory research processes, the distinction between the components of a research process and the research process on the whole should be recognized. While it may be useful to isolate particular components or outcomes in order to evaluate them, this analytic approach may not be representative of the entire process. For example, in how many of the focus group's stages, or to what extent within each stage, does participation need to be present in order for a research project to be considered, on the whole, participatory? Is it preferable to achieve useful outcomes even if the process itself is less participatory? Or is it preferable to have a more participatory process even if the immediate outcomes are somewhat less than ideal?

In order to evaluate a specific participatory research project, then, it may be useful to predetermine the most important aspects of that project as well as how to weight them in the analysis. The research studied within this thesis, for example, was a participatory process; yet, ironically, this may have occasionally limited more inclusive and diverse participation. Would we have generated better "data" had we not been as flexible in our recruitment approach? Would the process have been improved if we had more thoroughly utilized community residents in the interviewing and analysis? To a great extent, the answers to these questions depend upon the parties involved, the research objectives, and other contextual factors. Taking these factors into account may help to better identify and apply participatory research standards, evaluate a project's participative nature and, in fact, improve the usefulness of the process. 
In this regard, a longitudinal comparison of participatory and conventional approaches to research would likely be useful for addressing some of these questions. A longitudinal comparison could help to identify if the choice between a more participatory process or a more useful set of data or outcomes is a zero-sum issue, if it is an issue only in the short term and is rectified over time, or if it is a non-issue because the outcomes are similar. The context-dependency of these considerations may come into finer detail with a longitudinal analysis as well. Thus, a final important aspect to consider for future participatory research studies is the time frame within which the research is analyzed and evaluated.

\section{Recommendations for Future Researchers}

Two recommendations stand out as relevant to the future use of focus groups as participatory research ${ }^{49}$. The first is to take seriously the importance of the relationship between the researcher and the host organization. In order to develop a participatory focus group process, these two parties need to develop and maintain transparent communication. This is specifically relevant with regard to their individual inputs to the project, such as their research objectives, their personal interests in the project, and their available time commitment, research expertise, funding, and other resource-related considerations. Then, based on a mutual knowledge of these individual inputs, it is important to coordinate in order to identify a shared understanding of how the focus groups should, ideally, progress. This ideal can be continuously revisited and revised throughout the research process so as to highlight successes and weaknesses, as well as

\footnotetext{
49 These two recommendations are made with the understanding that the foundational components of the focus group methodology, as indicated in the literature, are also taken into account.
} 
identify possible reasons to celebrate or take remedial action as is merited. A transparent development process such as this should help to identify where the two (or more) parties are coming from and how they might most effectively and realistically coordinate. It should also serve to elucidate what is possible and can be expected from their collaboration as well as give the process a strong foundation for recognizing and acting upon contextual strengths and weaknesses.

The second recommendation builds off of this thesis' evaluation that a participatory focus group process is most readily participative between the researcher and the host. If a further goal is to make the focus groups as participatory as possible with regard to the focus groups' participants and the communities that they represent, additional work will be necessary. The desirability of this more inclusive participation is, of course, dependant on the contexts of the research. If it is a goal of the project, however, a transparent communication process, similar to what was just described, should be initiated between the researcher, the host organization and the participants.

\section{Focus Groups and the Quieter Revolution}

The quieter revolution was not a central focus within this thesis. It was, however, a framework through which the host organization studied herein was situated. It also represented a context in which focus groups, as a participatory approach to research, could be potentially useful. The use of focus groups with regards to the quieter revolution therefore merits a concluding remark.

This research suggests that focus groups are, indeed, well suited to function as a participatory approach to research. Furthermore, many of the same features that make 
focus groups adaptive in this manner also make them suitable within the context of the quieter revolution. Focus groups are easily tailored to meet local needs and address local issues. They are also, by virtue of the group interaction that is integral to a focus group, potentially empowering and informative to their participants. And with regards to project development in particular - and perhaps also project evaluation and evolution - these features of the focus group process can also serve to expand the sphere of influence on a project. In the context of the quieter revolution, then, using focus groups as a participatory approach could result in the greater inclusion of local peoples in land management, from the identification of local goals and developing land management projects to evaluating the inclusiveness of such projects and making subsequent improvements.

As this thesis was a case study specific to the use of focus groups, I cannot offer a comparative analysis between focus groups and other research methodologies in the context of the quieter revolution. I cannot definitively say that focus groups are more suited to the quieter revolution than other research methods. I can, however, recommend the use of focus groups as a means for expanding people's participation in land management as just described, including the potential to educate, to create and strengthen community networks, and to empower local people. Thus, while bearing in mind the strengths and limitations of focus groups in general, and of focus groups as a participatory approach to research more specifically, I suspect that they are well suited to the quieter revolution. 


\section{REFERENCES}

Arce, Alberto and Norman Long (1992). "The dynamics of knowledge-interfaces between bureaucrats and peasants." In: N. Long and A. Long (Eds), Battlefields of knowledge: the interlocking of theory and practice in social research and development (pp. 211-246). Routledge, London, 306pp.

Ary, D., Jacobs, L. D., \& Razavieh, A., (2002). Introduction to Research in Education. Belmont, CA: Wadsworth / Thomas Learning, 582pp.

Baker, Rachel and Rachel Hinton (1999). "Do focus groups facilitate meaningful participation in social research?" In Rosaline Barbour and Jenny Kitzinger (eds.), Developing Focus Group Research: Politics Theory and Practice (p79-98). London: Sage Publications, 225pp.

Barbour, Rosaline S. and Jenny Kitzinger (1999). "Introduction: the challenge and promise of focus groups." In Developing Focus Group Research: Politics Theory and Practice (p1-20). London: Sage Publications, 225pp.

Beierle, Thomas C., and Jerry Cayford (2002). Democracy in Practice: Public Participation in Environmental Decisions. Washington, D.C.: RFF Press, 149pp.

Berg, Bruce L (2001). Qualitative Research Methods for the Social Sciences. Boston, MA: Allyn and Bacon, 304pp.

Bohman, James (2003). "Critical Theory as Practical Knowledge: Participants, Observers, and Critics." In Stephen P. Turner and Paul A. Roth (eds.), The Blackwell Guide to the Philosophy of the Social Sciences (pp. 1-382). Malden, MA: Blackwell Publishing, 381pp.

Bordieu, Pierre, Jean-Claude Chamboredon, and Jean-Claude Passeron (1968). The Craft of Sociology. Berlin, Germany: Walter de Gruyter, 271pp.

Chase, Lisa C., Decker, Daniel J., and T. Bruce Lauber (2004). "Public Participation in Wildlife Management: What do Stakeholders Want?" Society and Natural Resources 17: 629-639.

Columbia County Environmental Management Council Website (2008). Retrieved from http://www.columbiacountyny.com/depts/planning/demographics.html on 9 December 2008.

Community Development Academy (2007). Collaboration Matrix (course handout). Columbia, Missouri: University of Missouri, section \#8.

Conley, Alexander, and Margaret A. Moote (2003). "Evaluating Collaborative Natural Resource Management." Society and Natural Resource Management 16: 371-386.

Cornwall, Andrea and Rachel Jewkes (1995). “What is Participatory Research?” Social Science and Medicine 41(12): 1667-1676.

Cunningham-Burley, Sarah, Anne Kerr and Stephen Pavis (1999). "Theorizing subjects and subject matter in focus group research.” In Rosaline Barbour and Jenny Kitzinger (eds.), Developing Focus Group Research: Politics Theory and Practice (p186-199). London: Sage Publications, 225pp.

Farmscape Ecology Program (FEP) Website (2008). Retrieved from http://www.hawthornevalleyfarm.org/fep/fep.htm on 23 February 2008. 
Fontana, Andrea (2002). "Postmodern Trends in Interviewing." In Jaber F. Gubrium and James A. Holstein (eds.), Handbook of Interview Research: Context and Method (p161-175). Thousand Oaks, CA: Sage Publication, 981pp.

Freire, Paulo (1970). The Pedagogy of the Oppressed. New York: Continuum, 186pp.

Gatseyer, Stephen and Cornelia Butler Flora (2000). "Measuring ppm with Tennis Shoes: Science and Locally Meaningful Indicators of Environmental Quality." Society and International Resources 13: 589-597.

Guba, Egon and Yvonna S. Lincoln (1994). "Competing Paradigms in Qualitative Research.” In NK Denzin and YS Lincoln (eds.), Handbook of Qualitative Research (p105-117). Thousand Oaks, CA: Sage Publication, 643pp.

Hawthorne Valley Farm (HVF) Website (2008). Retrieved from http://hawthornevalleyfarm.org/ on 23 February 2008.

Hayward, Chris, Lyn Simpson and Leanne Wood (2002). "Still Left Out in the Cold: Problematising Participatory Research and Development." Sociologia Ruralis 44(1): 95-107.

Israel, Barbara A., Schulz, Amy J., Parker, Edith A., and Adam B. Becker (1998). "Review of Community-Based Research: Assessing Partnership Approaches to Improve Public Health." Annual Review of Public Health 19: 173-202.

Kloppenberg, Jack Jr. (1991). "Social Theory and the De/Reconstruction of Agricultural Science: Local Knowledge for an Alternative Agriculture." Sociologia Ruralis 32(1): 519-551.

Krueger, Richard A. (1998). "Moderating Focus Groups.” In Morgan, David L., and Richard A. Krueger. The Focus Group Kit. Thousand Oaks, CA: Sage, 139pp.

Krueger, Richard A (1994). Focus Groups: A Practical Guide for Applied Research. Thousand Oaks, CA: Sage, 255pp.

Krueger, Richard A. and Mary Anne Casey (2000). Focus Groups: A Practical Guide for Applied Research. Thousand Oaks, California: Sage Publications, pp215.

Krueger, Richard A. and David L. Morgan (1998). The Focus Group Kit. Thousand Oaks, CA: Sage, $139 \mathrm{pp}$.

Lauber, Bruce T., and Barbara A. Knuth (2000). Citizen Participation in Natural Resource Management: A Synthesis of HDRU Research. Ithaca, NY: Human Dimensions Research Unit (HDRU) Series No 00-7.

Litoselliti, Lia (2003). Using Focus Groups in Research. New York: Continuum, 104pp.

Mason, Robert J (2008). Collaborative Land Use Management: The Quieter Revolution in Place-Based Planning. Lanham, Maryland: Rowmann and Littlefield, 363pp.

Meine, Curt (2004). Correction Lines: Essays on Land, Leopold, and Conservation. Washington, D.C.: Island Press, 296pp.

Morgan, David L (1996). “Focus Groups.” Annual Review of Sociology. 22: 129-152.

Morgan, David L (1997). Focus Groups as Qualitative Research. Thousand Oaks, California: Sage Publications, 80pp. 
Morgan, David L (1998). “The Focus Group Guidebook.” In Morgan, David L., and Richard A. Krueger, The Focus Group Kit. Thousand Oaks, CA: Sage, 139pp.

Morgan, David L (2002). “Focus Group Interviewing.” In Jaber F. Gubrium and James A. Holstein (eds.), Handbook of Interview Research: Context and Method (p141-159). Thousand Oaks, CA: Sage Publication, 981pp.

Orr, David (1992). Ecological Literacy: Education and the Transition to a Postmodern World. Albany, New York: State University of New York Press, 210pp.

Pain, Rachel and Peter Francis (2003). "Reflections on participatory research.” Area 35(1): 46-54.

Rowe, Gene, and Lynn J. Frewer (2000). "Public Participation Methods: A Framework for Evaluation." Science, Technology and Human Values 25(1): 3-29.

Seale, Clive (1999). The Quality of Qualitative Research. London: Sage Publications, 214pp.

Stoecker, Randy (1999). "Are Academics Irrelevant? Roles for Scholars in Participatory Research." American Behavioral Scientist. 42(5): pp840-854.

Stoecker, Randy (2005). Research Methods for Community Change: A Project-Based Approach. Thousand Oaks, CA: Sage Publications, 271pp.

Strand, Kerry, Marullo, Sam, Cutforth, Nick, Stoecker, Randy and Patrick Donohue (2003). CommunityBased Research and Higher Education: Principles and Practices. San Francisco, CA: JosseyBass, pp 261.

Yin, Robert K (2002). Case Study Research: Design and Methods. Thousand Oaks, CA: Sage Publications, 181pp. 